University of Rhode Island

DigitalCommons@URI

Open Access Master's Theses

1996

\title{
The Curriculum of Consciousness: The Disciplines from the Greeks to Post-Modernity
}

Daniel Novak

University of Rhode Island

Follow this and additional works at: https://digitalcommons.uri.edu/theses

\section{Recommended Citation}

Novak, Daniel, "The Curriculum of Consciousness: The Disciplines from the Greeks to Post-Modernity" (1996). Open Access Master's Theses. Paper 1536.

https://digitalcommons.uri.edu/theses/1536

This Thesis is brought to you for free and open access by DigitalCommons@URI. It has been accepted for inclusion in Open Access Master's Theses by an authorized administrator of DigitalCommons@URI. For more information, please contact digitalcommons-group@uri.edu. 


\section{B105 (4)7 \\ N693}

THE CURRICULUM OF CONSCIOUSNESS: 194 THE DISCIPLINES FROM THE GREEKS TO POST-MODERNITY BY DANIEL NOVAK

A THESIS SUBMITTED IN PARTIAL FULFILLMENT OF THE REQUIREMENTS FOR THE DEGREE OF MASTER OF ARTS IN ADULT EDUCATION 


\section{ABSTRACT}

"The Curriculum of Consciousness" can be seen as one way of demonstrating how the progression of consciousness creates history, how humankind 'comes to' or awakes to its own nature. It is the story of how consciousness determines history and, coordinately, how history determines consciousness.

The focus of this historical-philosophical study is how the 'disciplines' - the arts, sciences and cultural pursuits in the widest sense (ranging from religion to commerce, technology, medicine and politics) - have been configured according to distinct priorities in the different eras of Western Civilization under the aegis of certain particular enterprises, i.e. philosophy among the Greeks, theology in the Middle Ages, science and technology in the Modern World and the philosophies and yogas of consciousness and awareness in the late Twentieth Century. The dominant perception of an era creates that era and its 'world', including its dominant discipline or chief conduit to success and worthwhiledness.

The disciplines of knowledge are traced through three major historical modes of inquiry, or 'organons', that have directed research and have provided rationales and frameworks for methodology and practice in the West. These three Canons of Inquiry are shown in the matrix of their worldviews. Special attention is given to the roots, pioneers and significance of the Third Organon, the 'perennial philosophy'. 
The above involves tracing the nature and evolution of the curricular constellations of 'higher' education and, in particular, versions of the 'iberal arts' , the premier preparation for leadership in various societies. Accordingly, the regimens and propaedeutics are sketched for the ideal personage of each era: the warrior, king. noble. philosopher, saint, gentleman, scientist, entrepreneur, revolutionary, professionalspecialist, whole person/ planet steward.

In doing this culture history and synoptic analysis we wish to lay the foundation for 1) developing one model of awareness based education, with applications, 2) developing a philosophy/phenomenology of collective enterprise and curricular inquiry, and 3) showing the reciprocal connection between the 'inner curriculum' and global-planetary awareness. 
To Gail, without whom, not 
TABLE OF CONTENTS

INTRODUCTION: HISTORY AND CONSCIOUSNESS

I THE ORGANON OF THE GREEKS AND THE

CHRISTIAN ACCOMMODATION

II NOVUM ORGANUM: THE RISE OF MODERN SCIENCE AND

Transition: John Dewey

68

III TERTIUM ORGANUM: THE CURRICULUM OF CONSCIOUSNESS IN THE GLOBAL AGE

Five Roots of the Counter-Culture, New Age and the Perennial Philosophy 88

1. Romantic-Existentialist Reactions to Science $\quad 88$

2. Developments in Twentieth Century Physics

3. Utopian Educators and the Advent of World Teachers:

The New Humanities 96

4. Marxist Revolutionary Thought and German Critical

5. The Eastern Turn 


\section{INTRODUCTION}

Humans have always engaged in a variety of pursuits in response to the call of their nature, the demands of circumstance and the needs of society: from hunting, fishing and farming, to engineering and medicine, to piloting ships and people, to plotting each other's demise, and to exploring the reasons, if any, for sheerly existing. Famous Nineteenth Century Swiss historian of the Renaissance Jacob Burchardt [1] noted three 'forces' motivationally and causally interacting in any civilization: Religion, Culture, and the State. American Marxian literary critic Kenneth Burke has noted seven "offices" or typical functions at work in any society whatsoever: governing, serving (providing for materially), defending, teaching, entertaining, curing and pontificating (ministering in terms of a 'beyond') [2].

How have the major human enterprises - and consequently their implementing or enabling disciplines - been orchestrated in Western civilization? What have been the guiding ideas that have defined their curricular development? What practices and discoveries have shaped 'higher' education in the West? 
How were the ensemble of societal activities seen in the Greek city-states, one of the founts of Western Civilization? How were the arts, sciences and disciplines assembled in Greece? In the Medieval Era? In the Modern World? In the Twentieth Century? How did the Greeks divide up their world? How did they codify their understanding? What view of the world did they express? How did their educational system, the transmission of the ideals of their culture, come about? What tensions were there in their educational practices as they attempted that transmission? What have been the enduring legacies of those tensions?

The Greeks were the first to originate traditions and institutions that we consider characteristically Western. Our parliaments had their origin in the political deliberations in the Athenian agora. Our notion that a certain harmony of form constitutes beauty is a Greek notion. The very idea of 'science', of knowledge gained through sustained inquiry, was born in Greece. And, of course, friendship with fundamental ideas, the cultivation of affection for and the gravitation toward wisdom, the philia/sophos, as a collective pursuit, was born there. [3] We must start with the Greeks.

There is the image of the Greeks as the innocent, halcyon, rational adolescents playing at the eastern end of the Mediterranean projected by the early classicists and Hellenophiles. But there is another image of Greece, first propounded by Nietzsche [4] the darker Dionysiac side, the side of their character drenched in blood-lust, Viking-like conquests, internecine rivalry, orgiastic 'mysteries' and rituals, a febrile imagination filled with child-eating rituals, divine jealousies and horrible retributions. And, as in most cultures, ostracisms and executions of prophets, pioneers and the heterodox. Aristotle toward the end of his career had to hastily leave Athens so that the city 'would not sin twice against philosophy' (a reference to the execution of Socrates for 'impiety'). 
We can't tell the full story of the Greeks here. [5] Nietzsche's brilliant insights into how a culture evolves and rationalizes and justifies itself to itself, how it 'interprets' its own history and motives, [6] initiated major anthropological and philosophical reconsiderations of Greek culture in the late nineteenth and early twentieth century.[7] One of Nietzsche's most insistent questions was how - given the background of a lying, self-serving and bellicose nature - the strange ideal of 'pure knowledge' arose. How was the cultural phenomenon of rationality possible? Not only did the early 'viking' Greeks raid other civilizations (Minoan Crete), fight with other city-empires (Troy), stand in curious awe of others (Egypt), struggle for survival against other empires (Persia), but they struggled with their own internally discordant impulses. That precious and precarious balance known as 'rationality' was the result.

There are many anthropologists of religion and mythologists (not in the Edith Hamilton sense of mythology as children's stories of the deeds of fabled gods and heroes, but in the Jungian sense of tracers of archetypes or motifs of consciousness), notably Mircea Eliade and Joseph Campbell, who tell the story of the phylogenic progression of consciousness (found in the matrix of groups), just as contemporary developmental psychologists - like Howard Gardner, Lawrence Kohlberg and William Perry - chart the 'maturation' of ontogenic (individual) consciousness. [8] Others use a daring mix of Freudian and behaviorist perspectives to map the cultural transition from the projectedonto-the-'other' unconsciousness to the conflictual form of self-consciousness [9]. Still others, working this vein of 'vertical' psychology and cultural history, locate the origin of an enterprise like philosophy in a perennial impulse in human nature, the desire to just understand, and emphasize the ahistorical genesis of characteristically human pursuits. [10] In the last view, commerce, art, engineering, science, religion and politics are all 'perennial plants' of human nature, sprouting in all times and places. 
The 'story of consciousness' or the 'Consciousness-Story' is appropos because how we put the disciplines together depends heavily on what the significant levels of development are seen as. If the disciplines are avenues of development, what are the goals of a society that determine 'peak' development? Does a society always consciously determine them? If not, how are they determined? Or do articulated 'goals' actually come last in a sequence of development? The 'facts' are mute: we must make them 'talk'. History is always hermeneutical: it is always interpretation.[11] In fact, History seems positively Mandelbrotian: like the infinitely complex and beautiful 'fractal' patterns that swirl, replicate and resonate endlessly just as a coastlline becomes more irregular - and yet pregnant with larger patterns - the closer it is looked at! History, like any art pursued to the end, perforce inculcates humility. A mind-numbing infinitude presents itself in every direction. All an honest interpreter can do is merely start in what is conceived to be a right direction. History, like any other field of human endeavor, is a Borges-like 'garden of forking paths'.

Hegel of course was the grand master of the Consciousness Story. His Phanomenologie des Geistes was the account of the progression of consciousness in and through cultural forms. August Comte, as we shall see, gave voice to the story that consciousness in its infancy expressed itself in the form of religion and myth. Its 'adolescent' form was speculation and philosophy. Its mature form was 'positive' and truly productive science. By contrast, the arc of Christian development in the paradigmatic personage of St. Augustine of Hippo went from worldly knowledge and sophistication to philosophical perplexity to powerful religious conversion. Which is the true 'story' of humanity - the Comtean or the Augustinian? Which represents true ascent, real progress? 
Again, the historian doesn't merely recount 'res gestae', the lateral infinitude of things done, but recounts deeds with a purpose, perspective, or within some kind of framework. S/he makes markers, guages importance, periodizes [12]. S/he. the historian. is always expressing a metaphysics, emphasizing what is really real, an account of Being which thereby 'reflects back' and helps determine what is truly happening. Tooth and claw, atoms and quarks, divine messengers and celestial teachers are some of the different crucibles that have been used for history and historicizing. 


\section{THE ORGANON OF THE GREEKS}

"There are two sorts of knowledge, one genuine, one bastard (or 'obscure'). To the latter belong all the following: sight, hearing, smell, taste, touch. The real is separated from this. When the bastard can do no more - neither see more minutely, nor hear, nor smell, nor taste, nor perceive by touch - and a finer investigation is needed, then the genuine comes in as having a tool for distinquishing more finely."

- Democritus, The Canon

The Greeks: we must at very least admire their efforts to put things together into some kind of coherent form, a "cosmos". An ordered universe (vs. dark fears or the similarly irrational imperial edicts) had intelligible form, a pattern the mind could apprehend. The lyre gave off music, olive trees olives, and humans gave off arts, things produced via human ingenuity. One classical scholar argued that the Greeks 'discovered' mind (reason, 'nous') in tandem with their discovery of an ordered world.[13] This of course didn't mean there wasn't 'mentation' or thinking before the Greeks. But the cunning of a hunter or of a courtier in the court of a potentate was different from the sustained observation of the stars. Herodotus gave us 'historia', literally an inquiry that sought to establish facts versus fables. Euclid gave us mathematics (mathematical form as ratio, proportions, relationships) that could be concisely and sequentially established ('proof'). Aeschylus and the other tragedians gave us dramatic form. Solon gave laws. The Greeks also gave us cautionary tales, like Oedipus deciphering the riddle of the Sphinx and having to bear the traumatic consequences of peering too deeply into the mysteries. 
Before the Greeks there were mainly two kinds of polity or associations: tribes and empires. City-states occupied a kind of mid-range between amorphous but nonetheless bonded tribes and large empires administratively governed. Chieftains consulted shamen, kings consulted priests. In the geographical enclaves that became city-states (the 'polis') nobles, the warrior scions, consulted with each other regarding common issues. This 'practical' form of deliberation, or considering together, was one root of Greek rationality. Another root of rationality lay in the bold speculations of individuals in the Greek coastal towns, cities and trading centers in Asia Minor. Marxians in their economically bent histories see the development of commerce and trade as key in the production/clash of ideas. [14] Others see the origin of such early speculation as grounded atemporally in our human nature. [15]

A third root of rationality can be seen in the development of the crafts, trades, professions. These forms of 'practical' reasoning - ingenuity, craftiness, artisan adaptation of means to ends, careful assessments of ills and medicinal cures - all tended to go by the Greek term 'art' or 'techne'. [16] Any skill handed down was techne. Any expert activity or functioning requiring training was techne. Skills, aside from answering specific needs, provided social/educative continuity. 'Arts' literally and figuratively held society together.

The arts, how things were done, were the stuff of tradition. 'Traditio' meant handing down or handing over, carrying on a given activity. Once a technique proved successful, it tended to be replicated. It was impious to question that which had been handed down from time literally 'immemorial', beyond memory. 
The advent of Socrates (he was preceded by others - persecuted thinkers like Anaxagoras and approved thinkers like the Sophists) signalized a crisis in Greek culture: custom vs law ('nomos' vs 'logos'). No longer was the body of traditions sufficient. Oracles continued to be consulted but now people were beginning to consult themselves. the locus of authority was passing from outside to within. The gods were being questioned: maybe there was a lawfulness in things that guided their activity. Maybe the gods were supererogatory. Maybe there was a form or pattern that 'made' the olive tree produce olives.. (The first recorded philosopher, Thales, made a killing in the olive market because of his astute observations!) What had hitherto been part of the assumed now became vulnerable to impious inquiry. Societal consensus was threatened by individualistic speculation into the nature of things.

What was there beyond the group to unify the group and to which it owed allegiance? The land? The ancestors? The gods? In times of adversity the answer was always easy: the gods. The gods must be consulted and properly propitiated. In times of war the answer was easy: the enemy was the focus of the group's powers. Hector and Priam must be beaten. Or Xerxes. But in times of prosperity and/or rising expectations: who or what unifies the polity other than the "me" and my advancement. This increasingly became a question for leisured Greeks, especially Plato (427-347 B.C.).

Socrates (469-399 B.C.) and his ilk seemed to threaten the very sacred character of the state. It was a muddled time in Athens in the fifth century B.C. Socrates seemed to be one of the travelling media-consultants of the time: the Sophists - or even worse, one of those atheistic 'physicists', studiers of the secrets of nature ('physics'). The primary medium of Athens at this time was speech, public discourses, and expertise in this medium guaranteed influence among the always contentious and litigious Greeks. (The Greeks had sublimated much of their warlike energies into the 'agon' form, the contest - the most illustrious of which were the pan-hellenic 'Olympian' games.) 
Plato went his martyred master one better: he used Socrates' famous encounters/conversations and forged them into a 'conservative' (in one of the many meanings of this term) critique of his society. In dialogue after dialogue, Plato had Socrates face expert after expert, and showed again and again that their "knowledge" was really "opinion". Mere know-how (techne) was not knowledge. Socrates, for instance, grilled the Army officer general Laches on the nature of courage to see wherein it differed from impetuous or foolhardy action [17]. The general didn't know. This core and true knowledge Plato ultimately identified with the unique "form" of the Good. The conservatism of tradition was always vulnerable to attack because of its non-clarity with respect to fundamentals, to the true Measure that determined all other measures. Knowhow could never substitute for know-why. The best defence against naive and dangerous views of power Plato demonstrated in his ideal polity (where, as with Hegel, "ideal" means most real) the Republic was the well-ordered state whose helmsman, whose 'cybernetikos', was in touch with true knowledge. Paraphrasing Gertrude Stein, Plato would say 'confusion is confusion is confusion'. Plato held that true knowledge given a proper regimen of inquiry was possible (his famous 'dialectic'). [18] 
The political atmosphere of fifth century Athens was charged with intrigue on the one hand and confusion as to basic values and directions on the other.[19] It was not clear who was the defender of the faith: the itinerant educational entrepreneurs, the nervous aristocratic families, or the military junta. The putative saviors of democracy, the military despots, were to Plato a degradation of the true form of the State. The polity had a true form that was neither tyrannical rule of the one, the few or the many, but a well ordered whole, a 'harmonia', governed by one who embodied both detachment and knowledge of the Good. Perhaps on the model of the Mystery Schools (e.g. the Pythagorean Brotherhood) Plato founded the first university in the Western World, The Academy, to provide a regimen of inquiry leading to 'higher' knowledge and ultimately a training ground for its application to the guidance of the state. Without true knowledge all experts were merely 'technicians', skilled people, 'artisans' in certain delimited areas (like warfare or giving a speech or mathematics). But, as with the discussion of courage in Laches, to know means to know the true implications of one's art, what is truly at stake without being paralyzed by such knowledge. As with the treatment of eros in the Symposium, there is a dynamism and concern that contact with True Goodness communicates. (As in Spinoza's philosophy, a true conception constitutes a true motivation: lack of power to act is due to an inadequate 'idea'.) 
So the first university in the Western World was designed to not only protect and enshrine that precious knowledge of the Good that would secure right ordering in every field (e.g. the administration of the state) but also to so order the course of studies that they would provide a propaedeutic, a preparation, for the achievement of such knowledge. The Republic prescribes many aspects to this education from strenuous bodily training (a combination of gymnastic and morality: overcoming bodily impulses in a way that promoted self-conquest), to 'mousike' (an exposure to and study of harmony, rhythm and proper proportion in sensory modalities) and public service (the selfless discharge of duties with respect to the community).[20] Plato saw himself as the ultimate defender of the polis and its true interests.

Paramount among the studies in this regimen for knowledge-based leadership was mathematics, the study of 'internal relations', as we might say. Mathematics was another field for the vivid demonstration of harmony and proportion. In every field it was important to see the defining harmony, the true measure, that governed the right activity of a thing or action or subject. Discordance meant either an excess or a deficiency. (Aristotle eleborated on this in his discussion of the nature of virtue in his Nichomachean Ethics. 'Arete' or virtue was right mean or true measure in action.) Mathematics was a wonderfully illustrative form of mind training for two reasons: One, it showed how things were not haphazard or chaotic but had essential qualities: a triangle or cube had certain 'timeless' inner relationships that were as clear as they were strict - no guesswork required, no multitude of opinion, no external force or compulsion. And second, the procedures of mathematics, the study of 'elementary' forms, was exemplary: this careful and sequential building from the simple to the complex provided the model for Plato's famous 'dialectic', the ordered movement of the mind toward understanding. Mathematics provided the 'stills' of accurate perception and the movement of the mind that traced more and more comprehensive relationships. 
If opinion goes round and round, true knowledge is reached by a proper progression, an apprenticeship in the forms of each domain. The form of forms was the Good, giving a vision of a beautiful appropriateness, a harmony, in each domain. If you weren't in touch with the inner nature of things you were literally in a state of distortion by excess or defect. True conservatism for Plato was founded on the real: the inner natures, the defining structures of things. Human nature and society needed to be in accord with that.

But, alas, misunderstanding is possible and has dire consequences. Socrates was pilloried in comedy, in Aristophanes' The Clouds, as an ivory-towerist (literally with his head in the clouds!) and as a '60s radical' like Herbert Marcuse whose radical critique set children against their parents. The apparently slippery reasoning - 'sophistical' we would say - embodied in Socrates' conversations seemed to invite disrespect and rebellion. The powers-that-were were not amused. I. F. Stone in a revisionist history defends the interests of the state against Socrates' corrosive challenges [21].

Alfred North Whitehead's famous assessment was that 'the safest characterization of Western Philosophy is that it consists of a series of footnotes to Plato.' For Bruce Kimball in his masterful study of the history of the liberal arts, Orators and Philosophers,[22] Plato's influence has perhaps been unfairly overshadowing. We know not only Socrates but also the Sophists not solely but largely through Plato. In the Dialogues, Socrates is clearly canonized and the Sophists are clearly demonized. Plato gave the Sophists bad press by showing in several instances how these 'experts' could give marvelous trainings in technique (i.e. in their specialty: the tactics and strategems of persuasion) but were irresponsible because they lacked a true appreciation for the right ends or purpose of discourse. Successful persuasion, without knowledge of the good, leads to illegitimate power and influence. 
Kimball argues that ironically Plato himself was suspected of being a 'Sophist' by the prominent Athenian traditionalist and educator Isocrates (384-322 B.C.). In fact he claims that there are two traditions that originally composed what we call the liberal arts, and that their pedagogical tension has precisely mirrored the political tension of Athens in the fourth century B.C. The crux of the matter in an unsettled circumstance was: where was the locus of authority? [23] - the gods?... intrinsic goodness?... the mind?... the diffuse network of practices and traditions that was the 'community'?... the hands of power backed by swords?...

Kimball exhaustively charts all the permutations, ambiguities, contradictions of the idea of 'liberal education' in the West.[24] He maintains that the wellsprings of 'higher' education lie in the tension between the figures of Isocrates and Socrates. The former represents the tradition of the honorable orators (vs. the amoral sophists). The latter, the tradition of the philosophers. Cicero and Quintillian, both Roman orators and pedagogues, followed in the footsteps of the former (persuasive speech still being the primary republican ['res publicae' $=$ public matters] route to political influence vs. the exercise of raw military power). Plato and Aristotle elaborated the idea of fundamental knowledge as prior to the conduct of public life.

Both constructions of higher education (beyond rudimentary literacy, numeracy and gymnastic) presupposed the slave-holding foundation of Greek society. Both were concerned with the direction of the affairs of estate-holders: nobles, free men, 'liberales', 'aristoi'. "Schole" of course originally meant leisure: hence only the children of the wealthy could attend 'school'. 'Pedagogue' etymologically meant the slave who 'led' the privileged child to the place of lessons. 
This last term 'liberale', Latin for 'pertaining to free men', and the usage "artes liberales" indicates to Kimball [25] that what we call the 'liberal arts' is really a later invention of the Romans, again Cicero and Quintillian. Kimball is at pains to show there was no such educational consensus in fifth and fourth century Athens. What 'higher' education (i.e. preparation) was depended on what your primary value was: success, as with the Sophists; upholding traditional values, as with Isocrates; and reconstituting the state along truly rational lines, as with Plato.

Kimball presents the contrast between Isocrates and Socrates as representing the conflict between the authority of revered tradition versus the authority that acrues from critical inquiry. Socrates the iconoclast demolished his opponents but he clearly followed the authority of his inner or transcendent 'daimon' (conscience, voice, guide, calling, vocation, mission, destiny, his mystical 'rapts'). The delphic oracle had previously announced that Socrates was in possession of an unusual kind of knowledge: 'he knew that he did not know'. 'Not-knowing' was his particular forte, his excellence ('arete'), his distinction. (Was this Socratic irony or was it a necessary clearing for truer deliverances ?)[26] For Plato, criticism of prevailing opinions was the first step in the pursuit of authentic ideas, real currency, the highest knowledge. 
Isocrates apparently would have none of this: true education did not leave rampant confusion and doubt. Dazed participants and vulnerable youth should not be the upshot of the educative process. Rather, the consolidation of traditional authority and its sterling examples. Rhetoric should sharpen the commonly held truths and strengthen the underpinnings of the community - not knock its foundation down. In a twist that would have Plato turn in his grave, Isocrates, Cicero and Quintillian [27] stressed that it was possible to feign wisdom through the adroit use of the dialectic, but it was not possible to feign true 'eloquence', the beautiful and compelling speech that comes from moral and civic probity combined with consummate craftsmanship in expression. 'Speak, that I may know who you are.' Reason could mislead and be misled but not good character.

Kimball's conclusion is that there was no final Greek consensus on 'higher' education; that there was a tension between two contexts - the pure transforming knowledge of Socrates and the responsible allegiances of public-minded citizens. Kimball also concludes that the 'artes liberales' was really a Roman codification, an articulation of the orator's community-minded view of the world.[28] The Greeks always had a beyondthe-conventional bent, again, perhaps from their contact with the Egyptian Mystery schools wherein knowledge of the inner workings of things was held to be sacred and not approached except through a proper preparation or 'initiation'.[29] Whether it was a Parmenides or a Pythagoras, a Heraclitus or a Democritus, the Greeks always contrasted the inner rule, measure, or governing 'logic' ("logos") of things with their external 'appearance'. The hidden character of things often required great discernment. Conventions and customs frequently covered, misled, or got in the way of apprehending the true nature of things. The Greeks initiated the distinction between appearance and reality, between 'seeming' and 'being'. If things are simply what they are, and adhere to what they are, then there is no need for philosophy, for a wisdom-quest. 
The Romans, however, had a different bent. Farmers, engineers, statesmen and administrators, they focused on the 'res publica', the affairs of state. When the Romans did codify their educational practices beyond basic literacy and measuring, they did have the entire range of Greek culture, a civilization in its entirety, to reflect upon. In McLuhanesque terms, the process of one era became the content of the next. But the Romans did not pursue deep Greek inquiry ('historia") but rather singled out those elements (like Stoic philosophy for Emperor Marcus Aurelius) that shored up and rationalized sound public life. They had no taste for arcane mysteries. Stolid commonsense was their strong suit.

The dominating thought or perception of an era, its primary aspiration or conceived mission, becomes the organizer of its ensemble of disciplines and practices. For the Romans, arithmetic or geometry or astronomy or music were not so much to be pursued in themselves but rather subsidiarily as preparation for speech-making and public life.[30] The Greek explorers and systematizers, on the other hand, looked for the inner law(s) in every domain, from letters to lines to sounds to stars to ideas to statecraft. The latter impulse often required the consistent negation of outer form to get to the authentic governing dynamic of a thing or situation. Hence in Kimball's anatomy of disciplineconfigurations, the uniting discipline of the orators was rhetoric, the construction of good speech, just as 'dialectic', the ordered movement of reason traversing the skein of forms, was the discipline par excellence among the philosophers. 
Through the whole history of liberal education in the West, Kimball sees the tug. the tension between these two conceptions of higher education, as determining the subdisciplines and curricula of different eras. The advent of Christianity, for instance - after a series of early skirmishes and face-offs in which the Church Fathers tried to adjust their transcendent perspective to 'pagan' learning [31] - made all the disciplines in one way or another 'handmaidens' to theology. In the early Middle Ages rhetoric, as the summit of worldly learning, served as the preparation for and the instrument of 'higher' wisdom (called by different names at different times, e.g. 'Holy Sophia' and 'Gnosis'). In the later Middle Ages the sharp dialectic of the philosophers (particularly the 'new logic' of Aristotle) served as the common language to translate theological insights.[32] The famous 'seven liberal arts' of the Middle Ages (grammar, logic and rhetoric; arithmetic, geometry, astronomy and music) basically served as a preface to the study of Scripture. The New Revelation had provided a new perspective and a new mission. The meekness of Jesus and the salvation of the soul was now the goal and task at hand. Christians turned things around, if not upside-down. Historian James Bowen recounts early 'father' of the Church, Clement of Alexandria, describing Christ as the 'paidagogus', the bringer of true illumination to the soul.[33] This was the reversal of the Greek 'paidagogus', the trusted slave who led the freeborn child to school, to his studies. Now it was the exemplar of Christ who led men out of their emotional and intellectual bondage. While not going as far as some polemicists against Greek studies, Clement said that 'the (true) Gnostic (seeker of spiritual truth) avails himself of branches of learning as auxiliary preparatory exercises...'.[34]

Bowen, again following Clement, gives an encapsulation of the Medieval worldview from its early chiliastic and eremitic rejections of worldliness to its later contemplative-mystical 'journeys of the soul to God': The realization of the Truth is "only achieved by the careful following of a total way of life that provides the optimum environment for its emergence. 
...(While) The traditional studies lead to rational demonstration, the exercise of physical and spiritual discipline provides that further awareness and sensitivity which leads to the final achievement, the ineffable transition to complete 'gnosis'..."[35]

Kimball sees the following as components of the 'artes liberales' ideal stemming from the tradition of the orators: 1. the goal of training the good citizen to lead society, 2 . prescriptions of values and standards for character and conduct, 3. the commitment to such, 4. a body of classical texts as a means of conveying tradition and authoritative models, 5 . a born elite who achieve greater merit by adopting the personal and civic virtues expressed by the classic texts, 6 . an epistemological dogmatism; i.e. truth can be known and authoritatively passed on, and 7. liberal education as an ideal in itself.[36] The components of what Kimball calls the 'liberal-free ideal', originating in the tradition of the philosophers, emphasizes the following: 1. freedom, especially from a priori standards and strictures, 2. intellect and rationality, 3. critical scepticism, 4. tolerance, 5. egalitarianism, 6. volition of the individual (versus the obligations of citizenship), and 7. concern for individual growth.[37] 
Clearly - even though he argues for interesting forms of historical 'accommodations' (like the Medieval adaptation of the 'artes liberales' to the reading and explication of divine texts) - Kimball's list of defining traits won't satisfy everybody. For example, although the first phase of Plato's philosophy is critical in intent, Plato can hardy be called 'egalitarian' in his approach. We will argue later that European early modernity, the Renaissance and Enlightenment, representing the shock waves of scientific discovery and nascent political liberalism, more fittingly expressed the liberal-free constellation of studies. But Kimball is certainly right in discerning a perennial tension between higher studies' seen in the service of the two values: commitment to the Community and commitment to Truth. What is conceived of as instrumental clearly depends on the primary end being pursued. Even with ostensibly 'identical' studies there is a different accent. The question is always what should people do to be properly prepared. Which world should people live in? Will any world do, or the one most most deeply in accord with what is real? What 'latitude' does "reality" permit us? Will technology ultimately permit us the widest possible latitude in defining whatever world we wish? Is that the meaning of technology? Are atomic building blocks ultimately the only constraints?... But we are getting ahead of our story!

We would amend Kimball's classification of educative ideals into two main traditions in the following way. Ancient Greek and Roman pedagogy, despite major differences, rested on a common normative view of the world: that there was something substantial (outer nature, inner nature) that had to be adapted to, adjusted to, or adhered to, for there to be right understanding, morality and/or politics. The alternative to this order was always chaos, figuratively and literally. Departing from Kimball, we see the 'artes liberales', with its authoritative texts mirroring the authority grounded in the nature of things, as receiving its classical expression in the philosophies of Plato and Aristotle. The world had intrinsic limits and happiness accrued from the theoretical and practical observance of those limits. 
Werner Jaeger, the great classicist, saw the rise of Western education/culture ('paideia' being the process by which character was formed in accord with the ideals of society) as being forged in the transit from the aristocracy of the blood to the aristocracy of achievement that took place in Athens, especially during the fifth and fourth centuries B.C.[38] This was the journey of 'arete' (excellence, virtue) from the chivalric codes of the warrior class to the culture of achievement, the first conscious educators, the Sophists, helped bring about. Success in war gave way to success in the civilized (i.e. agreed to limits) arena. Jaeger focuses on the importance and role of the Sophists who funneled Ionian science and the predominantly oral 'encyclopaedia' of the poets into Athens and thus created what we call education.

In a traditionalist society there was no such thing as 'education'- there was simply the passing on of skills and roles, usually from father to son. In the realm of 'things', things were automatically what they were. In a culture marked by achievement (like the new Athenian culture, in which democracy and debate were practically synonymous), things and people became what they were, achieved their characteristic excellence, through a process of cultivation, training, development. Aristotle's great metaphysical insight was to show how change or movement was not mere replication or repetition, but the development of the inner form, the 'telos' of an object or thing. The same went for persons. (In the politically charged atmosphere of Athens of the time, status was no longer an irretrievable given. The skills of contestive speech were now as important as horsemanship used to be.) The predominant Greek image was that of 'shaping the soul', the leading out of beautiful, i.e. appropriate, form, just as the artist-sculptor brings forth recognizable and harmonious form from marble.[39] The other signal Greek image was that of the 'agon' or contest of strength, a sublimation of its warrior culture. Games, whether physical or forensic, always had their rules. Neither tyranny nor chaos were avenues for the display of arete. 
So, by the time fourth century Athens arrived, what did the Greek noetic landscape look like? There was the corpus of poetic recitation, the first 'encyclopaedia' of knowledge, the Homeric tales being a blend of religion, heroic exploits and current information (what and where things were). There were the 'historia', the inquiries and investigations in all fields, from arithmetic, the theory of numbers, to anthropology, the investigation of tribes, customs and what "really" happened, a la Herodotus. There were the audacious speculations of the early Ionian and Milesian 'physicists'. In Greek parlance whatever was learned was called 'mathemata'.[40] There was no particular unity to these diffuse researches. They went where curiosity beckoned. Only later did Aristotle attempt to show that there was a distinct principle or form that defined an area of research and that that was grounded in the nature of the thing studied. In addition, there was the whole range of skills, crafts, arts - what the Greeks called 'technai'. 'Science' or 'knowledge' to the Greeks was 'episteme' (whence our epistemology, the study of how knowledge is possible, how it occurs and by what processes). Episteme represented not so much a particular area of knowledge as a level of achievement - the understanding of the nature/essence/cause of a thing, what its internal 'governor' or source of ordered motion was.

Socrates' great quarrel with the Sophists was that they possessed techne but not episteme. The Sophist training for success was not based on knowledge of the Good. In the Socratic view, techniques without that pivotal knowledge were harmless at best and dangerous at worst. Mind-training without the Good was hazardous, like an instrument not functioning in the context of proper control, proper governorship. If you didn't orient your activities with respect to true order, you were liable to have the chariot of your impulses race out of control - like mythic Phaeton's disastrous journey impetuously seeking to guide the sun in its course, instead of being guided by the sun. 
Plato established the first university in the Western world and the first ordering of the disciplines in the prescriptions of The Republic (the Roman name given to his treatise on the Polity) in order to ensure a proper and extensive apprenticeship in form for his philosopher-trainees. Rising on a vertical scale of forms to the Supreme governing reality of the Good would properly equip the select trainee for the highest forms of public service. For Aristotle, the quintessential biologist, taxonomical classifications and morphological studies culminated in a divine-like 'theoria' or contemplative beholding, a happiness akin to the gods. In theoria reason ('nous') was supremely active, contacting or resonating with the inner life of things via their formic structure. Aristotle distinquished three fundamental types of activities: making, doing and thinking - the productive, practical and theoretical sciences respectively.[41] In a slave-based society labor was mainly associated with unfreedom and most of the crafts by which society survived shared that stigma. For Plato and Aristotle the primary distinction was between those arts that could be called 'servile' and those arts that were 'liberal' i.e. pursued by those having some freedom and/or leisure - like affairs of state or affairs of the mind.

The Organon was the name given to Aristotle's organization of the disciplines as the collective instrument for the direction of inquiry and research. Every field had its 'arche' or first principle or defining form that allowed it to study all the variations in form in its bailiwick. There were 'theoretic' sciences (corresponding to knowing), like philosophy proper ('first science', what came to be called 'metaphysics') and physics. There were 'practical' sciences like politics and ethics (corresponding to doing). There were 'productive' sciences like rhetoric and poetics (corresponding to making). Aristotle startles the modern reader when he says things like poetry is more 'scientific' than history because it deals in universals (universal themes) whereas history simply recounts the particularities of events. The modern historian would tend not to agree! 
All the fields in Aristotle's Organon hinged on his brilliant analysis of movement ('kinesis') which in turn depended on the mediating concept of latency, potentiality, the constitutional predisposition to act or behave in certain predictable ways. Change in Aristotle involved the presence in entities, including man, of an inherent 'telos', the endtoward-which which defines the entity or species. Nature for Aristotle (apart from particular 'natures') as a totality was the realm of pre-determined ends. Leibniz, many centuries later, was to pick up this idea in his notion of 'pre-established harmony'. Refinement was possible and desirable within the confines of our nature. Excellence meant an entity perfectly in tune with itself, the proper (self-)shaping of its own material, its own endowments, the finding of its own internal measure. It was the task of reason in the human entity by virtue of its selective action to bring all its powers to fruition and into proper balance. For Aristotle all things followed their natural bent. But natural processes also gave evidence of much hidden artistry, much work, in the struggle to achieve their ends. Aristotle's metaphysics: an interesting blend of the concepts of stasis, direction and activity ('energeia'). To fully be was to be fully active in accord with the potencies of one's nature. Aristotle's biology gave the first intelligible account of freakish occurrences as well as of embryology - things developing not in accord with their nature as well as how things began their proper developmental pattern. 
Max Wertheimer, one of the founders of Gestalt Psychology, in a posthumus collection of heuristic studies and description of historically significant research/heuristic paradigms, gives the following summary of Aristotle's methodological battery of concepts:[42]

Table I

definition

comparison and discrimination

analysis

abstraction

generalization

forming class concepts

subsumption, etc.

forming propositions

forming inferences

forming syllogisms, etc.

Science, orderly investigation, arose out of the human effort to discern the pattern in things. 'Abstraction' was the process by which the mind, operating in its proper function, isolated and appropriated these patterris or forms. Aristotle's form was the structure of an organism determinative of its activity. Ontological genera (kinds) were the basis of 'genus/species/particular' and indeed all conceptual distinctions. The request to be more 'specific' expresses the Aristotelian mode of thinking in our speech. Definition in the Aristotelian mode was to first establish a kind and then note the specific difference.

Wertheimer goes on to say that

"(T)he system of traditional logic, as envisioned in its main outlines in The Organon of Aristotle, was recognized as final through the centuries; elaborations were added here and there, but these did not change its main character. A new branch started at the time of the Renaissance, a development that was essential to the growth of modern science. The central point was the introduction, as fundamental, of a procedure which until then had been regarded as of minor value because of lack of complete conclusiveness. This is the procedure of induction, with its emphasis on experience and experimentation, a 
methodological concept which reached its greatest perfection in John Stuart Mill's famous canon of rules of induction."[43]

It is important to add that Aristotle's codification of Greek thought represents a whole way of thinking, culturally embedded - a 'Weltanschauung'. Nature was the realm of the eternally given; thinking in all fields simply ascertained characteristic differences and made connections on the basis of that. Disciplines from biology to political science (the study of the different constitutions of city-states) to physics to poetics simply harvested the results of pre-given activities or practices. Poetics simply 'rationalized' pre-existent odes and dramatic activity. Aristotle's epistemology never raised the question of whether knowledge was possible, or what lay beyond its limits, if anything. The world was bounded and self-contained (as in the Greek favorite image of the sphere) and any residual problems, e.g. the retrograde motion of the sky-wanderers ('the planets') was a matter of the mopping up to be done by continued inquiry. Nothing new under (sic!) the sun. The disciplines needed no 'center'. They simply pursued and explicated the different types and species of things in accord with their different 'logoi' (internal logics of operation). Metaphysics was, in this idiom, supremely classificatory: following the natural distinctions of that which was already (and eternally) there. It was all rather calm and systematic. All that was needed was the patience of the intellect to unfold this huge paper-mache of the universe. The creases were the disciplines. Or, as Plato would say, all one needed to do is to 'cut at the joints' (whence our term, 'articulation'). 
The Greeks had drawn the perimeter. The Romans, when they waxed reflective. lived in that world. The Stoics, born on Greek soil and their tutors, defined its outer and inner edges, its cosmology and its psychology of resigned acceptance to a rather mechanical but orderly Providence. Hellenistic culture, whose 'Nobel' laureates frequented the House of the Muses (the 'Museum') and Library in Alexandria, like the astronomical epicycles it studied, offered exhaustive systematization and refinement but no basic innovations in the pattern of inquiry beyond the Greeks. All the Greek prototypes historia, drama, epic, music, philosophy - were eruditely cultivated.[44] One brave soul of that era, Sextus Empiricus (whence our term, 'empirical', oriented towards experience) criticized all the devotion to erudition.[45] Fires and Christianity did the rest.

The Krishna-like sect of early Christianity burst the bounds of the ancient world and created a larger space and a different basis for reverence. Things and people had a different 'standing' and 'dignity' as the creation and children of God. A new basis for behavior lay in the freshly revealed kinship between the lilies of the field and the 'wretched of the earth', both watched over by a loving Father. In time, however, the Church, the boat to salvation, the ecstatic community, came to resemble a cloistered and claustrophobic empire replete with repressive hierarchies. 
The early Christian rationalizers (the 'Fathers of the Church') struggled mightily in trying to reconcile and eventually mould into an appropriate instrument the literate culture of the Hellenes. What was the place of 'letters' in the new aeon of the Christians? What was the place of oratory, given a new 'Supreme Judge' of human actions, and accordingly a new heavenly forum? The old measure of excellence seemed to be inverted: 'the last shall be first'. What need was there for forensics when it was the state of your heart that was really significant? What was the need for erudition and display and ferreting out the world's mysteries when all one need be is brotherly? What was needed for the Christian was not oratorical training or philosophical speculation but 'metanoia', a complete change of heart that resulted in a new way of living ('meta'=beyond, 'nous'=reason). The mind was not the guide through the uncertainties of life - the exemplar of Christ was.

The early Christian apologists and zealots were sometimes violently anti-rational, 'pagan' culture being seen as the epitome of worldly wisdom. Tertullian mutilated himself in advocating extreme ascesis, disassociation with the worldly. A Christian mob literally tore apart and burned the cosmopolitan woman and prominent Hellenistic mathematician Hypatia in Alexandria in A.D. 415. Other apologists and thinkers, like Augustine, were more accommodating of the Greek philosophical tradition for reasons of faith and practicality. Truth could only be one, and therefore previous knowledge couldn't be opposed to Divine Wisdom. Besides, the increasing barbarian invasions made sheer literacy and the performance or rudimentary civic functions a premium in the medieval 'dark' ages. 
The titantic figure of St. Augustine, who had gone from libertine and sophisticate professor of rhetoric to Christian theoretician and bishop, set the tone in many ways for the ensuing centuries. He provided a political cosmology, a two-tier model of existence in his The City of God, which counterpointed the transitory 'city of man' with the heavenly polity benignly and securely ruled over by God. He blazed the trail to that secure divine order and consciousness through Inwardness and Transcendence, the psychology immanent in his Confessions. Memory for Augustine had an 'existential' dimension: it was not merely a matter of recall but the unearthing of divinely established archetypes in the soul. Thus for him, as for Plato, education was 'e-ducere', the leading or drawing out of those inner harmonies, those inner structures latent in the soul. And, in a late work, De Doctrina Christiana, he established the direction for the arts, sciences and pedagogy by justifying the role of classical learning in the context of Christian reasoned ascent to God.[46] Augustine's famous 'tolle et lege' conversion experience presaged a different kind of in-depth reading experience: the world was now a 'forest of symbols' (Baudelaire), 'fingers pointing at the moon' (Zen). The 'world' was now not a given 'natural' fact but part of the Divine Mystery. Explicating God's presence in His works was now the task to he assiduously pursued. All the arts, even the pagan intellectual arts, were given a rationale: to make clear His works and to provide regular avenues to holiness. This is a long way from early 'scandalous' Christianity with its vaunted irrationality ('I believe because it is absurd!') and its uncompromising opposition to antique culture. 
The canonical configuration of the 'Seven Liberal Arts', originated by Boethius and made popular in an ebullient treatise by Martianus Capella in the fifth century (The Marriage of Philology and Mercury, of learning and eloquence), underwent many vicissitudes. David Wagner's anthology, The Seven Liberal Arts in the Middle Ages, charts the ups and the downs of the trivium (grammar, rhetoric and dialectic or logic) and the quadrivium (arithmetic, geometry, music and astronomy). The shift from rhetoric as the key science, in the early Middle Ages, to logic in the later, largely echoes Kimball's move from the influence of the orators to that of the philosophers. But there were many variations and the accent was always changing.

Some variations: Alcuin, educational reformer at the court of Charlemagne, in his program for the instruction of the clergy states the primary cultural axiom: " The foundation, the state, and the perfection, of wisdom is knowledge of the Holy Scriptures'. The Seven Arts are the ancillary disciplinae... ."[47] Raban, his vigorous successor, "...treats 'Dialectica' more seriously. With him it is the 'disciplina of rational investigation, of defining and discussing, and distinquishing between the true and the false. It is therefore the disciplina disciplinarum. It teaches how to teach and how to learn; in this same study, reason itself demonstrates what it is and what it wills. This art alone knows how to know, and is willing and able to make knowers. Reasoning in it, we learn what we are, and whence, and also to know Creator and creature; through it we trace truth and detect falsity, we argue and discover what is consequent and what inconsequent, what is contrary to the nature of things, what is true, what is probable, and what is intrinsically false in disputations. Wherefore the clergy ought to know this noble art...." [48] 
Though it can be relatively safely said that the quadrivial group of studies got short shrift in the Middle Ages, Raban gives a typical testimony as to why they might be, and were, studied: In regard to the "'sublimity of the study of Astronomy '... (i)f pursued with chaste and sober mind, it floods our thoughts with immense love. How admirable to mount the heavens in spirit, and with inquiring reason consider the whole celestial fabric, and from every side gather in the mind's reflective heights what those vast recesses veil"[49] In one of the many twists and turns and ironies that attended their development, the trivium arts were thought of as the 'utilitarian' group of the seven, having to do with the arts of expression, reasoning (mirroring the order of Creation), and the effective arrangement of forms in discourse. Disputes in the 'four-path' arts - and most agreed that these also groomed the mind to appreciate form as the expression of divine order - had to do with such things as which discipline came after arithmetic, the science of number, ratio and proportion. Which was prior: music or astronomy?. The answer depended on whether the proponent was Platonically or Aristotelianly inclined, whether the Pythagorean tradition or the tradition of 'natural philosophy' was uppermost.[50]

There were interesting medieval bouts with Chomskian-like 'speculative grammars' (e.g. the 'Modistae' who studied the different modes and universal structures of language, and Anselm who called for a universal grammar beyond all particular languages)[51] The latter idea surfaced later in Leibniz's ideal of a universal symbolic language for discourse. With increasingly available and accurate translations, Aristotle's logic was put to use in Abelard's sharp contentions and Aquinas's architectonic 'summary' of theology. As the pendulum swung back and forth from Plato to Aristotle to Plato again, Peter Ramus could say in the 1500 's that mathematics, being the model of deductive reasoning, was 'the premier liberal art, without which philosophy was blind'.[52] 
While the medieval world had its variation of intellectual opinion and fashion as any other age, the consummate 'mystical' flowers of that age, the giants of Inwardness and Transcendence - Meister Eckhart, the anonymous author of The Cloud of Unknowing, Thomas a Kempis, Julian of Norwich - all would tend to agree with this 12th Century monk's assessment:

\begin{abstract}
"Accordingly, therefore, our master Christ in his school did not teach grammar, rhetoric, dialectic; rather he taught humility, meekness and justice. Nor did our master Christ in his school teach those arts that they call liberal, but that are neither free nor liberating and indeed may instruct greatly in sin."[53]
\end{abstract}

For the late Medieval mystics all concepts and worldly practices fell short of God. Intellectuality in all its forms was not only seen as an invitation to pridefulness but as a distinct barrier to the realization of God. The Christian acesis, the contemplative disciplines, aimed at creating the space whereby God could enter the soul. For Eckhart, the true task was not adding to erudition and controversy but stripping away everything till the nakedness, the nothingness of the soul, the 'true aristocrat', God's life at the core of the soul, was reached. 'Disinterest' (detachment, not uninterest), rather than multifarious inquiries, was the way. The author of The Cloud enjoined covering our habitually restless thoughts and vain imaginings with a 'cloud of forgetting'. God could only be reached by a primal gesture, a 'dart' of love, piercing through the multiplicity of things and concerns. Thomas a Kempis told his fellow monks that the Kindom of Heaven was 'within' and was indeed the very life of the soul. 
The inward path, the 'via contemplativa', pursued mostly in monasteries, explored the quiet recesses of the soul, while the outer centers of learning, e.g. the famed universities of Paris and Oxford, seemed to be mired in the eristic display and verbal disputation that so angered the 'new agers' of the Renaissance. Excessive reliance on syllogisms had made the trivium seem trivial. The mystics flourished while the 'worldly' disciplines seemed to be lanquishing for lack of a new unifying approach or galvanizing idea. 


\section{NOVUM ORGANUM}

"So men should cease to wonder that the course of the sciences is not yet run, since they have entirely lost their way, either abandoning experience altogether, or else becoming entangled in it and wandering as if in a labyrinth; whereas a method rightly set up leads them through the forests of experience to the open country of axioms by an unbroken path."

-Francis Bacon, Novum Organum, Book I, Aphorism 82

"An anvil struck by a hammer becomes quite hot, so much so that if it were made of thinner plate, I think it could redden like ignited iron, under repeated strong hammer blows. But this should be tried by experiment."

-Ibid., Book I, Aphorism 13, 31.

Medieval boundaries were burst apart with the rebirth of classical and more secular studies (where 'secular' means pertaining to this age, this time, this world): the Religious Reformation and the Advent of Science.[54] The so-called European Enlightenment not only popularized the new science of the day but laid the ground for its revolutionary political implications. Royal and churchly and philosophic 'ancient regimes' were in peril. Pugnacious Luthers and Galileos, and gentle Copernicuses, challenged Church authority on several fronts, the implications of the new cosmology being just as worrisome as contentious theological theses. Giordano Bruno was burned at the stake for metaphysically suggesting that there was an infinite plurality of 'universes'. If the pope had so much trouble trying to control the flock in one 'universe', imagine the difficulty with an infinite number! Our cosmic 'backdrop' defines for us what actions are considered 'rational'. It also has similar implications for what are regarded as reasonable ways to interact, i.e. the nature of political bonds, not to mention sacred bonds. Again, issues of allegiance and authority, how actions accord with the conceived nature of things. A new spirit of questioning and a new quest for freedom had begun.[55] 
It is a moot point as to whether this new spirit had its genesis in the Medieval training, and especially faith, in rationality, as Whitehead maintains in Science and the Modern World [56] - or whether the overreliance on the exercises of a jejune dialectic in late medieval thought (an oversophisticated turn comparable to linquistic-analytic philosophizing in the 20th Century) really needed an influx of new data and new life. In any case - whether a slow progression, a negation or a saltation - a new emphasis occurred infecting all fields of thought, action and manners. A new etiquette of thought with new protocols. The kaleidoscope of the disciplines would change accordingly.

The Renaissance rediscovered motion and poli-centrism.[57] The aspired for unity of the Medievals was no longer considered an ideal. There was the clamor of nationstates and new associations and new technologies. Galileo studied motion with as much gusto as nation-states took in taking initiatives apart from papal authority. Instead of rest being the assumed natural state (with everything in its 'proper' place), momentum came to be seen as primary. The world-horizon was expanding and consolidating at an unprecedented rate. The new mathematical tool of the calculus was developed to deal with the rates of change of entities. Although Louis the Fourteenth could say for a while, 'L'Etat - c'est moi!', new contracts would eventually have to be drawn up between ruler and ruled. The writing was on the wall and the graffiti-artists were the enlightenment 'philosophes'. Voltaire, the Betrand Russell of his time, popularized the new science of Newtonian physics with a missionary zeal. The new cosmic backdrop made new social relationships possible. New sciences, new explorations and boundary makings were in the air. Gambistto Vico (1668-1744) was a pioneer in attempting to trace the progression of collective human consciousness. He called his work "Scienza Nuova". 
Marshall McLuhan, in his inimitable polyvalent style, attempted to explain the phenomenon of science by seeing the recent invention and technology of printing as decisive. Just as we denizens of the late 20th Century take our metaphors for understanding the mind and world from computer technology, so too the analytic habits of early modern scientists may have been influenced by the visual-linear-segmentation bias of movable type.[58] Thus we go from the speech/persuasion style of the Greeks to the medieval (manu-)script with its inflections, a continuous hymn with commentaries, to the analyticity 'built' into the print medium and configuring perception along with the 'shape' of world. For McLuhan, the oral culture of the Greeks, and the dialogues and debates of the Medievals gave way to the modern penchant for individualistic privacy coupled with the 'space' of publication (the then new 'virtual reality'). The technology of print configured the modes of assembly. Many facets of the print medium threatened ecclesiastical authority: the proliferation of books (and therefore information), the secularity of literacy (breaking the clerical monopoly on reading and writing), private interpretation of scriptures, aggressive political expansionism, and the conception of abstract uniform space.[59]

The sense of segmented, replacable spaces (or parts of space) now allowed the Cartesian grid system of analytic geometry (also one of the newly minted sciences) to be the appropriate method of description. With Aristotle, space was a coordinate or 'attribute' of organic substances. Now, space - and time as well - became a continuous and mathematically defined quantity, a homogeneous field. And, we may add, as thus denuded, it became infinitely manipulable. Entities became atomic points, abstract and convenient centers of mass. Abstract Space, Time and Matter, rather than the modifications of substances in their locales, became the literal and figurative building blocks of the new philosophy. 
Universities were still the bastions of the status quo and the embodiment of the medieval ethos, namely that all human learning and all human society aspired toward God and hence were one under the divine aegis.[60] Whether reality or myth, the putative unity was shattered by these new iconoclasts. The later corpus of Aristotle's writings had been assimilated (Aquinas' Summa being the outstanding example). It had then become the reigning scholasticism of the universities that was derided as decadent, sterile and irrelevant by the new intellectual voyagers. It was part of the 'old world' and they were setting forth for new ones. The monasteries, tended by the religious orders and being the very soul of immurement, preserved their "inner" culture with infusions from baroque mystics like St. John of the Cross and St. Teresa of Avila. The universities were no longer the centers of action or ferment.

Kimball recounts the situation at this cusp:

"Consider the attitude of proponents of the New Philosophy and the New Science toward the schools. Most stood with Francis Bacon, outside the established institutions, objecting to their scholastic and gentlemanly preoccupations. Hobbes had been bored by the Aristotelianism of Oxford and wanted his own doctrine taught in the universities rather than that of the ancients. Descartes did not find the study of rote syllogisms or ancient authorities helpful in pursuing truth, and Locke thought the disputations of the universities useless. These attacks on the schoolmen persisted in the eighteenth century, as when Gibbon derided the universities for their dogmatism and Hume suggested their libraries be weeded out..."[61]

And Moliere lampooned Aristotle's physics by saying opium put men to sleep because it had a 'dormitive power' - the epitome of empty reasoning! Reason itself apparently needed fresh infusions, new data to process. Enter Francis Bacon and a new respect for sensorial experience championed by the British 'empiricists': Locke, Berkeley and, its enfant terrible, David Hume. 
Kimball continues:

"The New Philosophers were equally critical of the adulation of Greek and Latin letters. They did not disdain the vernacular: Descartes, Rousseau and Voltaire wrote important works in French; Bacon, Locke, Hobbes and Hume in English; Lessing and Kant in German. And they criticized the pedantic approach to teaching literary classics... These New Philosophers fundamentally rejected the oratorical conception of liberal learning... In consequence of these attitudes, and notwithstanding midseventeenth century efforts at reform... the freethinkers, experimenters, modernists and philosophes basically worked outside educational institutions. Until late in the seventeenth century, scientists usually conducted research as individuals, scattered with their helpers in private workshops and homes. Gradually, formal institutions to support these endeavors were established apart from the universities in the form of scientific societies dedicated to the New Philosophy. These included the Royal Society of London in 1622, the French Academie des Sciences in 1666, and, subsequently, the Societas Regia Scientarum in Berlin Shortly thereafter, free journals arose to publish their findings. In 1682, Leibniz founded 'Acta Eruditorum' in Leipzig; and Holland, ever a tolerant land and thus mother of new ventures, gave birth to others."[62]

The importance of the founding of these extra-curricular scientific societies with their 'journals' was paramount. They were the organs of transmission of the new knowledge and disciplines. Without their advocacy and protective preservations of inquiries and results, individuals, along with their flashes of insight, could be burned at the stake. These gifted amateurs, spurred on by the excitement of their discoveries, operated in the penumbra of non-legitimacized knowledge. Their spirit of scepticism, experimentalism and enterprise was symbolized in the resolute motto of the Royal Society, 'Nullius in verba' ('on the word of no one').[63] 
It is difficult to do justice to the ferment that has been called the Renaissance. The Holy Roman Empire was disintegrating into incipient nation-states with their expansionist imperatives. The vigorous civic independence of Florence, for instance, saw the spawning of private academies and fellowships that studied the Greek and Latin classics with a keen aesthetic and philosophical interest (the pendulum had swung back to Plato)[64]. One of these, the fraternity of the 'lynx-eyed', published some of Galileo's initial researches on sun spots, which, along with his work on the irregularity of the moonscape, destroyed the hard-and-fast distinction between the celestial and the terrestrial.[65] The city-state mentality in Italy, as with the Greeks of Anatolia - centers of flourishing trade routes seemed to foster intellectual freedom and venturesomeness. Trade, new ideas and a refreshing scepticism seemed to go together.

In the Renaissance and early Modern era there was in effect three traditions current and jostling for dominance. The first, the new 'humanistic studies', which harkened back to Cicero's 'humanitas' ideal of the well educated civic minded citizen, the living example of Kimball's 'artes liberales' configuration. With Petrarch (1304-1374), the disciplines of knowledge were history, poetry and philosophy.[66] With Vergerio (13491420), knowledge meant history, 'moral philosophy' ("...which is indeed, in a peculiar sense, a 'Liberal Art' in that its purpose is to teach men the secret of true freedom") and eloquence.[67] In neither case cited was history used in the nineteenth and twentieth century sense (i.e. after Kant and Hegel) of a universal history of mankind. For the Renaissance scholar or courtier, history meant more concrete examples of general precepts inculcated by philosophy.[68] 
The second tradition present in the Renaissance was persistence of the Sacred Tradition, which spanned the archaic-shamanistic, the Mystery schools, the Gnostic and Revealed Religions with their cultivation of the Transcendent Divine. Islamic and Jewish culture had gone through a similar cycle of development as did the Christianity in the Middle Ages: from charismatic founder and contagious conversions to philosophical rationalization and explication, to esoteric manifestations (like the Kabbala mysticism in Judaism). In the West, the "inner tradition" was played out in external theologizing in the schools, pietistic and 'reformation' movements, 'counter-reformations' and finally in religious wars. Political and religious diversity (if not contradiction!) seemed to be Europe's destiny: delicate mystical flowers and gentle souls, like St.Francis of Assisi and 'the cherubic wanderer' Angelius Silesius, coexisted with wars, persecutions and acrimonious theological debates that filtered down to everday exchanges between butchers and bakers.[69] Nice points in theology determined whether you were going to go to heaven or hell, as well as how much effort you should put forth in proportion to divine grace and why. Once again, image of the world determines what kind of actions make sense. Whether (and what kind of!) God exists, and whether the world is round or not, determines what's heroic and what's foolish. The 'shape' of space with respect to action is always ideological. 
But an Atlantic tsunami was coming, the new wave front of physical science with its ardent rationalizer, Francis Bacon (1561-1626). This was the third and distinctively defining force of the modern era: the promethean wedding of science and technology, foresight and power. The term modern comes from the Latin 'modo', meaning 'just now'. The 'moderni' was the generation charged with significance, charged with a mission. As the apostle of the new intellectual-practical order, Bacon set his guiding ideas in direct counterpoint to Aristotle. His major work was called Novum Organum. Here was the technologically inspired tool of tools, a fulcrum of discovery, a compendium of the new methodology, a new and productive orientation to experience. For Aristotle, and the Greeks generally, the 'liberal' arts (arts, sciences, pursuits) were always contrasted with the 'servile' arts of slaves, trademen and artisans. But for Bacon the 'mechanical' arts were integral to the new way of thinking in a truly productive manner:

"From the very outset of his Novum Organum, (Bacon) places on the same plane doing and understanding, the hand and the mind; hence the vital new meaning which he gives to Aristotle's metaphor of the organon, or tool, as a designation of logic. Neither the bare hand nor the isolated and unaided mind can dominate things: material and mental tools together lend hand and mind their true efficacy..."[70]

The epitome for Bacon of the old style of reasoning was the syllogism, the warp and woof of scholasticism.

"Out of the insight into the unfruitfulness of the syllogism, which could merely set forth in proof or refutation that which was already known, [our emphasis] or apply the same to a particular case, arises the demand for an ars invendi, a method of investigation, a sure way to the discovery of the new."[71] 
Bacon published his call for a new heuristic in 1620. Descartes published his similar and powerfully influential call, Discours de la Methode, in 1637. Both considered their new approach systematic, revolutionary and the blueprint for generating new sciences. Start with the facts of nature rather than faulty or dubious notions and idle debates, said Bacon, and be led to an exact and useful knowledge. Asking questions of Nature, rather than verbal reshuffling or opining should be our goal. 'Our only hope lies in true induction...' he says in Novum Organum. [72] The various 'idols' (e.g. of the 'tribe' and the 'marketplace'), the perennial sources of misconception, should be cleared up and nature should be faced with new eyes.[73] The canny politician-statesman-philosopher said, in The Great Instauration (The Great Renewal), that nature needed to be obeyed before she could be commanded. Like his exploratory counterpart Sir Walter Raleigh, Bacon saw new worlds to conquer, given the prudent and expeditious outfitting of the ship of cognitive enterprise. 
Part of Bacon's breathtaking overview of the process of discovery was his utopian tract New Atlantis. A social program for the betterment of mankind was an integral part of his vision. More's Utopia, Campanella's City of the Sun and other utopian visions of social possibilities were in the air. Bacon's 'Solomon House' was to be an educational institution whose aim would be the seeking out of new knowledge as opposed to simply the conservation of wisdom. [74] 'Houses', field laboratories, would be set up for 'natural' experiments. Bacon saw these research institutes as combining science and technology, interests and instrumentation. New trades, new industries and new sciences were to be invented.[76] The 'advancement of learning' would, in effect, be the advancement of society. The New Atlantis and the revolutionary ideas it expressed was one of the chief stimuli in the formation of the Royal Society.[77] In the generation succeeding Bacon in England, a Ted Turner like figure, Samuel Hartlib, emulated Bacon's reformist and entrepreneurial spirit, and William Petty (1623-87) advocated the scientific-technical approach in the form of a 'practical curriculum', craft-centers that would teach dyeing, metallurgy, chemistry, globe construction, etc.[78]

Also around this time, on the Continent, Commenius (1592-1670) was formulating modern developmental theories of cognitive growth predicated on non-violence, that is, non-violence to the 'natural' progression of growth of the human being. Curriculum, i.e. appropriate sequencing, should follow 'natural development'.[79] An Englishman, John Dury (1598-1680) spelled out the powers of the mind - sense, imagination, memory, reason - and said in Baconian fashion that there was a 'natural subordination, with the level of sense being primary'.[80] John Locke's whole philosophy was a struggle of the British empiricist emphasis on the deliverances of sense (and sensory qualities) with Isaac Newton's physics of universal forces. Which were primary: sensory qualities, or the mathematically defined 'qualities' of space, time and mass? Locke tried to have two sets of qualia. With Descartes the problematic appeared as 'res cogitans' (the perceptions of the thinking subject) and 'res extensa' (again, space, time and matter, mathematically defined). 
Nature, in being seriously probed, 'interrogated' in Bacon's term, was in danger of being seriously, in Whitehead's term, 'bifurcated' into two separate and distinct sets of entities. While there were new 'sciences' cropping up all over the place, in the 1600's in Europe, philosophy was still the term that connoted kowledge in general. So Galileo in his 1638 publication of Discourses and Demonstrations Concerning Two New Sciences in his controversy with the Church urged the sharp division between 'natural philosophy' and 'moral philosophy'.[81] Historian Bowen writes,

"In Galileo's view the natural world, mechanical in its function and measurable in its effects, must be distinquished from the moral and social world...Philosophy...which formerly dealt with knowledge in general, must be divided accordingly, with natural science, using the methods of mathematics, confined to a study of the mechanical world."[82]

This was not only a shrewd diplomatic gambit on his part but was also beginning to represent a division in the sciences that would increasingly become manifest in academic world. There were two main curricular "branches" of knowledge, and this was the way the disciplines were to be conceived in relation to each other. For instance, in the Scottish universities of the nineteenth century, 'natural philosophy' meant physics and 'moral philosophy' meant philosophy tout court. Philosophy was still the honorary and titular head of the sciences but two cultures were uncomfortably side by side. What was the true unity of these two worlds? As Dilthey observed, "Knowledge of nature became distinct from the general life of the soul."[83] 
Hannah Arendt gives this tantalizing thought appropos the encapsulation of nature in the mathematical language of Galileo, Descartes and Newton: "With the disappearance of the sensually given world, the transcendent world disappears as well..."[84] So, strangely enough, when the metaphysical status of the senses is put in doubt so too is the status of the 'soul' with its peculiar access to the Beyond. Thus mathematical language albeit powerful becomes a mono-language of single-valuedness rather than a resonant device. Nature was to be read in clockwork or mechanical terms and the parts, probed with ever increasing precision, were to be manipulated according to our will. Arendt rightly points out the eventual despair resident in this Baconian-Kantian position: ultimately man finds his 'fingerprints' everywhere in nature, and nature becomes completely subservient to man. Philosophically minded scientists in the twentieth century, like Eddington, Jeans, Heisenberg and Schodinger, say that we eventually end up simply encountering the patterns and designs of our own minds.[85] Mathematical objectivism becomes promethean self-creation (we can create whatever we wish) and therefore a kind of cosmic solipsism.

Sensorially resonant nature, given only or predominantly the mathematical reading, becomes, in Whitehead's famous description, "... a dull affair, soundless, scentless, colorless; merely the burrying of material, endlessly, meaninglessly."[86] And Whitehead is right, the 'Romantic Reaction' from Blake to Goethe, follows as a result.[87] In Whitehead's account the scientific abstraction (and philosophical fallacy!) of 'simple location' is contrasted with the organic interpenetration of all elements of nature. In addition to this Whitehead saw all nature as charged with 'value', immediate and given. Things not only had aims, or were for aims, but were for their own sakes.[88] Peter Gay sums up the general trend:

"The irresistible propulsion of modern scientific inquiry was toward positivism, toward the elimination of metaphysics, and the clean separation of facts and values, foreshadowed by Bacon, implied by Newton, triumphantly announced by 
Hume, taken for granted by the leading scientists of the late eighteenth century. Scientific thinking exacted the stripping away of theological, metaphysical, aesthetic, and ethical admixtures that had been a constituent part of science since the Greeks [our emphasis]; scientific philosophers of the eighteenth century, with justice, treated these admixtures as impurities, as survivals from earlier stages of consciousness. Every scientific discovery weakened the hold of theological explanation, metaphysical entities, and aesthetic considerations: the orbits of planets were neither beautiful nor ugly; the law of gravitation was neither cruel nor kind; observed irregularities in the skies proved nothing about divine activity."[89]

Gay goes on to say that while all this expansive scientific ferment was exhilarating, it was not without its misgivings and nostalgia.[90] The avant-garde philosophes were one-third gentlemen, one-third scientists and one-third (somewhat uncomfortable) revolutionaries! They were the midwives of the modern, secular world in which all things, including and especially political relations, could be called into question. Ultimately science would be the humane guide of an 'enlightened' society. There was a tremendous faith that a new science of human nature would perfectly parallel Newton's great discoveries in the field of matter and its relationships. Hobbes was the first to import Newton's Nature as a field of forces into a treatise on human nature. Thereafter the 'forces' in the human breast, the 'brutish impulses' and 'passions' were deemed more worthy of serious study and not merely dismissed as 'sins'.[91]

Adam Smith, in fact, saw the engine of economic activity resident in the 'passions', 'sentiments'and 'selfish interests' of mankind. Not only was the new science of 'political economy' emerging but a new justification of human existence: nothing but the fiats of human desires circumscribed the human world. Conscience ('sympathy', 'the moral sense'), like political reality, was a construction superimposed on these innate projectiles of human wants.[92] Economic activity and labor, the production, transference and consumption of goods, was its own reason for being. No transcendent perspective need apply. 
The secularist trend of the Enlightenment continued: Hume and Kant in their critiques of unaided reason discredited metaphysics as ungrounded speculation. Locke and Rousseau discredited the divine right theory of government. The American and French Revolutions carried out the implications of their questions of the proper locus of authority. Ultimate authority now rested in the contracts of individuals and their corporate agents. Gods, kings and nobles represented in their tyranny a kind of (to adapt Whitehead's phrase) 'misplaced concreteness'. The real power lay in ourselves. Reason was no longer an access to the divine but the adjudicator of practical enterprises. Once again fire had been wrested from the gods. Francis Bacon heralded the invention of the technique of invention. No longer was man left to the haphazardness of chance or to floundering in speculation that was tantamount to wishful thinking, or what Freud called the 'omnipotence of thought'. This is the Deweyan motif of consciously applied instrumental reason as being the only true agent of progess in human affairs.

This second 'organon', or methodology for conducting systematic inquiries and enterprises, a set of principles for organizing - and indeed multiplying - the disciplines, can be conveniently summarized by the second table in Wertheimer's Productive Thinking:

Table 1a [perhaps more clearly expressed as 'II a']

empirical observation

careful gathering of facts

studying problems empirically

introducing experimental methods

correlating facts

developing crucial tests [93] 
To this list Wertheimer might have fittingly added, 'drawing tentative conclusions', part of the stock and trade of inductive logic. Wertheimer correlates the above table with an accompanying one that attempts to summarize the historically associated empirical psychology from Hume to B.F. Skinner:

Table II [perhaps better called 'II b']

association, acquiring connections-bonds on the basis of repetitions

role of frequency, of recency

recall from past experience

trial and error, with chance success

learning on the basis of repeated success

acting in line with conditioned responses, and with habit [94]

Wertheimer eventually goes on, after his historical and pedagogical case studies, to contrast Table I (Aristotle's organon or classificatory logic) and Table II (Bacon's organon or scientific inductive logic with its associated psychology) with Table III, his own attempt to construct a 'gestalt' heuristic or holistic way of approaching problems. Wertheimer sought a 'structuralist' methodology that investigated how things do or don't fit into contextual patterns, how parts figure in whole thought/action complexes. In a word, how meaningful patterns guide our activity. Thomas Kuhn's The Structure of Scientific Revolutions is pure gestalt psychology applied to the history of science. For Wertheimer and the gestaltists, cognitive dissonance is often quite fruitful and indicative of deeper order. 
Some amplifying notes: In Aristotelian metaphysics, the ontological units are substances and they exist in a wide variety of kinds. In severe versions of the Baconian scheme of interpretation, units are bare particulars, atomic facts, as it were. In Aristotle. causality is multi-dimensional: how a thing arises, its defining purpose or end. its internal constitution, formal and material. The scientific method, on the other hand, emphasizes purely functional relationships, correlations arising from 'head counts' of instances frequency distributions. No causal connections are asserted, only co-variations. Propositions in Aristotle are relatively speaking, simple affairs - the joining of a predicate or attribute to a subject. In science, propositions can be vastly complex deductive mathematic - systems; but the manner of attribution is highly tentative and probabilistic. Karl Popper's twentieth century version of 'fallibilism' is perhaps the most influential statement of this facet of scientific methodology[95] and he is squarely in Bacon's lineage. Popper, not so incidentally, has been a staunch advocate of political liberalism, and, in The Qpen Society and its Enemies he launched a blistering attack on Plato and Hegel as purveyors of totalist ideologies and closed, repressive societies.

Methodologically sceptical science and political liberalism, with its emphasis on the rights of individuals in society, are key components of Kimball's ideal constellate of the 'liberal-free' tradition in higher education.[96] Another scion of Bacon in the nineteenth century was John Stuart Mill. Mill combined the social-meliorist concern of Utilitarianism with the Liberal emphasis on individual freedom and a powerful refinement of Bacon's inductive logic. Mill's articulation of the scientific organon focuses on the concatenation of events: perceived 'concomitant' variations in similarity and differences. 
Interestingly, James Bowen, in his voluminous philosophical and institutional history of Western education, makes clear in many places the strong analogy between how sensations are epistemologically conceived in relation to general concepts, and how individuals are conceived in their relation to the state. For Aristotle, the abstractive process was like the responsible decision making of members of the polis 'won over' by cogent argument. For the British Empirical tradition, particulars (whether cognitional or political) form tentative and revocable 'contracts' that were the basis of unity. How unity is conceived pervades all facets of a weltanschauung.

The evolution of university curricula in the seventeenth and eighteenth centuries showed the slow amalgamation and consolidation of natural science inquiries under the rubric of 'natural philosophy'. Side by side existed the older literary tradition, the education of the 'gentleman', with Greek and Latin culture studies - language, literature, history, philosophy and the fine arts.[97] And the French Philosophes made being a social progressive popular. In the eighteenth century, Thomas Jefferson was a gentleman, amateur-scientist and political revolutionary. In the nineteenth century John Stuart Mill was a gentleman, scientist-logician and an advocate of progressive liberalism. 
The Epistemological and Social program of Bacon in England and the Philosophes on the Continent (along with the flowering of scientific luminaries from Halley to Hooke. from Laplace to Lavoisier, from Buffon to Cuvier, Faraday to Fraunhofer) culminated in the architectonic rationale of science enshrined in Comte's 'Postive Philosophy'. Like his progenitor Bacon, Comte was a spokesman for the whole modern era. Explicit in him is the cultural axiom that progress in the sciences goes hand in hand with the improvement of man's lot. Comte's image is a powerful one: mankind emerging from the childish worship of (and hence slavery to) the external, to the adolescent romance with sheer possibility and the intoxication with speculation, to the sure, steady path of adult scientific corroboration.. Curriculum theorist Joseph Schwab argues that Comte's influence has been pervasive and the internal ordering of his hierarchy of disciplines still poses significant and interesting questions.[98] Wilhelm Dilthey's assessment:

"Inasmuch as Comte brought under investigation the connection between this logical order of dependence between truths and the historical relationship of their order of appearance, [our emphasis] he created the foundation for a true philosophy of the sciences. "[99] 
To understand the scientific summa of Comte, and the nineteenth century generally, the genius of Hegel and his enunciation of the historical principle, must be understood. The Philosophes in their secularist zeal associated mankind with progress and progress with betterment. The American and French Revolutions and the triumphant marches of Napoleon seemed to sweep away all vestiges of the old order. Hegel gave voice to modernity and its revolutionary spirit (and set the stage for the nineteenth century) by trying to show that history was simultaneously divine manifestation, the progression of consciousness, and the unfoldment of cultural forms. A full philosophical plate. An incredibly audacious project. Just as Spinoza saw Nature as the other side of God's visage, so Hegel saw History as theodicy. Instead of God being the bastion of the status quo, His Spirit was now envisioned as the hidden force moving mankind in the direction of full social justice and a truly rational completeness. But first all the contradictions inherent in mind and society needed to be faced up to. The history of consciousness was that tale.

For Hegel,[100] the dynamic of history is that man doesn't know himself. He projects onto nature forms of perception and desire that he doesn't know originate in himself, and often with tragic consequences. He has no self-awareness: 'external forces made me do it', 'kings made me do it', 'the devil made me do it', 'the world is like that'. Men tend to see history in this blindsighted partial way. The result appears to be a 'vast altar of suffering', a scene of scattered ruins, 'a tale told by an idiot'. It is not, says Hegel. It is told by God and is the story of His manifold disguises. Hegel goes beyond previous theodicies which attempted to reconcile and justify the bloodshed and omnipresent evils of human existence with a benign and all-powerful God. These previous justifications implicitly assumed two separate and distinct realms, as with Augustine's secular 'city of man' and the heavenly 'city of God'. 
For Hegel there was but one world, but temporality had to be completely traversed for that one world, in its divine aspect, to be achieved, to be 'real-ized'. Hegel took Leibniz's conclusion of 'the best of all possible worlds' and said that these worlds, in their constituting principles (the type of attitude or philosophic nucleus that 'constructed' them) needed to be gone through, rehearsed or reprised. Intellectual short-cuts and merely conceptual realizations would not do. Only full consciousness, keenly cognizant of all the contrasts and struggles involved, one that would pervade and lift up all the forms of human activity, could see the real reasonableness of things. Only a truly sobered and synoptic vision could see the ideal fully congruent with the real and the real fully embodying the ideal. Only complete knowledge would be coexistent with societal justice. Consider how absurd and far this view is from Hume's conception of mind as the shadowy reflections of sense impressions!

History was the story of the progressive overcoming of partial perspectives and it was crucial to discern its 'logic'. The 'dialectic' for Hegel in not one of mere notions but of the caravansaries of human enterprises. How man understands is mirrored in and generated by his practices. So the evolution of his institutions and political arrangements become an essential part of the whole picture. True understanding must journey through all man's symbolic forms, the manifold realm of culture, before finding harbor in the real polity, the true civic order, the incarnation of reason and divine embodiment. 
Whether Hegel's compelling journey of the spirit ('Geist'), in coming to itself via a series of appropriations (a simultaneous widening of horizon and deepening of awareness), is a feat of legerdemain, or whether it is the accurate ascent of truly active and comprehensive reason, we can't begin to judge here. The difficulty in interpreting Hegel is that the Subject that undergoes the arduous and circuitous development we call history is called by different names: Mind, Understanding, Spirit, God, Absolute Reason, Human Consciousness of Freedom, the Final State. The historical process serves many ends, again simultaneously. This is what Hegel referred to as 'the cunning of reason'. Suffice it to say that his project was to show that God's voice, consciousness of freedom and the evolution of human institutions were all of a piece.

Hegel's 'phenomenology' of mind is the road map of the successive weltanschauungs, from naive and primitive nature-consciousness to the absolute serene comprehension of the totality. Stoic resignation in the face of implacable fate is one of the many attitudinal stances (representative states of mind or typical persuasions) he highlights. Understanding of the world shapes the world at every point. For Hegel, 'reason' is an active principle, culture the result, history the process. The Phenomenology was the Finegan's Wake of the early nineteenth century, tracing mankind's waking from his dreamlike states. 
With his principle of historicality Hegel showed that temporality was, as philosophers are wont to say 'constitutive' of man's identity. What he goes through becomes an essential part of him. Time was 'abolished' and subsumed in an ongoing process that became more comprehensive as 'time' went on. Time was not, as with Aristotle, a mere 'accidental' property of a thing, substance ' $x$ ' existing at time ' $y$ '. Nor did time flow on 'equably' and absolutely, irrespective of human circumstances, as with Newton. Hegel fulfilled the Enlightenment dream of a universal history of mankind. He created a framework in which extensive historical research made sense. And after Hegel came the birth of 'social' sciences like philology, anthropology and especially sociology, with German scholarship and universities in the vanguard. The brothers Grimm and the brothers Humboldt led this omnivorous thirst for systematically cataloguing every conceivable kind of phenomena.

August Comte perfectly articulated this nineteenth century vision. Ironically what happened to Hegel paralleled what happened earlier to the theologies of thinkers like Descartes, Spinoza and Newton. For Spinoza, for instance, Nature was the manifest or 'passive' aspect of God. For Newton the clockwork order of nature was the handiwork of God and space was God's 'sensorium'. The self-restricting purview of science eventually led scientists to exclaim with Laplace, 'We have no need of that hypothesis!' God was dropped from all the equations, seemingly with no ill effects. Comte did the same with History as the visage of God: the divine 'hypothesis' was again dropped, not simply as superfluous but as a puerile historical vestige. From here it is but a stone's throw to Freud's Totem and Taboo and Moses and Monotheism. Science became the exclusive account of both Nature and History, and thence Culture. Anthropology and Sociology supplanted theology regarding accounts of origins and process. 
At the same time, early-middle nineteenth century, - almost as an indirect confirmation of Hegel's idea of a 'zeitgeist' or spirit of the times! - the doctrine of evolution was emerging. Just as Hegel tried to make sense of the fractured strata of human consciousness, geologists like Lyell were trying to make sense of the fractured record of the rocks and see a 'logic' in it. Lyell and Darwin saw in lithic and biological phenomena more than static classificatory schemes. They saw a sweeping panorama of development and a simple and elegant mutation process that explained the bewildering plenitude. Lyell's (and Darwin's) thunderstruck insight was that the process(es) that created past formations was clearly at work in the present right under our noses.[101]

The logic of mere classification of forms gave way to the scientific penchant for discerning the essential modus of change, deciphering the law(s) that governed the development of any class of phenomena. When Maxwell in the nimeteenth century came up with his theory of electricity and magnetism it was not merely a reclassification. He showed by his famous equations that both sets of phenomena 'obeyed' the same dynamics. The scientific organon always laid emphasis on how things worked rather than why.

The synthesis of Comte uniquely combined the perspectives of Science and History, the two paradigmatic disciplines of modernity. Using Hegel's principle of historicality, Comte endeavored to show that the sequence in which disciplines appeared on the human scene was significant. By most accounts the regimen of early humanity in all places and times was worship. Whether gods or God, animism or monotheism, mankind, suffused with a sense of fear and powerlessness (vis-a-vis the powerful and seemingly inscrutable forces of nature) had always, in its early stages addressed and worhipped something outside itself. This was clearly a stage of childlike dependency. 
When Thales, the first recorded Greek 'philosopher' and Milesian 'physicist', said 'all things are full of gods', he was not being religious per se. He represented a trend of explicit speculative thinking that moved mankind from its mythic-religious way of apprehending the world to one of trying to understand it. Thales' inspired guess that 'water was the primal cause of all things' was a bold step. This 'adolescent' phase of thinking as it grew in sophistication represented a self-consciousness and the step toward self-empowerment in mankind's evolution. The scientific ethos, one of systematic understanding and action based on that, represents the maturity-consciousness of mankind, the acknowledgment of its own self-determining destiny. According to Comte history exhibits this triptych of developmental stages.[102]

Another summary of Comte:

"The positive science is a discipline of modesty; and this is its virtue. Positive knowledge adheres humbly to the things; it comes to a halt before them, without involvement, without leaping over them to fling itself into a deceptive play of ideas; it no longer seeks causes, but only laws. And, thanks to this austerity, it attains those laws, and possesses them with precision and certainty. But it so happens that this situation is not primary; just the contrary: it is the result of the efforts of millennia to restrain the mind, which was dashing off to the farthest distances, and force it to limit itself docilely to the things. These efforts make up all of history...".[103]

This is a pure Baconian philosophy of history! - learning how to be humble and docile before the facts in order to progressively control nature for the betterment of mankind. 
Comte's schema of the disciplines, based on the foundation of mathematics, was a scaffolding of physics, chemistry and biology and the ultimate science of human interaction, sociology. Social 'statics' and 'dynamics', as with French utopian St. Simon, were in the air.[104] Comte's philosophy terminated in reverence, a 'religion of mankind'. Twentieth century positivists, the 'logical positivists', have all but entirely forgotten or ignored their nineteenth century predecessor. And they certainly don't have much truck with visionary histories or value statements in any binding sense. Nonetheless, positivism along with materialism, continued to dominate late nineteenth century thought and is the unarticulated vision assumed by a variety of kindred twentieth century schools. The common assumption is that real progress consists in going beyond a religious view of things (although it's OK to make religious or ethical statements in other than a veridical sense), beyond empty philosophical speculation, and getting to authentically verifiable and cumulative results, the latter produced by strictly adhering to scientifically sanctioned methodology. (There are refinements to be sure in the twentieth century versions of positivism: statistically warranted probablist conclusions, and being heuristically 'fruitful' in terms of discoveries and technological applications. But 'truth' is given a very narrow berth, if one at all. Instead, 'convenient description' is the favored circumlocution.) 
In any case Comte's vision represented the spirit of modernity: unlimited faith in the scientific method and the correlative unlimited historical progress of mankind. Comte's synthesis, like the popular industrial 'world-expositions' of the nineteenth century, expressed the sense of surety and control of the bourgeois mind as it admired its own business-industrial-commercial wonders. It was the Crystal Palace of Secular Progress compared to the Cathedrals of religious aspiration expressed by the medieval mind.[105] Karl Marx also tried to combine the arch-disciplines of History and Science in a utopian direction. And the other son of Hegel's troublesome intellectual offspring, Soren Kierkegaard, rejected entirely the notions of systematic knowledge and serene social progress. Along with Nietzsche, Kierkegaard represented the ongoing revolt - taking the forms of Romanticism and, in the twentieth century, Existentialism - against the pretense of science to be the all-encompassing oracle of and for the human condition. But the predominant ideology of middle and late nineteenth century industrial Europe was positivist and materialist science. Fin de siecle philosophers of science like Ernst Haeckel boasted that in a few more years of 'mopping up' operations, physicists would tell us everything we needed to know. 
Around this time, Gustav Fechner (1801-1887), the quintessential German scholar and founder of modern psychology by way of 'psychophysics' - the application of experimental physics to questions of sensation, perception, etc. - was undergoing a profound religious conversion. Fechner went literally from blindness to a new way of seeing. At the same time Haeckel and others were dotting the 'i's' and crossing the final 't's' of western science, Fechner was writing extraordinary works like his Die Tagesansicht gegenuber der Nachtansicht (The Daylight View versus the Nighttime View).[106] The 'nighttime' or dark view was Newton's cosmology, essentially godless and soulless, atoms and force fields governed by blind and inexorable physical laws. The 'daytime' view was the vision of nature and man as alive, endowed with consciousness, and harkening to an organic and spiritual evolutionary 'logic'. An ardent admirer of the two Fechners, the scientific and the mystical, was William James. Fechner's prophetic works lay in the watershed between the positivism of Ernst Mach and the physics of Albert Einstein.

One facet of Baconian-Cartesian-Newtonian science was its famous division of nature into two distinct spheres, external/material and internal/human. Galileo's distinction between 'natural philosophy' (the physical and experimental sciences, with mathematics as its most concise expression) and 'moral philosophy' (ethics, morality, theology, metaphysics and the like) pervaded university curriculum assumptions. Wilhelm Dilthey (1833-1911) underscored this division when he tried to establish a new discipline that would study the historical and cultural 'productions' of mankind. He called these new studies 'Kulturwissenschaften' (sometimes 'Geisteswissenschaften'), or human sciences. He contrasted them with the Naturwissenschaften', the sciences that studied nature. 
Dilthey also shared Comte's assumption,[107] and the post-Kantian assumption generally, that metaphysics as a "science" was impossible (being unrestricted and ungrounded thinking, mere speculation with no corroborative tests possible) and therefore philosophy was more accurately viewed as 'historical expression', the feelingapprehensions of individuals, societies and eras for the whole of existence. With Dilthey philosophy devolved into a kind of aesthetics, the intuition of essentially art-works, the physiognomy of weltanschauungs. While Dilthey broke important new ground, his key distinctions actually reinforced two very separate domains or sets of studies. This is what C.P.Snow in the 1950 's echoed when he referred to the antagonism, or at least dangerous misunderstanding, of the 'two cultures', the scientific and the literary, or the sciences and the humanities.

Comte and John Stuart Mill, as systematic rationalizers of science with social agendas, albeit with Continental and British accents, were perfect examples of Kimball's 'liberal-free' constellation of thought. The liberal-progressivist scientific-ideology way of thinking was also represented in England by T.H.Huxley (1825-1895) and later by the social Darwinist and evolutionary theorist Herbert Spenser (1820-1903). Universities in the nineteenth century were really an amalgam - or perhaps tension would be better - of two very different curricula sandwiched together, again with 'natural' and 'moral' philosophies indicating the contrasting directions.

These two orientations played themselves out in the universities in England, Germany and America. On the one hand, there was the old elitist education of the 'gentleman', centering on the Greek and Latin classics. On the other, there was the new scientific-technical education, focusing on mathematics, experimental (hitherto taxonomic or classificatory) researches, the birth of university laboratories, the introduction of 'technical' subjects associated with engineering, and, finally, modern languages, history and geography.[108] There was, of course, much resistance to the addition - let alone integration! - of mathematics and science to the classically oriented curriculum.[109] 
Historian Bowen sees the rise of modern nationalism, particularly in Germany, as exerting pressure for the introduction of the new technically emphasized studies and research.[110] The modern industrial state had needs not only for universal and compulsory education - a well-trained work force - but for well-trained scientists and host of civil servants to manage and foster the domestic and imperialistic imperatives of industrial competition. One could almost say that verbal competency and Chemistry were the paramount disciplines of this time. Resources needed to be gotten, processed and sold. The state needed to be the embodiment of efficiency. A ruthless Baconian New Atlantis', turned Moloch, and began gobbling up whole continents like Africa. A wellhoned scientific edge was essential in the late nineteenth, early twentieth century nationalist rivalries. Prussian organization pervaded both its military and its educational establishments.

In England the clash of the two pedagogical streams, the 'artes liberales' traditionalist education of the gentleman-leader, and the 'liberal-free' connection between science and the general betterment of human circumstances, was less decisive. Father James Mill and son John Stuart Mill took on the Anglican elitist establishment as advocates of the poor and their melioration through education.[111] Herbert Spenser fumed that classical education was fit for 'parasitic celebates' (!) and science was the only knowledge worth having, 'the study of surrounding phenomena being superior to grammar and lexicons'.[112] Kimball exhibits the clash of educational ideologies in the dramatic late nineteenth century confrontation between Matthew Amold, the 'apostle of culture' and Thomas Henry Huxley, 'Darwin's bulldog' and the 'apostle of science':

"In 1880, Huxley delivered a public address entitled, 'Science and Culture', in which he attacked Arnold's wellknown view of humanist culture. Huxley argued that liberal education' should be dedicated to increasing human knowledge and founded upon 'an unhesitating faith that the free employment of reason, in accordance with scientific method, is the sole method of reaching truth'. 
Appropriately - especially for someone who had crusaded on behalf of Darwin's Origin of Species and extolled Joseph Priestly [the experimental chemist] as one who 'set a much higher value upon the advancement of knowledge and the promotion of that freedom of thought which is at once the cause and consequence of intellectual progress' - Huxley maintained that the study of natural sciences should be prominently included in liberal education. During a lecture tour of the United States in 1883, Arnold responded in 'Literature and Science'. He staunchly defended his proposition that teaching 'the best which has been thought and said in the world', derived from a body of classical texts, conveys the proper standards for the formation of culture, the human personality, and, consequently, liberal education. In this exchange, the disagreement between Huxley and Arnold can be understood as an instance of the longstanding conflict between the perspectives of the liberal-free and the artes liberales ideals."[113]

Other similar juxtapositions illustrating the curricular tension of the time could be adduced. Lord Kelvin, preeminent physicist and technical consultant to the first laying of the transatlantic cable, and Cardinal Newman, whose The Idea of a University is almost a biblically revered apologia for liberal education (in contrast to its utilitarian and commercial uses), represent the two sets of interests, progressivist and humanist, and the two defining educational ideals.[114]

Kimball notes that American universities more quickly, and then eventually the English universities of Cambridge and Oxford, followed the German model of free scholarship and academic research that was gaining dominance. He quotes this summary of the movement and the late nineteenth century scene:

"...(A) new centre was found and a new justification for liberal education ...It appeared first in Victorian times. It was the result of the knowledge revolution, of the research ideal, of a belief in the power of the intellect, of specialism and professionalism, of the breakdown of the teleological universe and even the positivist universe, and of the disintegration of a traditional confidence in the strength of education to produce a reliable social type. The new meaning of a liberal education that superseded all others 
was the search for truth - not abiding truth, but contingent truth, based on facts and sources."[115][our emphasis]

A suble shift occurred: the liberal arts as induction into absolute truths became 'mind training'.[116] Latin, Greek and geometry: all went that route - from gateways to absolute truth to calisthenics of the mind. 'Disciplining' the resources of the mind fit, like the extraction of minerals at home and from distant colonies, into the pattern of civil service and the economically driven needs of the modern state.

While there had always been the tension between 'liberal' studies and 'utilitarian' concerns (Aristotle, Cardinal Newman, Thornstein Veblen, Dewey, Whitehead, Mark Van Doren)[117], in the last decades of the nineteenth century liberal studies were almost defined negatively as those that were not 'technical' (i.e. precise) or 'pursued without regard to their marketable value'.[118] Defenders and detractors began to call liberal studies 'useless'. How they fit in, other than preparing students for well defined professions, was now becoming problematic. The 'gentleman ideal' was clearly an anachronism in the industrial era.

As always, curriculum follows worldview. Geography as well as chemistry as well as 'civic' education all expressed growing nationalist and imperialist ambitions.[119] In America, the discoveries of Henry Ford (1863-1947) and Thomas Edison (1847-1931) rapidly evolved into the industrial logic of efficiency. The organic thing (made by husbandry or craft) became a fabricated configuration of replacable parts assembled by a sequence of interlocking processes. There was a compelling need to become aggressive, to find appropriate raw materials and consumers of that which was produced en mass. Mechanism and materialism needed workers who could be trained, efficient and docile operators of these land-based juggernauts and superdreadnaughts. Education needed to serve the State. Literacy and numeracy had new roles to play akin to indoctrination. A premium was being placed on efficiency, technically and commercially defined. 
Even earlier in the nineteenth century, Froebel (1782-1852) famed educator and father of the 'kindergarten' (the place where children could grow organically like plants), sensed the tendencies of early industrialism and decried German parochialism, vocationalism and schools as 'state machines'.[120] "Must we go on stamping our children like coins instead of seeing them walk among us as the images of God?"[121] German Naturphilosohie, and European Romanticism generally, with its organic analogies constantly counterpointed itself to the increasing influence of the reigning 'logic' of mechanism with its imperatives of centralization (of facilities and planning), specialization and aggressiveness. In general, the late nineteenth century was in no mood for sunlight and patient growth.

In commenting on twentieth century German political sociologist and philosopher Habermas, Richard Bernstein notes "...the 'dark side' of the Enlightenment [Aufklarung] legacy and indeed of all social and cultural modernity - the way in which the Enlightenment gave rise to and promoted a 'totalitarian' instrumental rationality that infected every aspect of cultural, social and personal life - even reaching into the inner recesses of the human psyche."[122] One example of the Enlightenment project of complete rationality had been the completely secularized calendar of the French Revolution with its carefully designed workers' holidays, totally eliminating any references to sacred holidays and remembrances. Other notorious attempts at totally efficient rationality, complete control and the complete ability to design human affairs, have been twentieth century fascism, communism and the bureaucratization (and 'media-ization'?) of liberal democracy.[123] 
From the Great Ancestor Hegel came, along with Comte, the figures of Marx and Kierkegaard. The nineteenth century saw economic commercialism combine with industrial machine procedures. Comte gave unconscious voice to the hierarchicalorganizational model of efficiency implicit in it, while Marx and Kierkegaard both in their different ways acknowledged the importance of this new phenomenon. Marx saw economic-industrial nexus as part of the dialectical movement of the historical process. Kierkegaard excoriated the bourgeois mentality and morality he saw as associated with the this 'spiritless' and 'mechanical' age.[124] Both saw the power of commercialism married to industrial capacity in the shaping of society.

But the Comtean model was the accepted summation and refinement of the ideal European Enlightenment curriculum: mathematics was the base, with physical science being the next echelon and the prototype for all the other sciences. While Comte meant for the sciences to culminate in a reverential sociology, the new flowers of the sciences tended to be instead their applications to technology. In fact 'technology' was the realm of scientific applications. Nontheless, the historical principle as guiding research, the supremely successful methodology of science, and the new awareness of the plurality of 'primitive' (tribal, archaic) cultures gave rise to the array of empirical social sciences. It was the age of Durkheim and Weber, the great age of anthropological and sociological study. The Germans embodied in their academic institutions the French positivist ideology. 
The theme of the relation of science to culture was the great conundrum. The curricula of the scientist was jostling with the curricula of the gentleman-leader. The new values of research were colliding with the old ethos of the aristocrat. It was in this context that Dilthey tried to found a rigorous approach to the 'human sciences', to provide a basis for understanding cultural phenomena as such. Field studies and empirical generalizations, however, dominated the disciplines and left little room for the 'subjectivistic methods' of empathy, sympathy and understanding. Comte did not recognize psychology as a science, feeling that the details of biology and/or sociology (the study of the interaction of men) would explain such data. In the twentieth century, Pavlov, Thorndike and Skinner endeavored to put psychology on a scientific, i.e. quantifiable, base, physics again being the model. As organizations became more fine-tuned in the twentieth century, psychology became more useful. The merchandizers of the 1950 s began to consciously exploit the domain of the 'unconscious' that Freud had discovered fifty years before.

Colonization of the outer and inner worlds, domestication of the wild and unruly, cataloguing human traits and making predictable human responses, all seemed in the interest of the aggressive and bureaucratically ordered modern state, honed to perfection in Prussia-become-Germany. Specialization, expensive, institution-bound laboratories, status and emoluments, all made research science excel in Germany and in fact changed the character of science.[125] No longer was it the domain of amateurs but of professionals. Robert Boyle, experimenting with the kinetic theory of gases with homemade apparatus, would now be out of place as industrialists worked hand-in-glove with chemists.[126] Researchers, quipped historian Bowen, observed the regimen of science and technology on weekdays and moral scruples on Sundays.[127] Alfred Nobel and Andrew Carnegie, when their work was done, became philanthropists. 
Late nineteenth century Germany likewise oversaw pedagogy's recasting from an intuitive art to the 'science' of pedagogy - a technology, the application of the scientific method to higher education via systematized techniques and the new 'seminars' - and quickly translated to the eager American scene.[128] As with Comte's visionary history and quest, psychologist-pedagogues like Herbart were shorn of their metaphysics and made harbingers of the new scientific rationality/technology.[129]

But again, in seeming obedience to Hegel's dialectical logic, the success of materialism and positivism spawned its opposite. As with Freud, the late nineteenth and early twentieth centuries saw the birth of many 'irrationalisms' and recognitions of phenomena that didn't fit into the dominant scientific account. Vitalism, Spiritualism, Christian Science, Theosophy arose. This counterpoint also expressed itself in Bergson's 'creative evolution', in James' 'radical empiricism' and in Husserl's 'phenomenology'. These and other philosophical and religious movements affirmed life as opposed to mechanism, direct and empathetic insight ('intuition') as opposed to inductive generalizations, and cosmic - if not religious - forces other than those recognized by the physics of the time.[130] The high tide of positivistically interpreted science coincided with the growing disenchantment with science as the only mode of veridical perception and discourse. William James' Gifford Lectures, The Varieties of Religious Experience, published in 1902, was a landmark in this era. It protested the shackling ideology of the times and demanded that phenomena be studied in a fresh light. There was a crack in the block of the $\operatorname{mind} / \mathrm{man} /$ society/world as machine metaphor. 


\section{TRANSITION: JOHN DEWEY}

The next step in our tale is a tale of two Deweys. Born in the same year as Henri Bergson and Edmund Husserl (1859), John Dewey had a life that spanned almost a century (he died in 1952) and was a kind of bridge between nineteenth century and twentieth century modes of thinking. His seminal and influential figure towers over the twentieth century. We shall argue, however, that there is really no monolith but in fact two significantly different John Deweys.

The first Dewey was the enemy of static and absolutist metaphysics, a dedicated apologist of science, the heir apparent to Francis Bacon. This is the Dewey of The Quest For Certainty (1929). This John Dewey follows in a line of scientifically oriented philosophers from Lucretius to Bertrand Russell. This is the lineage that aims to liberate mankind by dispelling fearful fantasies of the gods, cultivating the systematic and productive scepticism of scientific inquiry, championing individual freedoms via a liberal political philosophy, and working out a progressivist pedagogy. This is Kimball's liberalfree' core of thought and curricula par excellence. 
The other John Dewey was a more characteristically American figure, the philosophical son of William James. This was the John Dewey of Experience and Nature (1925) and Art as Experience (1934). This strand of Dewey emphasized experience, temporal process, holism and organismic logic. The successor to this brand of pragmatism - moving from Peirce to James to Mead to Dewey - was the 'process metaphysics' of British transplant to America, Alfred North Whitehead. An in-depth account of American Pragmatism in its metaphysical dimensions - despite its overt antipathy to 'metaphysics' - is still yet to be written. We would argue that Whitehead's metaphysics of temporality in Process and Reality (1929) perfectly amplifies and extends Dewey's themes of organic perception and development in Experience and Nature. The Deweyan emphasis on experience also accorded with the development of Phenomenology on the Continent, which similarly called for a return to the rich deliverances of the immediately given in consciousness.

What unified the two strands in Dewey of course was his attack on the 'substantist' - and, he felt - dualist metaphysics (mind vs body, subject vs object, good vs evil, God vs world, being vs becoming ) stemming from Plato and Aristotle. Like Galileo, Dewey felt that a world conceived as being populated with 'substances' did not do justice to the dynamism in things. Aristotle's philosophy with its tendency to make processes into things, according to Dewey, led to static conceptions, invidious hierarchies and insidious either-or thinking. His pedagogy, following James, basically said that terms like 'attention', 'interest', 'will', 'mind' 'intelligence', 'discipline' were all functions of an integral organism - rather than entities in themselves.[131] According to Dewey, the organism and its functions were inconceivable without its correlative environment. Entities, aside from having individual 'careers', were intrinsically in communication with their environments. In fact, they were unthinkable apart from their environments. 
A proper attention to the 'interests' of an organism is one of the keystones of his psychology/pedagogy.[132] In his classic How We Think (1910), Dewey tried to root scientific thinking in the processes of everyday thinking or deliberation. The activities of hypothesizing and testing were not arcane or esoteric but simply, when looked at closely, the way we as humans actually think. Science was merely an outgrowth of that. Just as Whitehead said 'all entities speculate', that is, throw up a spray of possibilities with each action or gesture, Dewey said all living entities find themselves in problematic situations which demand resolution. Culture is the repertoire of past solutions. As conditions change, the past constantly needs to be reappropriated and updated as new solutions are found.

The articulation of a genuine philosophy of organism had, for Dewey, great implications for democracy and a democratic curriculum. The focusing on the internally vital interests of the organism would, in Bowen's summary,

"...lead to the disappearance of one of democracy's greatest enemies: [the] dualism, inherited from the Greeks, of leisure and labor. Nothing is intrinsically liberal or illiberal: anything that helps solve problems is potentially liberating and is not the province of any special class of studies. [our emphasis] On the other hand, anything that hinders creative activity, as does much of the traditional humanities curriculum, is potentially illiberal."[133]

The enlightened support of activity that resolves internally-defined issues, that is intrinsically rewarding (as opposed to answering to extrinsic motivation schemes, or even worse, compulsion) makes for good psychology, good pedagogy and good democracy. Learning how to solve problems was the quintessential art for an individual; learning how to solve problems collectively was the life's blood of democracy. 
With John Dewey, Kimball says, came an avalanche of references to the liberal arts as 'the liberating arts'.[134] A Deweyan at Columbia, philosopher John Herman Randall, said that in the past the liberal arts have never been fully 'liberal' or emancipating because they comprised certain definite subjects; that the 'liberality' of an art lay not in its content but its function.[135] Randall noted that the sciences in the 1940's were just as obstructive as the (Greek and Roman) classics had become in the teaching of the liberal arts.[136] While he personally leaned toward philosophy in its traditional mission of attempting to articulate the 'context of the whole' (comparing the assumptions and methods of all the disciplines), Randall quotes William James on geology 'You can give humanistic value to almost anything by teaching it historically', and then opts for the historical treatment as coming the closest to a (the) liberal art perspective.[137] (He goes on to say that to treat the modern phenomenon of engineering 'in a liberal spirit' would be a crucial pedagogical test case(!)[138])

In Deweyan progressivist parlance, all subjects or disciplines - including the inherited and venerated congerie of the liberal arts - were measured by their fitness, utility, contribution and relevance to life. But here a seminal ambiguity! It is not impertinent to ask - as many did of Dewey! - what life? which life? what is the truest form of life? communal-social, individual, scientific, aesthetic, religious...? Metaphysics, the attempt to articulate the Ultimate, returns with a vengeance. 
We interpret Dewey to be the last of the European Enlightenment philosophers with their unique blend of moral concern and emphasis on scientific method as the right road to human salvation. Dewey stood on the cusp of a new age with a new vocabulary with his ambiguous usage of terms like 'experience', 'attention', 'interaction', 'environment'. 'organism', 'value', 'life' and 'freedom'. Dewey represented the crossroads between scientific-positivist modes of thinking (his famous 'instrumentalism' version of pragmatism) and a new organic way of thinking. The Deweyan lexicon can be read as an associationalist-behaviorist psychology of stimulus-response, or, as the beginnings of a phenomenological psychology of lived-experience, consciousness and awareness. One of the twentieth century's chief architects, Dewey's philosophy was Janus-faced, one face looking toward the nineteenth century and one face looking toward the twenty-first century.

Industrialism, with its proliferation of techniques and procedures, and Science, with its proliferation of data and knowledge, both demanded occupational and professional specialization. The German 'value-free' research-ethos combined with the preeminence of historical studies had tumed the liberal arts from the study of a few luminous examples and significant texts to an ever widening knowledge-research industry. With this tendency toward specialization - and increasing fragmentation - what were the liberal arts, aside from bromides about broadening perspective? What 'principles', if any, held this venerated tradition together? And what were the life-arts appropriate to the industrial age that was in full swing? Some Deweyans saw vocationalism, the preparation for work life, as the new point of gravity for the liberal arts and as a way of unifying the disciplines.[139] Other Deweyans like Sidney Hook, emphasizing preparation for secularly defined civic life, tried to articulate the minimal requirements of 'general education' as the essence of liberal education.[140] 'General education' is a Deweyan legacy that attempts to find common tools, languages and and /or core disciplines to deal with the multiplicities of disciplines and ideologies in American civic life. 
Against the Platonic-Aristotelian tradition (which was preoccupied with the 'antecedently real' and thereby fostered the dualism of the 'really real' versus the 'merely phenomenal' world), Dewey advocated a 'Copernican Revolution' in thought: namely the underscoring that reality is an (organic) 'moving whole of interacting parts' and 'a center emerges wherever there is an effort to change them in a particular direction'.[141] Authority, in this view, does not derive from some other-worldly source - with its typical claims of being absolute - but from the consensual activities of men in the (scientific) process of 'verification', 'warranted assertability', 'tentative belief', etc.[142] Getting rid of the divine right of religions, kings, moralities and preternatural structures was part of Dewey's Enlightenment project of establishing 'one world'. 'Mind' or 'thinking' would therefore not be a glimmer of immortality or divine expression, but simply a constantly adjusting component part of the world's functioning ecology. A 'center' was always a tentative center, a temporal focus, arising from the determining forces at work in a problematic situation. Good thinking is heuristics, productive work in reorganizing and transforming situations into satisfying wholes - not a guide to eternal verities.

Gestalt Psychology of the twentieth century[143] was also an attempt to frame neither a syllogistic nor a simple inductionist but an organic account of how thinking functioned. In trying to work out this 'holistic' view (mostly with regard to the dynamics of perception) it shared with Dewey a transition to a new organon, a new compendium and new compass that related human activity, the world and a new sense of the Ultimate. Much of the new canon would come from the long-standing opposition to the exclusivist and (often) reductivist claims of science. Much of the new canon would come from "new data", new inputs to the European-American scene. But some of the inspiration of the 'new age' would come from science itself: new discoveries in physics and astronomy, new vistas in cognitive and developmental science. 
Progress in science and human society had hitherto been presented as a linear. almost inevitable progression. Gestalt inspired philosophers of science like Michael Polanyi, Thomas Kuhn, Norwood Russell Hanson and Paul Feyerabend,[144] all were projecting a newer, subtler and more comprehensive picture of how scientific activity actually functioned. Integral to their vision is that perception is a far more complex and richer phenomenon than previously imagined in associationalist and mechanical rationales of science. An appreciation of the texture and inherent drama involved in perceptual acts had been missing. As Whitehead might put it, the entire world, in gradations of relevance, is involved in the simple perception of green. The world as isolated bits was a fable.

'Gestalt' means shape, form or pattern. Max Wertheimer, again after fascinating case studies, gives a third table, a summation of the Deweyan and Gestalt characteristics of 'productive' (vs. Aristotelian, and naive associationalist-inductivist) thinking. We find this table to be an adumbration of the new canon or 'organon'. 'Structural' here is equivalent to meaningful whole or significant complex.

Table III

Thinking consists in

envisaging, realizing structural features and structural requirements; proceeding in accordance with, and determined by, these requirements; thereby changing the situation in the direction of structural improvements, which involves:that gaps and trouble-regions, disturbances, superficialities, etc., be viewed and dealt with structurally; that inner structural relations - fitting or not fitting - be sought among such disturbances and the given situation as a whole and among its various parts;

that there be operations of structural grouping and segregation, of centering, etc.; that operations be viewed and treated in their structural place, role, dynamic meaning, including realization of the changes this involves; 
separating structurally peripheral from fundamental features

looking for structural rather than piecemeal truth.[145]

It is to be noted that the productive 'middle term' or midwife in this DeweyanGestalt schema of thinking was 'trouble' or dissonance. Paradoxically, ill-fittingness was the potential gateway to better structures! Trouble, rightly conceived, was the key to better organization. Mistakes and crises were integral to the way life functioned and were not simply a falling away from perfection, or to be avoided at all costs on the steady march to perfection. A logic of life was being probed: one which would neither be circular (as the ancients tended to be) nor linear (as the moderns tended to be) but one which would take into account cycles and circuitry, regressions and saltations, spirals and cul-de-sacs, lonely terminations and abortions, surprising emergences and bright springings-up, and... in Nietzschean terms...the whisper of far-off and portentious events....

American Process Metaphysics and Gestalt Psychology were but two of the many strands in the twentieth century that were laying the groundwork of a profoundly new vision of things. Change, for instance, in the new lexicon would mean neither the actualization of pre-determined ends, nor linear progress in a single given direction. Rather it would mean a self-referential, reticular, resonant process that has indefinite ramifications. Literally the ripple effects of one drop in a sensitively conceived, life-imbued universe can change the world. Or, socially venerated powerful mega-complexes can come to naught in a twinkling. Welcome to a world of omnidirectionality, interdependence and radical contingency. Welcome to Gaia, electronics and zen. 
We are setting sail for a profoundly new world-horizon, as different from Bacon's Renaissance and the Enlightenment of the Philosophes as theirs was from the PlatonicAristotelian world-view. The new cartography we shall explore emphasizes dimensional depth as well as the more conventional euclidean coordinates of length and breath. We will also explore some complex navigational processes: Sometimes the thing to do is quite simple - take the next obvious step and/or persevere in the same direction (and that will bring 'success', as the venerable IChing, Book of Changes puts it). But sometimes, in the new canon of thinking, it means to turn 180 degrees and go inward. The Tertium Organon' is largely, but not exclusively, about going 'inward'.

The proposition - the invitation! - the imperative! - to see life in all its manifestations as endowed with sentience and consciousness; to see that the degree of life is measured by intense and intimate interaction, such that it is inherently and at every stage both individual and social; and to see all life as the ongoing expression of an omnipresent creative emptiness, was, to put it mildly, revolutionary. But these were the axioms of the new worldview.

The new world is seen as expanding and contracting in surprising, beautiful and sometimes tragic ways, in ways always correlative to our mode of presence. We are cocreators of this world whether we like it or not. Even by default. 


\section{THE TERTIUM ORGANUM}

"Nan-in, a Japanese master during the Meiji era (1868-1912), received a university professor who came to inquire about Zen.

Nan-in served tea. He poured his visitor's cup full, and then kept on pouring.

The professor watched the overflow until he no longer could restrain himself. 'It is overfull. No more will go in!'

'Like this cup', Nan-in said, 'you are full of your own opinions and speculations. How can I show you Zen unless you first empty your cup?"'

- Paul Reps, Zen Flesh, Zen Bones

"When the iron eagle flies in the sky, the teaching of the Buddha will come to the land of the red man."

- ancient Tibetan prophecy

"Form is emptiness, emptiness is form."

- The Heart Sutra

"The carrot symbolizes financial success; a promised, often illusory reward. A carrot is a wish, a lie, a dream. In that sense, it has something in common with perfume. A beet, however... a beet is proletarian, immediate, and, in a thoroughly unglamorous way, morbid. What is the message the beet bears to a perfumer? That his chic, elitist ways are doomed? That he might profit from a more natural, earthy, straightforward approach? This beet, this ember, this miner's bloodshot eye, this apple that an owl has pierced, is it a warning or friendly advice?"

- Tom Robbins, Jitterbug Perfume

"It is not a question of soul or not soul, but of how much soul."

-Alfred North Whitehead

"Your true educators and molders disclose the true original meaning and the basic material of your being, which is something quite incapable of being educated or molded, and to which access is in any case difficult since it is fettered and chained as it is. Your educators can be nothing more than your liberators. And that is the secret of all education: it doesn't provide artificial limbs or false noses..."

-Friedrich Nietzsche, Schopenhauer as Educator 
"And whoever has felt what it means in our times of tragelophine humanity to find a whole, harmonious, free and uninhibited natural being that moves around its own pivot..."

-Ibid.

A brief summary thus far. We have traced disciplines that befitted the warrior, the aristocrat, the saint/theologian, the gentleman/amateur scientist, the revolutionary, the reactionary bourgeois professional and technical expert. We moved from tribal configurations to ancient empires to the Greek (and Roman) city-states to the medieval would-be empire (although in actuality, struggling fiefdoms) to Renaissance utopian projects, to modern nation-states (born of revolution and violence) to the industrialbureaucratic form of society.

The tribal form had its 'curriculum': the austere bodily regimens and ascesis of the hunter-fighter and the shaman. Both partook of fasting and privations to build their strengths: the former developed into gymnastic, the latter into techniques to achieve paranormal visions, ecstasies and healing. The tribe was writ large in the regal variant of the empire (Latin, 'imperium'=royal rule, authority) with the most powerful warrior or his scion the supreme potentate. In this rigid hierarchical pattern ('hieros'=sacred, 'archos'-ruler) with its finely articulated caste system, each necessary function of society priest, scribe, warrior, farmer, trader was reproduced with great accuracy by the transmission of relevant skills usually from father to son. 
After the Greeks threw off their much hated tyrants, the function of collective consultation and public deliberation became very important. The way for these nobles or oligarchs (=rule of the few) to achieve eminence (aristos=the best, outstanding virtue) and maintain their rights was the way of skillful speech or the forensic arts in the deliberative assembly. A class of teachers called the Sophists taught these arts of effective presentation. Thus the warrior ethos was transferred to the realm of public discourse as the Sophists chose heroic and poetic examples, as well as the slippery movements of an often self-aggrandizing reason, in plying their trade. (Thus, the beginnings of logic, or the canons or agreed upon rules of rightly ordered speech, might have had their origin in the wranglings about property and legal disputes.) The Sophists became so good at their preparatory regimens for public life that the resulting Greek individualism became a threat to the conventional social order, 'democracy' being always a kind of tension - the contesting of individuals no one of whom had absolute power. 
Another threat to the established order took place with the new 'investigations' ('historia', while the things learned, the results of investigations, were called 'mathemata'). especially those of the Ionian and Milesian inquirers called 'physicists'. Their speculations about the nature of things (the discovery of a realm called 'nature') seemed not to take the gods very seriously. Thales' bold act of speculation was that water, not the gods, was the essence of things. The Greeks discovered the thinking device of 'essence', that the multiplicity of 'phenomena' could be reduced to a unifying element or structure. This was clearly sidestepping the gods. The charge of impiety was a serious one and, while there were always (it can be presumed) human expressions of curiosity, scientific inquiry or the quest for 'knowledge' or the cognitive enterprise, when also taken seriously, ran into conflict with the other main establishments of human society. It seemed as though the cultivation of knowledge for its own sake (which the Greeks finally achieved with Aristotle's first research center, the Lyceum) always exists in a kind of tension with the state, civil society, (which in a sense prescribed as well as proscribed the hubris of eminence) as well as with religious or ecclesiastic society (the traditional locus of unquestioned authority - whether embodied in stories, king-gods, oracles, augurs, priests, rituals, ecclesiastical organizations, etc.).

The Romans did a reprise of the Greeks when their orators and senators looked to the Greek tutors and Greek prototypes for effective speech. One would wonder with Nietzsche (and other moralists like Isocrates and Cicero) whether the exclusive reliance on explicit speech wasn't in fact a sign of a civilization's decline, the end of the binding character of mores, the legal, logical and philosophical taking the place of the early ethical-spiritual animating core. In Nietzsche's view, critical, sceptical and rational discourse tended to undermine the delicate balance of tacit factors that constituted the health of a civilization. Once the gods are questioned, it's all over. And, in empires, speech is either dictatorial, ceremonial... or frivolous. 
The Christian appropriation of the Graeco-Roman corpus was ambivalent. Like the present day Amish sect in America, anything beyond rudimentary literacy and numeracy was looked upon with suspicion by early zealot Christians as transmitting the false values of the dominant 'worldly' culture. After a long struggle for definition (how did Christian insights fit with classical culture?) the brilliant teacher of rhetoric, Augustine of Hippo showed how intellectual forms (Platonically defined) could serve God, i.e. the ends of sanctity. Augustine's powerful portrayals of the mind and society guided Christian culture. Other syntheses later followed: Aquinas and Aristotelian science, Eckhart and others in the culture of the inner life, the 'inner aristocrat'. The 'seven' liberal arts in vogue in the middle ages really came down to two, rhetoric and then dialectic, being emphasized in turn. They both were preparation for theology, the only question being whether the right ordering of words (rhetoric becoming mostly literary) or the right ordering of concepts (dialectic and then logic) was the best instrument. Other arts - architectural, legal and medical - continued in their traditions, and were represented on the congealing assemblages (university 'faculties'), but with a lesser status.

Toward the end of the Middle Ages and early Renaissance and Reformation, much ink was spilled on the issues of what constituted the 'good courtier' or the place of 'pietas' in the education of the 'Christian gentleman'. The 'Christian Humanism' of Petrarch and Erasmus demonstrated that new currents were flowing in Europe. Renaissance Florence, for instance, showed the delicate balance between the cultures of civic loyalty, religious faith and devotion to learning - as well as to the increasing importance of commercial trade. 
The Renaissance and the sixteenth and seventeenth centuries saw the disciplines of the gentleman combine with the new avocations, the 'new age' bordering-on-the-impious pursuits of experimentation and the renewal of mathematics as a living language. These amateurs and entrepreneurs founded learned societies and journals to record their tinkerings and eccentric dabblings. At the same time, during this age of exploration (the roots of European expansionism being still a moot question - the civilization of China, for example, despite the invention of gunpowder did not become aggressively expansionist) many 'utopias' were being projected, new lands, new worlds, new societies. Among these was Francis Bacon's projection of a new method of attaining (especially useful) knowledge and the improvement of society by intelligence alone without primary recourse to divine aid and/or guidance. The New Atlantis and Novum Organum were parts of this manifesto toward 'the advancement of learning'.

Similarly, the Philosophes in France took the new scientific pursuits and the triumphant synthesis of Newton as the basis for societal reconstruction. Again, human intelligence operating on its own, carefully, with full attention to method, and most emphatically without appealing to the divine, could bring about the progressive betterment of society and achieve the perfectability of man. The eighteenth century in America and France (and Russia in the early twentieth century) saw the fruits of these revolutionary postulates. Someone like Jefferson - gentleman-aristocrat, amateur-scientist and revolutionary - was a product of the early modern era. Classical learning, scientific pursuits (slowly gaining academic legitimacy) and political critiques were the 'paideia' of modern Western Europe, and a series of revolutions its upshot. 
The Industrial Revolution of the nineteenth century brought a major reaction: a tremendous reinvestment in the status quo. Technical tinkering became 'Techne' with a passion: the perfection of technology, the 'invention of invention', turned amateurs into specialists and resulted in the 'professionalization', the fine tuning, of society. The discovery of interlocking industrial processes required the offices of interlocking 'experts'. Skills could no longer be haphazard. Nationalism combined with the new industrialism to produce what Weber called 'the bureaucratic society' ('burel'=woolen cloth used to cover desks, therefore desks, therefore offices, departments; bureau-cracy= rule by departments, rule by precisely defined functionaries). This meant a tendency toward a completely 'rationalized' society, i.e. one in which everything was geared to a certain purpose and perfectly subdivided according to function. Universal public schooling, 'technical' education, and the methods of research science gained ascendence in late nineteenth century Europe and America with Germany taking the lead. Historical scholarship and the applications of the scientific method provided the dual rationale for humanity's vision of itself well into the twentieth century.

The question arose in John Dewey's tenure: what kind of education fit both civic preparation (in the democratic idiom) and technical expertise? 'Fit for life' was the central ambiguity of pragmatism's process metaphysics. One answer was the conversion of the gentlemanly-liberal arts into 'general education'. And the scientific method, or way of thinking, was to be its model of effectiveness. Good, i.e.scientific, thinking fit one for good work life and good civic life. In America, the Soviet raising of Sputnik only seemed to underscore the need for increased training in scientific and engineering skills. 
The ideological differences between the United States of America. with its individualist emphasis, and the Union of Soviet Socialist Republics, with its communitarian emphasis, was perhaps less important than: 1 . their both being organized bureaucratically, and 2 . their both promoting and aggressively protecting economic markets for their respective federations-become-empires. In both polities, despite the existence of parliaments (forums of rational discussion and debate), propaganda and popular media substituted for thinking. Democratic and communistic ideologies seemed less consequential than the Industrial Model of Society that had production and consumption of manufactured goods as the double reason for its existence. Mid-twentieth century places like Berlin, Korea, Vietnam, Angola and Guatemala, were the outposts and flashpoints of the two political/economic behemoths obeying only one logic, that of growth driven by organizations and engines that couldn't stop. (History quiz: Was it the assassination of Archduke Ferdinand, political alliances, armaments build-up, or economic competition that caused World War I, and thence, WW II)?

Education in the bureaucratic state was preparation for expertise - mostly manufacturing, managerial and entertainment skills that dovetailed (or should we say hawktailed!) in the reigning political economy. Sports, for example, metamorphized into fascist calisthenics, and then more subtly, from amateur into professional status, providing entertainment-narcosis for the working masses. Thus entertainment skills became as vital as 'technical' skills. All skills were expected to become scientifically cadenced and hence, 'professions'. Few questioned the direction of the ship of state. Orwell's fascist/communist dystopia in 1984, ruled by pain, and Huxley's capitalist dystopia in Brave New World, ruled by pleasure, both required obedience to the goals implicitly posited by the state. 
Perhaps the only autocrat resident in the 'System' (aside from criticisms of elitism and oligarchic conspiracy) was very phenomenon of its interlocking parts. Into this technocratic setting came another type of flashpoint, one that was internal to these societies (and not merely played out as another war fought on some 'foreign' colonial soil) - the cultural rebellion of the 1960's and 1970's.

What were the historical roots of this so-called 'counter-culture'? Was it merely surface protest? How deep did it go? What was/is its significance? Was this a true revolution in thinking or just a reshuffling of ideas? What was new about it? What does it portend and what are its achievements? What was/is its way of organizing the disciplines? How were the liberal arts conceived in its context?[146]

'Tertium Organum' represents a new pathway through space and time, through human action and reflection, a new way of calibrating 'here' and 'there'. It is a new definition of space and time. In a book by that title, P.D. Ouspensky, a Russian student of Sufi teacher George Gurdjieff, begins with the inscription:

"I have called the system of higher logic TERTTUM ORGANUM', because for us it is the third instrument or the third law of thought after Aristotle and Bacon. The first was ORGANON, the second NOVUM ORGANUM. But the third existed before the first."[147]

When Ouspenky says, 'But the third existed before the first', he is referring to the preexistence of the mystical tradition in all the world's religions. These mystical traditions antedate the rationalist elaborations in the Western world, but it is only in the coming dawning aeon, he contends, that these core traditions and their chief exponents can be fully appreciated and assimilated by humankind. Ouspensky published his manifesto in 1920 and it represents, depending on one's use of imagery, a 'vertical' or depth psychology of human nature and its possibilities. It sees itself as a contemporary expression of a tradition thousands of years old, antedating Western rational traditions. And yet completely new. 
Aristotle's logic, and the modern elaboration and refinement of the scientific method, represent the two great canons, the two great compendiums of methodology in the 'Western' world - around which the disciplines of knowledge, imagination and expression have accreted and constellated. What are the characteristics of this third touchstone, and in what ways does its manner of thinking differ from the previous two?

There are three key ideas in the new 'instrument' or, as we shall sometimes refer to it, ORGANON III. They are reminiscent of the Buddha's 'four vital truths' which are 1. existence is suffering, 2. there is a cause for suffering, 3. there is a way out of suffering and 4. that 'way' is the eight-fold noble path. The new canon can be summed up thus: 1 . Consciousness or sentience belongs to all life. 2. There is a path, a yoga, a regimen of awareness, that can be practiced to achieve full consciousness (hence full aliveness). 3 . The achievement of full consciousness is Liberation (human freedom, human fulfillment, union with the divine, solidarity with and service to the human community).

Here we are not dealing with intellectual enlightenment as with Diderot's 'Encyclopedie' but with enlightenment as coming into wholeness or whole-being. The coming into its own of a being is, in one of the paradoxes of this logic, its going beyond itself. 'At-one-ment' is self-transcendence. There is long didactic poem by eighth century Buddhist poet Santideva in which he gives a hymn to the very idea of 'enlightenment', of full liberation from human confusion, needless suffering and crippling limitation. Just that such an idea could appear on the immensely variegated human scene was itself marvelous.[148] Just the very idea of genuine and full freedom. In Hinduism, it was 'moshka', release from the inherent pain of existence. In its Zen Buddhist formulation, 'satori', the dramatic personal breakthrough, was complete penetration to the understanding of existence. This kind of 'enlightenment' (not simply more social latitude or political enfranchisement) is the pivotal notion of this new vision. Perhaps it is more correct to say that it represents the full concordance of the spiritual, the social and the political senses of freedom. 
All human disciplines, in this new dispensation, hinge on the primary discipline of awareness. Every discipline becomes a way of becoming aware of oneself, of others. of the world and of the Center of all life. Every discipline indeed becomes a total 'way of life'. As with the heuristic of physical science, new disciplines come to the fore as particularly relevant: e.g., somatic arts and therapies, meditation, group-work, ecology. And, rather than the arts as being cast aside as irrelevant or icing on the cake (i.e., decorative and nice, but not essential to human affairs), every discipline - from potterymaking to aikido to physics - becomes an art, a potential liberal art, that is, a 'liberating art'.

Every activity or domain becomes the scene of potential precision, beauty and generality in being conceived as a form-of-concentration. The new 'fine arts' become, in one set of authors' words, 'the fine arts of relaxation, concentration and meditation'. The distinctions between liberal and servile, between scientific and technical on the one hand and artistic on the other, fall away. A new orientation and perspective for the disciplines. Likewise the proliferation of retreat centers and growth institutes served the same nurturing and transmissive functions that the founding of scientific societies had vis-a-vis early modern science. Universities were, and are, the last to know because their function is to conserve the previous canon (with its correlative set of disciplines) in its integrity. It took science about three hundred years to dislodge classical studies from dominance. 
FIVE ROOTS OF THE COUNTER CULTURE, NEW AGE, AND THE PERENNIAL PHILOSOPHY

There were five roots to this nascent culture complex that we shall variously refer to as 'the counter-culture', 'the new age', 'the perennial philosophy', 'tertium organum', 'Organon III'. Aside from American Process Metaphysics, the ground for the new consciousness was prepared by: 1 . Romantic-Existential reactions to modern physical science, 2. the revolutionary developments of Twentieth Century physics, 3. European utopian educators of the post- Great War era, the 20's and 30's, and the emergence of a number of 'World-Teachers', 4. Marxist Revolutionary thought and German critical social theory, and 5. the 'Eastern Turn'. We will give a brief sketch of each.

\section{Romantic-Existentialist Reactions to Science}

The first root of the Third Organon, from eighteenth century Romanticism to twentieth century Existentialism may best be described as a series of reactions to and criticisms of the picture of the world arising from taking Newtonian physics literally. 
The Newtonian point of view was almost synonymous with the mathematical description of nature. What Bacon pointed at with the hand of a Renaissance explorer, Newton meticulously and comprehensively described. 'Mathematical analysis' was both a habit of thought, breaking 'things' (of whatever kind - be they clouds or human bodies or tidal currents) into component parts or subsystems. The particular discipline of the differential and integral calculus rigorously defined procedures of division and recombination. Descartes' analytic geometry made it possible to project algebraic results onto a flat euclidean space. John Locke, Newton's philosophical rationalizer, tried to defend the wildly successful results of such approaches by saying, in effect, that there were in reality two sets of qualities: one set (like motion and speed and volume) that were 'primary', and susceptible to mathematical description, and another set (like 'green' and 'sweet' and 'soft') that were 'secondary'. The second set of qualities, amenable to 'subjective' human perception (the first set universally pertaining to 'bodies') did not fare well philosophically or scientifically as there were many attempts to 'reduce' them to the first set.[149]

Descartes had made a philosophical 'cut' similar to Locke's, namely the division of the world into the mental on the one side and the spatial or 'extended' on the other. The result of these divisions seemed to be an 'external' nature denuded of both sensuous and 'transcendental' qualities, and an image of the human that threatened to be so as well. Romantic poets in England - Blake, Wordsworth, Keats and Shelley - and in Germany Novalis and Goethe - all protested this apparent translation of nature into the ghostlike wraiths of the calculus. Poets protested this 'bifurcation' (Whitehead) of Nature (now being threatened and therefore being hallowed) into consciousness, on the one hand (and narrowly restricted to human beings), and mere matter-in-motion on the other. Whitehead traces some of the 'romantic reaction' among the English poets in Chapter 5 of his classic Science and the Modern World where he also sets out the first formulation of his philosophy of organism. 
Poet, translator and commentator Robert Bly, in his News of the Universe collected specimens and provides glosses on the poetical consequences of Cartesianism, especially among the German romantics. The consequences are largely a devaluation of animals, nature, women and the earth as having no (or little) consciousness - which usually was equated to ratiocinative and controlling consciousness.[150]

A sample of poetic protest against regnant scientific materialism, determinism and abstractionism:

"Golden Lines

'Astonishing! Everything is intelligent!'

Pythagoras

Free thinker! Do you think you are the only thinker on this earth in which life blazes inside all things?

Your liberty does what it wishes with the powers it controls, but when you gather to plan, the universe is not there.

Look carefully in an animal at a spirit alive; every flower is a soul opening out into nature; a mystery touching love is asleep inside metal. 'Everything is intelligent!' And everything moves you.

In that blind wall, look out for the eyes that pierce you: the substance of creation cannot be separated from a word... Do not force it to labor in some low phrase!

Often a Holy Thing is living hidden in a dark creature; and like an eye which is bom covered by its lids, a pure spirit is growing strong under the bark of stones!

Gerard de Nerval/1854 translated by Robert Bly[151] 
And, in the sardonic words of Holderlin/1798: '...the earth is a corpse, so why thank her?'[152] If the earth is a barren rock, inherently lifeless, or at best, a huge mechanical configuration of atoms in motion, what then does that make of man?... The privileges of (having) consciousness seemed to be diminishing like the privileges of the ancient regime.... Consciousness seemed an anomaly and an anachronism in an exclusively spatially and materially defined world. Romantics of many different stripes said we had it completely backwards, that we were neglecting the obvious as well as the wonderfully hidden.

The romantic protest wended its way through Europe and America in the eighteenth but mostly the nineteenth century: from educationists like Rousseau and Pestalozzi through the Naturphilosophie of Schelling, Goethe and Fechner, through the Transcendentalism of Emerson and Thoreau. The richness of both Nature and Man seemed to go hand in hand: the impoverishment of one echoed the impoverishment of the other. As the industrial revolution accelerated, nature and man were resources to be exploited. Kierkegaard and Nietzsche protested, in what can be seen as mature romanticism or early existentialism, against what they saw happening to the 'inwardness' or soul of European man. With the rise of the industrial economy the need for record keeping increased and accounting as a discipline came into its own.[153] Credits and debits of commercial transactions replaced the self-apprehensions of the soul called 'conscience'. The cult of efficiency was in full swing.

Around the turn of the century vitalisms and 'life-philosophies' (Simmel and Scheler)[154] flourished in counterpoint to the reigning scientific materialism. Scientific optimism generated a despair among many European intellectuals. Jacques Maritain, who was to become a prominent twentieth century Catholic philosopher, and his fiancee Raissa, made a suicide pact to the effect that they would kill themselves if they didn't find a philosophy that gave meaning to life. Their dire plan was aborted when they found the 'elan vital' and 'creative evolution' doctrines and inspiring person of Henri Bergson. 
Bergson taught that scientific 'spatialized time' was very different than 'lived time' ('duree') and that the direct intuition of change was very different from the mathematical imagination of it as a series of 'freeze frames'.[155] If man's "powers" are cultural artifacts, then what you see possible is a function of how you see. Many of the antiNewtonian traditions emphasized a contrasting faculty to the workings of the analytic intellect: Coleridge and Wordsworth - imagination, Goethe and Fechner - holistic and spiritual perception, Bergson and Husserl - intuition. Robert Bly, as a host of other contemporary commentators, see these divisions in the modalities of perception as mirroring the functioning of the left (spatializing, logical, digital) and right (musical, intuitive, analog) parts of the brain.[156] For Gabriel Marcel, the French existentialist, the relevant distinction was between thinking as problem-solving and thinking as the ineluctable participation in, and appreciation of, an indissoluble mystery that only grows as particular problems are solved.[157]

Bergson's theme of the immediate structures of consciousness was probed in depth in Edmund Husserl's (1859-1938) systematic and influential approach to philosophy called Phenomenology. He shared with William James and the American Pragmatists a fresh look at the richness of experience. Bergson's very characteristically twentieth century theme of time and temporality flowered in the masterworks of Whitehead and Heidegger in the 1920's: Process and Reality (1929) and Being and Time (1927). His theme of challenge and response was a central inspiration of Toynbee's monumental A Study of History. And his counter-Darwinian vision of evolution was also persuasive in Whitehead's writings as well as in the vision of Jesuit paleontologist Teilhard de Chardin embodied in The Phenomenon of Man. In his seminal Two Sources of Religion and Morality, Bergson saw bourgeois convention and the vital springs of mysticism as the two sources. 
Along with Bergson's and others' challenges to scientific orthodoxy, the rage in the teens and twenties of this century was another blockbuster: relativity theory. Aside from the steady protests of traditions from Naturphilosophie to Existentialism that criticized the positivist-slanted science, revolutions were occurring in the heart of science itself that would contribute to the new worldview. A second root of the new age was the ferment of physics in the twentieth century.

2. Developments in Twentieth Century Physics

Accounts of the revolutionary developments of twentieth century physics are legion.[158] We will note but two implications coming out of the two main theoretical triumphs.[159] First enunciated in 1905, Albert Einstein's Special Theory of Relativity was the first of a series of attacks on the old Newtonian conceptions of space and time. The trend of thought initiated by Einstein's paper culminated in the dethronement of space and time as separate self-subsistent entities. Henceforth, in the new geometry of the 'general theory' they would be spoken of as space-time. Quantum theory, originating in the work of Max Planck, dethroned the third member of the venerated physical trinity: matter. All three of these 'quantities' of space, time and matter, as developments in physics continued, seemed to be much more intimately connected and interdependent.

According to new conceptions of the sub-atomic world, most of everyday durable things was composed of empty space! Eddington wondered which was the real 'table', the everyday one you sat on, or the scientifically constructed one that was mostly electrons whizzing in empty space. Developments got much stranger as quantum physics penetrated more deeply into sub-atomic regions where apparently Alice-in-Wonderland rules obtained! As Einstein's thought evolved, he announced his almost mythical formula describing the equivalence of matter and energy. The concept of matter as the ultimate substance, advocated by late nineteenth century 'materialists', was vanishing. 'Energy' was becoming a central part of the new vocabulary and way of thinking. 
Every successful theory is a complex edifice built by many craftsmen. The complex of theories known as the Quantum Theory were primarily developed in the 1920s and 1930s by Bohr, deBroglie, Dirac and Pauli. One of its principal architects, Werner Heisenberg, promulgated his famous 'principle of indeterminancy' which seemed to 1 . belie the determinism associated with Newtonian physics and, 2. imply a deeper more integral role to the observer of sub-microscopic events as the prescriber or contributor to those events rather than merely the simple recorder of them.[161]

The impossibility of ascertaining simultaneously the position and momentum of sub-atomic particles meant to Whitehead the truth of 'non-locality' - that all nature is somehow involved in each happening, that 'there was no such thing as nature at an instant', that 'the event is the unit of things real', and that an event was 'the actual scene of the adventure of energy'.[162] These William Blakean postulates of Whitehead implied the temporal spread and the universal interconnectedness of things. There was much more to 'energy' than the skeletal motion of atoms nakedly combining with each other. And the supposedly clear and absolute demarcations between 'objective' and 'subjective' were beginning to be shown indefensible. So there were vast epistemological and metaphysical reevaluations coming out of the results of the quantum world. Heisenberg:

"The goal of scientific investigation is no longer a knowledge of atoms and their motions as such, independent of the formulation of our experimental investigations. Rather we find ourselves, from the very beginning, involved in the give-and-take between nature and man, so that the customary division of the universe into subject and object into internal and external world - leads us into difficulties."[163] 
Twentieth century science was dealt additional jolts - or 'exciting challenges'! - in the heart of what it also considered rigorously established. Goedel's famous 'incompleteness' theorems seemed to demonstrate similar paradoxes in mathematics: the impossibility of proving a mathematical system both complete and consistent at the same time.[164] Uncertainty in the very kitchen of the citadel of rigor! These and other developments shook the foundations of nineteenth century thought and especially its smug optimism. At the same time, twentieth century science and mathematics displayed an undeniable creative ferment and explosive excitement. There was the rise of statistics, the mathematical expression of uncertainty and contingency.

In this setting, ideas such as energy, delight, creativity, more intimate participation in, and construction of the real, were coming into vogue. Apparently neither the world nor science was a machine, and human creativity was required at every point. In Whitehead's philosophy of organism, the world is a plenum of feelings or 'prehensions'. "...(P)hysicists begin to suspect that objects, even down to the tiniest molecular particles, may have awareness of each other as well as 'intention'...things once more become interesting."[165] A new world-image was germinating. The impossibilities of the old were giving way to the possibilities of the new. Impossibilities become possibilities and then become common sense. And with a new sense of the world comes the realization that there have been a different set of heroes and prophets. 


\section{Utopian Educators and the Advent of 'World Teachers':}

The New Humanities'

A third root of the new age was a collection of educator-pioneers, eccentrics and utopians, many of whom flourished in the 1930's. In an essay entitled 'The Crisis in Education', Hannah Arendt says "A crisis forces us back to the questions themselves and requires from us either new or old answers, but in any case direct judgments."[166] The crisis that was the conflagration of World War I forced many thinkers to do just that. G. Lowes Dickinson, one of the architects of the League of Nations, wrote a little known book entitled A Modern Symposium in which he probed in Platonic style, how far radically different personality types - and hence worldviews - like the businessman, the literary man and the scientist, could understand each other and their common world. Aside from the interesting premise, Dickinson had one of his personae sum up the essential character of American civilization as not greed, not commercialism, not power, but 'acceleration'. This was a not uncommon perception of the quickening events of the time. Humanity had explosively decimated itself in the 'Great War' and needed to seriously reevaluate itself and its habits if it were to survive. The League was one utopian experiment along those lines.

We will briefly sketch the ideas of two utopian-experimenters of that time. Both were educationalists in the sense of seeing that 1 . it was humanity as a whole, in the transnational sense, that needed to be educated, and 2. that educational establishments merely reinforced deeply ingrained and manifestly destructive patterns of thought and action. These utopians thought in deeply evolutionary terms. John Dewey was certainly part of that overall movement that tried to see the peculiarly important role of education vs. inculcation in the species survival of humanity. 
Australian F.Matthias Alexander (1869-1955) pioneered a somatic based technique called 'conscious constructive control' of the individual that he thought was a crucial step in the evolutionary development of mankind. John Dewey agreed with him [167] Aside from earning the enconmiums and studenthood of Dewey, Alexander influenced many notables in Europe and America, including George Bernard Shaw and Aldous Huxley.[168] One of the reasons why the techniques and approach Alexander developed was such an innovation surrounds the very idea of discipline. Discipline in pre-Deweyan times was practically synonymous with drill, repetition and strict obedience. This was the dominant pedagogy for two thousand years in the Western world - and far longer if one counts the apprenticeships in archaic societies. Authority, usually embodied in the teacher (living or dead) and/or the text was the guiding principle.

Alexander, in overcoming a severe stuttering problem as a youth, made a remarkable discovery. He found that most meliorative regimens depended on abstract directions like 'Relax!' or 'Brace up!', whereas in truth they involved a series of directions that had a sensory perception as its basis. As St. Augustine pointed out fifteen hundred years earlier in his treatise De Magistro (On the Teacher), the directive, 'Do this!' is essentially ambiguous, whatever the particular content of the instruction happens to be. Till the student finally achieves the effect alluded to or indicated by the teacher, he doesn't exactly know what the latter means.[169] By carefully observing himself in the mirror, Alexander found in his attempts at self-correction that he thought he was doing one thing, when, in fact, bodily he was doing another. This startled Alexander into realizing that he had a faulty sensory appreciation of what he was actually doing, and that consequently all his self directives were systematically misapplied.[170] 
Four points are noteworthy in Alexander's analysis/observation of the quintessential teaching-learning transaction. First, the very equation of learning with discipline as it is commonly understood is crucially misleading. By watching closely what happens in the phenomenon of 'following directions', Alexander came to see the equation this way: effort=excessive concentration=the sensation of strain.[171] Concentration - as it is usually applied - is the insidious simulacrum of the healthy and eager immersion that is real learning. Real learning involves a fluidity and freedom in its focusing, whereas the discipinary act of concentration imports fear and perplexity into its very constitution and ends up being a paralysis of the organism.

"...(N)ote the psycho-physical manifestations of the person who believes in concentration during the act of reading, writing, thinking, or during the performance of any other of the numerous daily activities. First observe the strained expression of the eyes, an expression of anxiety and uneasiness, denoting unduly excited fear reflexes; in some cases the eyes may be distorted, and the whole expression one that is recognized as the self-hypnotic stare. Then turn your attention to the general expression of the face, and pass on to the manifestations of the body and limbs. You will notice that there is an undue and harmful degree of tension throughout the whole organism."[172] 
By proceding in this wrong exclusionary, rigidifying way - which seemed like the paragon of perfection to the old 'artes liberales' way of 'character building' and the newer industrial efficiencies - Alexander believed that the wholeness of the psycho-physical organism was impaired. An improper standard of sensory appreciation was inculcated, by focusing on the externalities of the situation rather than on an awareness that freed the student to really attend. Rather than integral functioning, all manner of splits were set up: $\operatorname{mind} /$ body, intellect/instincts, me/others, 'a state of civil war within the organism'. For Alexander, a truly coordinated organism was a truly integrated organism. "...(I)f an imperfectly co-ordinated person makes a subconscious effort to carry out such specific instructions as we are now dealing with, the result as $a$ whole [author's emphasis] must be unsatisfactory."[173]

The third point to be noted in Alexander's account is that fixation on the object or objective to the neglect of the awareness of the 'means-whereby', the process by which we attain results, is ultimately and understandably the self-defeating culprit. 'End-gaining' is the supreme expression of desire. It is how humans work. We focus on ends to achieve them. But this fundamental structure of activity, according to Alexander has a fatal and indigenous blind spot: we are usually oblivious to how, the process by-which we achieve things. If the scientific method was the great corrective this, in terms of the efficient application of collective human ingenuity, then Alexander's great achievement was that he focused on the somatic importance of attention to method. In our blindness in pursuing ends and things, we habitually forget about the prime instrumentality of the body.

"No one would deny that we ourselves enter as an agency into whatever is attempted and done by us. That is a truism. But the hardest thing to attend to is that which is closest to ourselves, that which is most constant and familiar. And this closest 'something' is precisely, ourselves, our own habits and ways of doing things as agencies in conditioning what is tried or done by us. Through modern science we have mastered to a wonderful extent the use of things as tools for accomplishing results upon and through other 
acts of life should be automatic and unconscious; for this reason they have become indifferent. The psycho-physical condition here indicated is one that induces stagnation in the organism, and, it is a condition which becomes more and more pronounced with advancing age, we gradually lose the capacity to take conscious interest in and derive pleasure from those normal and useful activities of life in the sphere of doing, hearing, seeing, etc. Small wonder then that, sooner or later, we seek satisfaction in less normal and useful activities, and create an undue and harmful demand for specific excitements and stimulations or for some other specific pleasure!"[177]

Like the mythic Tantalus, modern man is constantly straining to grasp objects of pleasure while unconsciously standing in the pool of refreshment that is his/her/our own nature.

The implications of this approach for the idea of discipline and the relations among the disciplines are enormous. For Alexander, true discipline was that which brings us in touch with ourselves, with the right use of our body-mind instrumentality, rather than lengthens the distance between what we experience and what we project. Teaching and learning on a conscious plane needed to focus on what was happening in the intimate regions of the body if a true accuracy was to be achieved. Method did not repose in a series of external steps alone. 
Like Alexander, Polish-born Count Alfred Korzybski (1879-1950), founder of General Semantics, maintained with utopian enthusiasm that the pedagogical principles embodied in all society's institutions consistently spelled disaster for mankind. And, as with Alexander, he felt a new super- or pre- or sub- discipline was required to bring mankind into 'sanity' and 'maturity' and out of persistently pernicious habits. Such a regimen would be radically different from the usual set of prescriptions that defined 'discipline'. As with Alexander, the problem was that, although humankind wanted to do the right thing, it didn't know how. In fact, trying to do the 'right thing' was part of the problem. And again, as with Alexander, a truly liberating reeducation had to do with reorienting to the intimate data of the obvious. Attention to the complex processes assumed in everday occurences was the key.

Whereas Alexander was an acute observer of bodily postures and what they implied, Korzybski found his treasure trouve in the way in which language is unconsciously used. In his masterwork, Science and Sanity: An Introduction to NonAristotelian Systems and General Semantics, 1933, Korzybski saw that the 'unspeakable' was the foundation of language and hence should govern its correct use. The pain of a toothache is most emphatically not the same as the symbol 'toothache'.

"The term 'un-speakable' expresses exactly that which we have up to now practically entirely disregarded; namely, that an object or feeling, say, our toothache, is not verbal, is not words. Whatever we may say will not be the objective level, which remains fundamentally un-speakable. Thus, we can sit on the object called 'a chair', but we cannot sit on the noise we made or the name we applied to that object. It is of the utmost importance for the present non-A [nonAristotelian] system not to confuse the verbal level with the objective level, the more so that all our immediate and direct 'mental' and 'emotional' reactions, and all s.r. [semantic reaction] states, and reflexes, belong to the un-speakable objective levels, as these are not words. This fact is of great, but unrealized, importance for the training of appropriate s.r. We can train these reactions simply and effectively by 'silence on the objective levels...'."[178] 
According to Korzybski, all meaning in any language system or theory ultimately depends on 'the meanings of undefined terms which we know somehow, but cannot tell'.

"From this point of view, all language can be considered as names either for un-speakable entities on the objective level, be it things or feelings, or names for relations. In fact, even objects, as such, could be considered as relations between the sub-microscopic events and the human nervous system. ...(A)n object represents an abstraction of low order produced by our nervous system as a result of the submicroscopic events acting as stimuli upon the nervous system."[179]

For the Korzybski of Science and Sanity, reality was the Space-Time Continuum of Einstein and best described by the relational language of modern science, as opposed to the noun oriented and subject-predicate form of the Aristotelian canon. Korzybski was at great pains to contrast his Einsteinian view with the outmoded physics, psychology and metaphysics of Aristotle, whose views he thought to underlie commonsense assumptions about the universe. Commonsense views, and the ubiquitous pedagogy that reinforced it despite the literally world-changing discoveries of science - included assumptions like every term had a single-valued meaning, and the penchant for seeing things and situations in an either-or fashion. Both these and related assumptions he saw as making human communication into a minefield and as systematically creating the conditions of misunderstanding and violent disagreement. Nobody knows exactly what they're saying and we kill each other to boot. He contrasted this Aristotelian orientation with his conscious 'non-A' training, inspired by the precision implied by a truly rigorous scientific approach. The crucial difference between the two orientations was what Korzybski called 'consciousness of abstracting'. 
In true Comtean fashion, Korzybski maintained that, although Aristotelian thinking represented a victory over primitive magical thinking, it still wedded humanity to a fundamentally primitive mode of thought and behavior. In Totem and Taboo, Freud noted a similar thread running through the thought-patterns of primitives, little children and severely disturbed neurotics, a syndrome he called 'the omnipotence of thought'. Korzybski likewise distinquished between the infantile mode of thinking that hinged on a false objectivity ('identification' with the object, hence wishful thinking, unlimited fantasy projections of power, etc.), and a mature mode of thinking, brought about by training, one that was cognizant of the abstractive process and especially of how reactions were generated.[180] Just as the Eskimo have a host of terms to discriminate the nuances of an umbrella term like 'snow', so too, says Korzybski, the deceptively simple Aristotelian generalization 'apple' masks a plenitude if not infinitude of examples, situations and reactions.[181]

The full weight of Korzybski's point comes home when we think of using names like 'Maria', 'John', 'Samuel' and 'Isadora' in a univalent way. Even trickier are what Korzybski calls 'multiordinal terms', terms that describe relationships, like 'equal'. When we get to terms like 'history', 'reality', 'morality', 'rights', and the negotiations at the Treaty of Versailles, problems of interpretation increase exponentially! [182]

Abstraction happens like breathing: we do it all the time. The question is how skilfully and with what kind of awareness. Taking his cue from Bertand Russell's theory of 'logical types', Korzybski developed a theory-practice of levels of abstraction starting from the unspeakable space-time continuum of events to the neurological syntheses that produce the 'objects', or overwhelmingly simplified portraits, of our experience. 'Sanity' was literally a matter of knowing what level of abstraction one was operating on, and therefore awareness of one's reactions ('semantic reactions'). As with Matthias Alexander's work, awareness of one's reactions was the first and crucial step toward sanity, toward a maturity of consciousness versus mere chronological development. 
In Korzybski's 'non-Aristotelian training' - which goes significantly beyond commonsense generalizations and simple scientific inductions - what is aimed for, again as with Alexander, is a 'feel' for what is happening to us on the silent level and therefore a correctly formed kinesthetic standard of evaluation. This is very different from our usual habit of uncritically focusing on 'objects' as being the complete picture or whole situation of an event.
"Once we get the feel of...horizontal and vertical stratification, and learn to differentiate between orders of abstractions, identification disappears. Silence on the objective levels produces a 'delay', involves and trains the cortex; our reactions become more and more intelligent in the human sense...and the most important results are reached by the simplest means."[183]

For Korzybski and Alexander the role of conscious pausing, 'delay' and 'inhibition' of conditioned, automatic and seemingly 'natural' habitual responses, was an essential ingredient in this new training for humanity. Korzybski thought the implications of his work for war and peace were so important that he felt there ought to be an 'epistemological department' in the League of Nations![184] 
Besides Alexander and Korzybski, there were many other would-be 'trainers-ofhumanity' in the decades following the 'Great War'. In 1933 Buckminster Fuller published his eccentric utopian manifesto, Nine Chains to the Moon, an experiment in 'integrativeevolutionary' thinking. His Operating Manual for Spaceship Earth was to become one of the guiding manuals of the coming ecological consciousness. In 1937 Olaf Stapledon published his vast symphonic novel, Star Maker, presenting an overview of the collective evolution of human consciousness as it expanded through galactic embodiments toward a supreme consciousness. Personal tragedies and the collective experience of the Great War convinced these and others in the growing intuition that colossal destruction would attend mankind's conducting of business in the usual way. Great calamities issued, yes, from perverted governments and leaders. But these were but the dramatic expressions of the distortions and violence inherent in seemingly 'normal' consciousness. If defending one's turf was considered normal, why wasn't defending nationalist ideologies?... The conviction grew among thinkers, artists, therapists, socialists and 'spiritual' explorers who went beyond blaming other countries and other ideologies - that what was considered normal was, in fact, deeply 'neurotic'. How else explain millions of ostensibly ordinary people slaughtering both combatants and civilians in the millions? 
Nonetheless the ideologies of fascism, communism and capitalism (all masking a fundamental identification with the needs of industrial organization) swirled in the thirties preparing the next maelstrom. Was it true that only one man - Adolf Hitler - could stir an entire planet to war? Or was there a deep complicity in how social systems indoctrinated their young, no matter the doctrine?... What was the true measure of sanity - given the extirpation and subjugation of peoples by the Western 'democracies' under the aegis of 'manifest destiny' and colonialism, by the 'international unification and liberation of the workers' of Communism and by the vengeful Nazi self-affirmation of the recently humiliated Germany...? Japan, of course, had recently 'gotten it': it had perfectly assimilated the Western industrial expansionist logic of organized power earlier in the century.

The Freudian tradition also spawned its utopians, like Wilhelm Reich, who also began to deeply question normality and its institutional underpinings, after the Freud of Civilization and Its Discontents. It was as if Rousseau had been resurrected and asked whether the 'progress of the arts and sciences' up to that point had done anything to improve the condition of mankind other than forge ideational and material tools of greater and greater destruction under the strain of 'externalization'... Clearly there was something wrong in the way mankind (ab)used itself. But the growth of this evolutionary selfapprehension in the thirties was itself a significant fact. Utopians of different stripes believed that humanity-as-a-whole was facing a crisis, that a crucial evolutionary step needed to occur, and that this step involved a new way of thinking/feeling/proceeding - a transmutation in consciousness. The conflagration that was called The Second World War' justified their worst fears. 
The 1920s and the 1930s saw the emergence of the phenomenon of "worldteachers". These teachers all addressed humanity; they all had their roots in the vedic and yogic traditions of India; and they all had deeply prophetic messages about the dawning of a new age of human consciousness and simultaneously apocalyptic warnings about the potential destructiveness of mankind's 'business as usual'. Increasing technological power had concentrated and accelerated man's impulses. Now, like the projectiles of the Big Bertha cannons, unprecedented damage could be amplified and unleashed at a distance. New technological advances, from the chemical, radio and aeronautical industries, foreshortened space, time and material, and underscored the uncertain and hate filled psyches controlling it all. Who or what was truly in control?

For the supreme sages of the twentieth century, only a revolution in the inmost part, the central core of the psyche, could bring genuine order to human society. The magnitude of the present and coming crises seemed to point to the deepest point inward; everyday, commercial and political 'orders' seemed spurious, if not actually contributory to massive distortions. We will briefly consider three such world-teachers and heralds of a new world age: Gurdjieff, Aurobindo and Krishnamurti.

George Gurdjieff (1873-1949) was a Russian Sufi teacher who had travelled widely in the Middle East, India and Tibet.[185] In agreement with many other sages, Gurdjieff's basic assessment of humankind is that it is functionally asleep. Ordinary waking consciousness is really a series of mesmeric trances. People popularly think yogis specialize in trances. In fact, the opposite is the case! Men are thoroughly conditioned creatures with the illusion of freedom; people are collections of automatisms.

"Gurdjieff's basic teaching is simple, almost stark. Man is a mechanical puppet twitched by every outside event, he said. $\mathrm{He}$ is the prey of his fears and desires which never remain consistent, so that he is constantly changing and is never the same person for long. He is such a bundle of impulses and reactions that his individuality is non-existent: '...(A)ll the people you see, all the people you know, all the people you 
may get to know, are machines, actual machines working solely under the power of external influences...Machines they are born and machines they die...."'[186]

Other than continuing to manipulate illusions or shuffle circumstances, the only way to surmount this basic human condition of obliviously disjunct personalities was the process of self knowledge. This arduous regimen Gurdjieff called 'self-remembering' or 'self-observation'. Only then was there a chance for freedom. "When a machine knows itself it is then no longer a machine...It already begins to be responsible for its actions."[187] As with Whitehead's famous aphorism, Gurdjieff declared that it was not true that man was a conscious being. Rather he was only 'fitfully conscious'. The task, then, was to develop consciousness. The task was a practical one that proceded through a series of experiments and hard work. Intellectual assurance or theoretical conviction wasn't enough; that simply split off the thinking 'center' from one's 'whole-being' which was already laboring under a host of unconscious splits and schisms.

Full integration of the human personality was the goal. One of Gurdjieff's favorite exercises was the STOP! exercise in which he would ask his students to freeze in the midst of their kitchen or gardening work and simply be aware of their bodily and mental postures at that moment.[188] As with Matthias Alexander, Gurdjieff taught that the usual approaches to 'relaxation' and 'voluntary' effort were misguided. (Later, another serious philosophic prankster, Alan Watts, made fun of what was implied in a Harvard psychologist's book title, 'You must relax!') Rather than the Newtonian 'push-pull' orientation, based on the application of force, a new more sensitive and comprehensive approach was needed to effect basic change in the psyche. Force was inherently counterproductive, and moral exhortations were a waste of time. Ways to bring about authentic self knowing was the essential task. 
Gurdjieff's Institute near Paris in the 1920's, later carried on as 'the Work', very much resembled the core esoteric Pythagorean school of Platonism. There were gymnastic exercises and rhythmic movements to develop bodily harmony; there were cosmological discourses and inquiries into the deeper vibrational structure or 'octaves' of the physical and astral universe; and there were the silent expriments aimed at engendering self-knowledge. Gurdjieff's doctrines, approaches and school were a repository of the esoteric and mystery traditions. And, of course, the inspiration and charisma of his personality was no small part of the mix. As with the message of the Buddha, Gurdjieff taught that man could transcend his ordinary suffering-producing condition by becoming 'awake' to what he habitually was and did. It was not the intermittent fact of consciousness that counted, but its alchemy, its transformation, its flowering. Man needed to become what he truly was. Consciousness was the medium.

British educated Sri Aurobindo (1872-1950) was another teacher of world stature. Imbibing the revolutionary traditions of Western modernity, he returned to his homeland and, around the turn of the century, became an anti-colonialist agitating for Indian independence. [189] His dramatic confrontation with the civil authorities after his arrest for sedition resembled other dramatic confrontations between the religious and the secular domains: Socrates and his Athenian junta accusers, Jesus and Pilate, Bodhidharma and the Emperor of China. During the court hearings, Aurobindo ecstatically experienced his prosecutors as embodiments of the divine. His prison stay was flooded with such experiences and he eventually left his seditious activities - but not his activism, which was different in kind from Gandhi's - and retired to the French protectorate of Pondicherry to pursue the reassimilation of Vedic and yogic culture.

Aurobindo's life was roughly coterminous with another great Indian sage who threw off Western trappings to reembrace his great culture: Ramana Maharshi (18791950). Carl Jung comments on him and the St.Francis-like universal saint Sri Ramakrishna (1834-1886) could as well apply to Aurobindo: 
"...(O)ne may look upon Sages like Sri Ramakrishna and Sri Ramana as modern prophets. They not only remind us of the thousands of years' old spiritual culture of India, but also directly embody it. Their life and teachings form an impressive warning not to forget the demand of the soul in all the new things of Western civilization and their materialistic-technical and commercial concerns of the world. The breathless impulse to obtain and possess in the political, social and intellectual fields, which is rummaging the apparent, unappeasable passion in the soul of the Westerner, is also spreading continuously in the East and threatens to bear consequences not yet to be overlooked. Not only in India but also in China, much has already been lost in which once the life of the soul lived and flourished. The externalization-culture of the West can truly clear away many evils, the destruction of which seems to be very desirable and advantageous. But, as experience has shown, this progress is bought too dearly with a loss of spiritual culture. It is undoubtedly more comfortable to dwell in a well-ordered and hygienically furnished house, but that does not answer the question as to who is the dweller in this house...."[190]

Aurobindo reappropriated the familiar doctrines and practices of his homeland as 'integral yoga' and expounded a breathtaking vision of the ascent of humanity, his The Life Divine. This work had startling resemblances to Stapledon's vision of cosmic evolution in Star Maker. The evolution of the sage is really, according to Aurobindo, the prototype of human evolution generally. '...(T)he exceptional is only a normality not yet mastered.'[191] '...(O)uter circumstances are merely the unfolding of what we are.'[192] Going back to Patanjali, the Vedas and the Upanishads, Aurobindo says 'All kinds of discoveries are made, in truth, when the mental machinery stops...', with the 'witnessing' of the 'silent mind'.[193] In truth, 'yoga is not so much a way of learning as of unlearning a crowd of so-called imperative habits which we have inherited from our animal evolution.'[194] Psychic clearing creates immense possibilities for the human entity.[195]

If the seeker would try to restrain the rush of thoughts for but five minutes 'will see what stuff he is made of!': 


\begin{abstract}
"He will find that he lives in a clandestine turmoil, an exhausting whirlwind, but never exhausted, where there is room only for his thoughts, his feelings, his impulsions, his reactions - himself, always himself, enormous gnome who obtrudes everywhere, veils everything, hears only himself, sees only himself, knows only himself (if that) and whose perpetual themes, more or less alternating, can give him the illusion of novelty. In a certain sense we are nothing but a complex mass of mental, nervous and physical habits held together by a few ruling ideas, desires and associations - an amalgam of many small self-repeating forces with a few major vibrations'."[196]
\end{abstract}

In the attempt to quiet the mind, it is important not to make the mistake of struggling mentally with the mind.[197] The way to peace is not to struggle violently with the mind and instinctual currents but to get to know its workings intimately as a part of an all-embracing 'saddhana' or way of life. Desire and its permutations inevitably lead to restlessness. Aspiration or faith initiate another kind of process entirely.[198] But this 'faith' is not faith in the mode of blind belief. Yoga is based on direct inspection of the contents of consciousness. One is enjoined to 'see for oneself.

In the West, following Descartes famous axiom, 'I think, therefore I am', there is the tendency to identify consciousness with mentality or thinking. But for Aurobindo, thinking represents but a fairly narrow range of consciousness. In fact, customary thinking 'jams' - via its perturbations, desires and fears - the deliverances of the Universal Mind.[199] Aurobindo characteristically observed:

"Mental consciousness is only the human range which no more exhausts all the possible ranges of consciousness than human sight exhausts all the gradations of colour or human hearing all the gradations of sound...So there are ranges of consciousness above and below the human range, with which the normal human has no contact and they seem to it unconscious, - supramental or overmental and submental ranges..."[200] 
The yogin, for Aurobindo, is at home everywhere, his being having become peace.[201] In a famous passage he describes that state:

"The substance of the mental being...is still, so still that nothing disturbs it. If thoughts come, they...cross the mind as a flight of birds crosses the sky in a windless air. It passes, disturbs nothing, leaving no trace. Even if a thousand images or the most violent events pass across it, the calm stillness remains as if the very texture of the mind were a substance of eternal and indestructible peace."[202]

In the 1960's an American, Michael Murphy, after having practiced in the Aurobindo ashram in Pondicherry, returned home and founded the prototype of human potential/consciousness growth centers, the Esalen Institute in California.

The third representative world teacher and herald of the new age was actually announced as such. In 1910 on a beach in India, clairvoyant and theosophist C.W.Leadbeater found a dreamy boy who was soon proclaimed by the Theosophical Society as the Lord Maitreya, the incarnation of the Buddha of this age. The diffident boy was given a gentleman's English education and was exhaustingly prepared for the mantle of spiritual leadership.[203] In 1929, Krishnamurti (1895-1986) rejected this messianic role and disbanded the large organization, the Order of the Star, that had surrounded him. He rejected hierarchies, ranks, religions and organizations with their inculcation of slavish ways of thinking. No amount of following an external idea or personage or ideology could lead one to the Truth. For the next almost sixty years, till his death in 1986, Krishnamurti became a peripatetic anti-guru enjoining a radical independence of mind and an uncompromising self-awareness as the gateway to the Truth, "a pathless land". 
According to Krishnamurti, nationalisms, ideologies, religions, methods of mindcontrol and formulaic techniques of awareness, were all species of self-deception: all diverting mankind from looking unflinchingly at 'what is'. Only by looking directly at the endemic violence involved in everday life could one hope to understand how millions of parents could send their children off to war to be slaughtered. To most, 'idealism' seemed beautiful and redemptive; to Krishnamurti it was the habitual mechanism by which atrocities were consistently justified. Unless we come to see clearly our own agonies and contradictions with a 'choiceless awareness', we wallow in religious, political, scientific, artistic and other rationalizations. In Eckhart's words, we merely prate of God, and pass the ammunition. In Krishnamurti's iconoclasm, all methods - whether to God-realization or to achieve the perfect state - were forms of mesmerization, being hypnotized by some idea. 'Knowledge' always represents the past; awareness allows us to dwell in the present with its contradictions, exigencies...and authentic possibilities Only from the true present does true and effective action, transforming action, emerge. The essence of violence was, according to Krishnamurti, action in accord with an 'idea'.

The pattern of following and conformity that most people consider order, is, for Krishnamurti, rampant disorder. Identification with anything - self, family, profession, nationality, moral code, 'God' - creates division and misery. The larger and more hallowed the identification, the more mischief under the bridge. Only by coming to see clearly and intimately the process of defensive self-enclosure that is everyday consciousness can one 'go beyond' oneself to what mankind has always dimly intuited to be the case. Krishnamurti is an unimpeachable mystic. 
A step backward. Toward the latter part of the nineteenth and at the turn of the twentieth century, there flourished in Europe and America a wide variety of spiritualisms. occultisms, psychical research and related currents that probed and cultivated what the reigning scientific ideology of materialism said didn't exist. Examples were Mary Baker Eddy's Christian Science, the Theosophy of Mme. Blavatsky and Col. Olcott and the Anthroposophy of Rudolph Steiner. Particularly Theosophy was 'esoteric' in the precise sense of cultivating an 'inner' or secret knowledge that could, by its nature, only be discerned by a select few. 'Tllumined' ones would pass the message on and engage in 'saving' humanity at large. According to Steiner (1861-1925), who was originally a theosophist,

"...(T)he objects and occurrences which the senses perceive are in space. But, just as this space is outside of man, so there exists also within man a sort of soul-space which is the arena of spiritual realities and occurrences."[204]

This was a great internal 'chain of being', an astrally full world, complete with elaborate invisible hierarchies of beings at all 'grades' of perfection. Just as musical or mathematical talents needed to be sharpened, so too, in this gnostic vision, the spiritual 'organs of perception' latent in all men need to be developed. Perceiving auras and following the bodily centers of energy, the 'chakras', was available to all who made the effort to open their 'wisdom eye' or 'spiritual' faculties. Steiner was a link with the luminous psychology, physics and botany of Goethe and Fechner. Founder of the Waldorf Schools, Steiner and his pedagogy had much in common with the gestating-soul pedgagogy of Maria Montessori (1870-1952). For both, for example, motoric skills were not simply incipient occupational skills but the ongoing expression of spiritual physiognomy as well.[205] 
'Fast forward' to California in the late 1930 s and during the early years of the Second World War. America was a refuge for Krishnamurti, English novelist Aldous Huxley (1894-1963), of the famous Huxley clan, and British Vedantists Christopher Isherwood and Gerald Heard. Huxley wrote his very influential The Perennial Philosophy during the throes of the war. This extraordinary compendium was an anthology and commentary on the saints and sages of all the world's core mystical traditions: Christian, Jewish, Islamic, Hindu, Taoist and Buddhist. In this historical/ahistorical 'ricorso', or return to primal roots, Huxley attempted to gain first hand acquaintance with the figures who were at the direct perceptive core of their respective traditions. In that time of crisis Huxley sought the true guides of mankind:

"With the unaided eye a small, faint smudge can be detected in the constellation of Orion, and doubtless an imposing cosmological theory could be based upon the observation of this smudge. But no amount of such theorizing, however ingenious, could ever tell us as much about the galactic and extra-galactic nebulae as can direct acquaintance by means of a good telescope, camera and spectroscope. Analogously, no amount of theorizing about such hints as may be darkly glimpsed within the ordinary, unregenerate experience of the manifold world can tell us as much about divine Reality as can be directly apprehended by a mind in a state of detachment, charity and humility."[206] 
Huxley's text cites abundant passages from the great mystics of each tradition: Rumi, Eckhart, Siddartha Gautama, Lao Tzu, Shankara, etc. In the heart of the war's invasions and bombings was a search for the 'still center' of all the chaos. For Huxley the key to the concentrated mind or spirit was to be found in the core meditative and contemplative practices found in all the world's religions. 'Be still and know that you are God'. Only a concerted journey within, not ardently held beliefs, affiliations, external rituals or pious observances, could bring order without. Unmindful of its true fulcrum, the world was tossed in the sea of 'samsara', going round and round painfully chasing its own tail, or, in the words of the Gita, 'imprisoned in its own activity'. 'Moshka', liberation, was the central message of all the world's religions. While Huxley recognized the value of the different kinds of yogas or paths to the 'divine ground' of experience - the Hindu 'karma yoga', the way of work, 'bhakti yoga', the way of devotion, and 'gnana yoga', the way of knowledge, all in accord with the perennially different human temperaments - he clearly gave emphasis to the last, the yoga of awareness: the combined way of concentration, meditation and contemplation. 
The phenomena of mysticism had been studied extensively in the twentieth century: Richard Bucke's Cosmic Consciousness and William James' rejuvenating Varieties of Religious Experience around the turn of the century, Evelyn Underhill's classic studies, e.g. Mysticism, and Rudolph Otto's phenomenological The Idea of the Holy. All these works, and the work of trail-blazing commentators like Ouspensky and Huxley, did two things. First, they studied religious experience apart from its hitherto strongly dogmatic and sectarian context, i.e as Catholic or Protestant or Mohammedan. They sought and attempted to describe the core experience. Second, they portrayed religious experience as experience, as something naturally occurring in human affairs and temperaments and accessible to human perception, effort and practice. Perhaps the experience was ultimately a gift of grace. Perhaps it was something ultimately and finally mysterious. But it was important to dispel false mystery. In truth, what created false mystery was all the 'veils', the multitude of concerns, of our confused and beguiled everyday consciousness. All the sacred traditions maintained that there were many things one could do to 'prepare the way', 'clear the ground' - and let the Spirit blow where it would. There were certainly no guarantees, but something much more intimate was sought than the pro forma following of rituals, the having of beliefs, or holding membership in a congregational body or association. 
One of the hallmarks of the Third Organon is a depth psychology. Huxley quotes Eckhart on divine 'immanence': 'To gauge the soul we must gauge it with God, for the Ground of God and the Ground of the Soul are one and the same.'[207] Secondarily the 'rungs' or 'frequencies' of the psyche 'correspond' to the rungs of the cosmos or planes of being.[208] Despair creates or 'tunes into' a very real world. So does a life of renunciation and service. Just as the Second Organon of organized scientific inquiry ushered European mentality into a much wider world than the neat Aristotelian cosmos, so too the Third Organon proclaimed a much wider universe. More accurately put, life was seen to be filled with expanding and contracting overlapping worlds, each punctuated by different psychic accents. A literally mind-bending infinitude of heavens, hells and transitional worlds exist, subsist, abound, vanish and metamorphize. Enough to keep a 'googol' of William Jameses occupied for an infinity! 
Another hallmark of this Organon, directness or immediacy of experience. both was true and yet needed to-be-made true. Experience is both illuminated and in need of illumination. The most transient and inconsequential impulse flashes a light upon the world. Every mental state has an internal 'clarity' and rationale. Every state is what it is and arises for (a) reason(s), whether articulatable or not. In one important respect there are no absolute 'mis-takes' in this worldview: we all experience exactly what we experience with utterly flawless precision. (This, incidentally, is the basis for the rigor and richness of the enterprise of Phenomenology. It is also the basis of Parapsychology. Things may or may not fit into a current paradigm of explanation.) By the same token, aspired-to states and/or conditions are achieved or not, with analogous strictness. Like it or not, one is where one is. It is as if there is an 'astral' space that expresses exactly one's constellation of feeling(s). According to Aristotle (in his Ethics), there is not a name for every emotion. To paraphrase Kierkegaard, there is no cheating in the existential sense. Again, one is where one is. Therefore, there is a third emphasis on yoga, the 'yoke' or joining, the way of 'connecting' that transforms one's whole being. Huxley uses yoga in the traditional Hindu sense of union of the small empirical self with the transcendent Divine Self. Yoga: connecting one's immediately given states of mind - and therefore being - with the Ulitimate as experienceable, experienceable because latent at the heart of the montage-like self. 
In the early 50's Huxley wrote philosophical-pedagogical essays [209] stressing themes sounded by Krishnamurti: e.g., the difference between accumulated (although necessary) knowledge and direct intuitive apprehension. He introduced the concept of a 'non-verbal humanities' based on awareness, and different from the 'classical' and 'progressivist' families of educational theory. Huxley in 'The Education of an Amphibian' starts with the announcement that man is a creature who lives in many worlds, 'many different and even incommensurate universes'.[210] He then goes on to diatribe against Descartes' notion that what is human is identifiable with the conscious self. There are, Huxley insists, a host of 'not-selves', 'indwelling intelligences' that make up our being and constitute reservoirs of natural wisdom for that little would-be tyrant of our conscious self.[211] He discusses a number of pedagogical texts like New Pathways in Piano Technique by Bonpensiere, Zen and the Art of Archery by Eugen Herrigel, and The Use of the Self, The Universal Constant of Living and other works by Matthias Alexander.

"Each of these books bears witness to the same fundamental
truth. When the conscious will is used to inhibit indulgence
in the bad habits which have come to seem natural, when
the ego has been taught to refrain from 'straining every
nerve', from desperately trying to 'do something', when the
personal subconscious has been induced to release its
clutching tensions, the vegetative soul and the
intelligences...can be relied upon to perform miracles."[212]

The marvelous action of instinctive activity is released when the conscious self learns how to 'get out of the way'. 
In looking at sports and skills, Huxley notes that precisely the same challenge is in the combination of relaxation and activity.[213] He agrees with Alexander that 'bad' habits usually have to be unlearned before one can truly exercise one's native flexibility and its implicit intelligence. The guiding kinesthetic sense needed to be trained, as Alexander emphasized, to develop accurate and free proprioception. Training in the usual sense results in imitation and not true proprioception. Harmonious and effective perception of oneself, as Dewey said underscoring Alexander, 'provides the conditions for the central direction of all educational processes'.[214] The summit of such a course in kinesthetic appreciation or reeducation, in contradistinction to our usual conditioning in 'end-gaining' procedures is, in Huxley's view, the 'virgin not-mind' of zen and its raft of insights.[215] And, on the way, we learn how to eat, sleep, play, learn, work and relate better. 
What all this amounts to is a need for 'the non-verbal humanities'. According to Huxley, the inescapable medium of education is language. It is saturated with language and its presuppositions. Language is a two edged sword: it not only lifts us up to function as humans but it also weighs us down with a cargo of conditionings and abstractions.[216] Conditioning - training in the usual sense - and conceptual-discoursive knowledge are both necessary in human culture. Indeed, they construct human culture. Man is the creature of symbols. But, Huxley asks, isn't there something further necessary for human freedom, and the flexibility to meet the circumstances of the present without the baggage of the past? Conditioning says Huxley is very much like somnambulism: we react flawlessly, reflexively and unthinkingly. But again, he asks, is that sort of 'post-hypnotic' reaction on the basis of 'charged memory' and/or accumulated knowledge, adequate to meet the everchanging circumstance of the present? We need a much more unemcumbered mind or sensibility to do that, and that is precisely what is missing in our educational practices. The 'power of images' - though a necessary substratum of human activity - vitiates our ability to 'respond spontaneously' to given realities.[217] While the stock of learning is culture, a certain species of un-learning is necessary for effectiveness and freedom. A 'virgin' mind is necessary to receive the present. 
There are two main families of educational theory, Huxley says in the essay "Knowledge and Understanding". The first, the Classical, he describes thusly: "The literatures of Greece and Rome provide the longest, the most complete and most nearly continuous record we have of what the strange creature Homo sapiens has been busy about in virtually every department of spiritual, intellectual and social activity".[218] The second, the Progressive type, he describes in the words of a critic (bastardized Deweyism, Huxley says) as "courses in such subjects as family living, consumer economics, physical and mental health, job information, training for world-citizenship and statesmanship and last,...training in fundamentals".[219] The two approaches Huxley says are not necessarily incompatible, but, he asks, are they enough? No, they aren't, he answers. They don't begin to address the all-important education in 'self-realization'.[220]

Again, his solution is that of the 'non-verbal humanities', a pre- and post-, and perhaps para-, conceptual education that would start with Alexander's and others' facilitation of a healthy kinesthetic sense - accurate cognizance of one's sensations, postures and movements, the precious art of working with oneself rather than against oneself, skill in proprioception - to 'the last and most important branch of non-verbal education (which) is training in the art of spiritual insight'.[221] Right now we fixate on either conceptual education or 'vocational' education. Neither, says Huxley, produces full human beings and both neglect the vital domains of the sensorial, the proprioceptive and the spiritual. To deny so much of our nature is to produce stunted and inevitably violent human (sic?) beings.

Huxley wrote the introduction to Krishnamurti's First and Last Freedom (1954), a clarion call to a 'revolution from within' through the 'choiceless awareness' of a 'silent mind'. There had been a definite shift in cultural sensibility. 'Know thyself' was the imperative for this new age. What had previously been a gnostic call to a few now defined an age, and became the mission of a generation. 
These explorations in self-knowledge took many forms and Huxley's explorations were quite wide ranging. "It was Huxley's competition with Sir Humphrey Osmond to find a neutral term for consciousness-expanding substances that led to the invention (by Osmond in 1957) of the word 'psychedelic'."[222] 'Psyche-delos' meant 'mindmanifesting', manifesting the deepest quality(ies) of the mind. Huxley explored that realm in his personal experience and wrote of it in The Doors of Perception. [223] The wise, if not sacramental, use of psychedelics, like LSD, mescaline and peyote, had introduced many to the possibility of a unitive and revelatory 'highest state of consciousness'. There were increasingly many interpretations of that state, including the Hindu 'moshka' or liberation, 'peak experience' as defining the very nature of religion, 'satori' or enlightenment, chemically induced 'biological ecstasy', etc.[224] (Recall William James' experiments with nitrous oxide in his Varieties that enabled him to understand the insights of his arch-enemy Hegel.)

It is important to note that Huxley and a rising tide of other investigators were approaching consciousness, not as the fixed subjective Cartesian quantum, but as capable of tremendous (albeit mostly untapped) ranges and frequencies and, most essentially, as revelatory of the Basic Nature of the Universe, called by so many ecstatic names by so many different traditions. It was as if all the sages of all the world's religions were pointing to the same core experience. 'Expanded consciousness' wasn't a 'thing' but an intense state of activity, a self-transcending movement, and a perception of one's life, and the universe generally, as the manifestation of the divine. It was a perception both immediately direct and all embracing. The question was, once this golden potentiality was glimpsed, how to reliably get to it. What was the 'raft' to the 'other shore', what was the bridge to Nirvana? Otherwise it was merely smoke in a bottle. 
Huxley wrote a pedagogical-utopian novel, Island (1962), in which he attempted to sketch how the newer techniques of awareness would work in the education of an enlightened society, and incidentally (with his protagonist), redress some of the psychic splits wrought by Western civilization - or civilized barbarism, as Huxley would have it. The 'psychic' $\mathrm{ABC}$ 's of dealing with common emotional states, and feeling generally, would be the foundation of the curriculum and would undergird reading, writing, ciphering and other useful skills. Huxley's message was that unless we are fully conversant with our own nature we will always be prey to the seductions of Power and Technology and Consumer Goods so prevalent in modern society. Island ends with the ominous fascination of a young heir-apparent with a shiny new motorcycle. Who would drive who?

Huxley's writings in his Tomorrow and Tomorrow and Tomorrow essays, his earlier Brave New World, and later Brave New World Revisited, were prophetic in describing how totalitarian societies (whatever the ideology by which they refer to themselves) can coopt and manipulate by means of pleasure. He saw the coming onslaught of the commercial-advertising-complex with its relentless use of images to condition human behavior (through 'hidden persuaders' and 'subliminal seduction'). Conditioning via a host of media techniques was about to shift into high gear, so it became more imperative to emerge from the 'cave' of culture in order to have even a rudimentary human experience, let alone a 'transcendent' experience. Huxley became an elder in the 'consciousness revolution' of the 60s-70s. Like Plato, Huxley said that human education first meant disabusing oneself of the wrap-around environment of manipulated and charged images. 
Huxley was exploring the same depth landscape of consciousness that others like Carl Jung (1875-1961) were also probing. There was the tremendous excitement that attends new discovery. Jung's charting of 'archetypical patterns of the Unconscious' seemed to harmonize with the researches of comparative mythologists and scholars like Joseph Campbell and Mircea Eliade. Anthropology and psychology were beginning to come up with strikingly similar patterns. Instead of Freudian infantile regression, motifs like the 'hero's journey' were beginning to emerge. Jung found in the dreams of his patients 'mandalas', or concentric-world-diagrams, that ethnographers like Evans-Wentz found in the iconography of Tibetan yogas.

In the early 1960's the psychotropic experiments of Timothy Leary, Richard Alpert and Ralph Metzner at Harvard discovered that the journey-of-consciousness patterns spawned by the use of LSD uncannily resembled the meditations on and the descriptions of the dying process in the Tibetan Book of the Dead. Like all true discoveries there was the sense of coming upon something, a structure, that was already 'there', independent of the investigators, waiting to be found. 
The psychic realms and energies found led Alpert to go to India and to assume the new identity of Ram Dass and write one of the guiding manuals of the new generation called Remember, Be Here Now. Metzner wrote Maps of Consciousness to show how different idioms - from the tarot to astrology to the I Ching to Hatha Yoga - were all paths aimed at the re-unification of consciousness. In his introduction he likened the psychic situation of modern man to someone sitting in a room with twenty plus television sets tuned to different channels and all going on simultaneously. How to get out of the madhouse!? Other investigators like Marshall McLuhan in Understanding Media: Extensions of Man and Alvin Toffler in Future Shock confirmed the progressively fragmented, overheated and overstimulated state of western culture. The problem was how to achieve personal sanity and unity, given the great influx of information and demands that were occurring. To those who remained in the cocoon of consciousness, there was no problem: pleasure and misery simply alternate in a perpetually self-enclosed circuit; no genuine outside contact. But, like it or not, a global awareness was beginning to dawn. Buckminster Fuller tried to go beyond the usual egoistic and nation-state thinking in his Operating Manual for Spaceship Earth. 
A new image of man in the cosmos was forming, one that saw human life in the truest sense, not as a given (hereditarily or environmentally), nor as identifiable with some external achievement, but as latent in the transformations of consciousness. Every transformation required the overcoming of a great personal obstacle or resistance. Peace in the New Compendium was not cheap. Dragons emerged that were undreamed of by medieval cartographers. At the end of the Second World War, Elizabeth Kubler-Ross compassionately and clearly looked at the dying process and saw a strange phenomenon. What was everywhere obvious in terms of factuality - the inevitability of death - was frequently 'denied' on a personal level. How was that possible? What was the structure of the psyche that permitted non-recognition or non-acknowledgment? That in itself was instructive. But Kubler-Ross saw that a human death, one that was peaceful and liberating, involved coming to terms with powerful and often subtle resistances. At the other end of the scale, the process of being born, studied and ministered to by the French doctor Frederic LeBoyer (Birth Without Violence), showed that, from the very beginning consciousness was developing and could be brought forth in a benign and dignified way . Both being born and dying could be humanly facilitated to bring out the maximum potential of consciousness possible.

An increasing number of teachers in the $1940 \mathrm{~s}, 50 \mathrm{~s}$ and $60 \mathrm{~s}$ went beyond their generic disciplines and 'filled in' the points on the 'line' from birth to death. Every major transition of human life was seen to be an opportunity for the transformation of consciousness. Any point on the continuum of human experience could be the occasion of enlightenment. Any situation or transition on the 'circumference' of human experience could be the site of 'human work' or education-in-humanity. 
A nameless core discipline was forming. Its subject was learning itself or learning how to learn in a way (pace B.F.Skinner!) that intrinsically expressed freedom and dignity. It wasn't pedagogy, it wasn't psychology, it wasn't religion, it wasn't therapy, it wasn't the usual form of calisthenics and training, or the customary forms of sociation and/or political action... It was all those things but something more fundamental still. Alexander tried to phrase it, and Dewey too, as the integral functioning of the organism, as the organism in tune with itself through the flow of accurate sensation. It wasn't as though a mistake-free environment was sought. On the contrary, an organism operating from a solid sense of harmony was not an organism afraid to make mis-takes. Not being fearful, and consequently not always straining 'to do the right thing', it would easily be able to selfcorrect and freely re-adjust to changing circumstances - said teacher John Holt, one of those carrying the new banner. A deeper 'standard of rightness' was sought.

There was a growing convergence of a number of idioms, practices, techniques, yogas and experimental approaches, all of which sought to encourage and nourish this integral functioning of the organism - the condition of harmony being seen as the precondition of true learning, optimal functioning and genuine effectiveness. Some of these novel 'disciplines' - or 'anti-disciplines', since they weren't predicated on mindlessly following a rule or regimen, were the 'autogenic training' of Schultz and Luthe, the 'gestalt therapy' of Fritz Perls, the 'sensory awareness' of Charlotte Selver, the many varieties of 'bio-feedback', and the 'body-work' of Ida Rolf and 'structural integration' of Moshe Feldenkris. 
These and kindred approaches emphasized the somatic exploration: the discomfiture, tensions and resistances in body (sensations, postures and alignment) that provided clues to the overall functioning of the organism, to the person's totality. Dualistic distinctions between 'soul' and 'body', or 'mind' and 'body', or 'mind' and 'emotion',etc. were completely artificial. What was happening, and exactly where, were the first questions of this inclusive inquiry/path. (Re-)Learning how to sense was the novel common curriculum of this school of the new humanities.

From Korzybski and Krishnamurti to the exponents of rolfing and t'ai chi, all agreed that the 'man in the street' was an inveterate and unselfknowing conceptualizer making a cornucopia of dubious judgments while standing on tip-toes. To regain his mind, he needed to rediscover his body - or more accurately - his/her/our concreteness. Likewise, with the esteemed experts of Western civilization - doctors, lawyers, engineers, military, politicians, academicians. From church to boot camp to art studio, Western culture had cultivated fragmented images of the human. Internal dividedness and external divisiveness was the near-universal result. The cry of the new age was 're-memberment', wholeness.

Charlotte Selver's work in cultivating sensory awareness was based on the earlier work of Elsa Gindler (d.1961).[225] Gindler, like Matthias Alexander, was afflicted in her youth with a - in her case, life threatening - condition, which she also responded to with a resolve to be healed. In order to survive her serious tubercular condition she developed a precise and sensitive awareness of her lungs and breathing. Through her meticulous observation she discovered how exquisitely interdependent all the sensory 'mechanisms' were: every disturbance could be sensed in its rippling effect. By the same token, ways of dissolving and consciously dealing with these disturbances also became apparent to her. Instead of a death warrant she found a new lease.

"But from then on she felt unable to continue teaching calisthenics. She was fired with the recognition that to learn 
to sense one's own functioning, and beyond that. to sense and allow changes in the attitudes accompanying it, was not only possible, but could in fact become an approach to living entirely different from learning methods and practices handed down by others. What had at first been an intuitive therapeutic attempt became a Weltanschauung far beyond any bounds of therapy."[226]

She called her work 'Arbeit Am Menschen', work on the human being, or 'Nachenfaltung', unfolding afterward.[227] This 'human work' could be seen as the germ of the new humanities or, as Huxley would say: 'the non-verbal humanities'. Not so much concerned with established domains of information - although of course not negating that - the new humanities would focus on learning how to learn, how to sense in the present. Particularly important is how to recognize blockages and resistances to a natural flow or natural unfolding before they become irrevocably conceptualized or made into judgments. ('I can't do it!' , 'T'm a bad person!', 'What I'm feeling I can't be feeling!', 'This is not happening!').

For all the new 'world-teachers' and teachers of 'human work', from Alexander to Gindler to Krishnamurti to Huxley, the functioning of pre-conceptual human experience was an invaluable guide. The domain of immediate reactions and responses was becoming legitimate and important. A realm hitherto deemed insignificant (philosophically inconsequential or as fodder for 'character building') was now seen as a richly abundant source of inquiry and data. Pre-interpreted human experience was seen as a gold mine! Terra incognita was under our very noses, wisdom latent in our very tissues. The new humanities would not deal with the culture of Greece and Rome but with, in Bergson's phrase, 'the immediate givens of consciousness'.

How to navigate in this new world? 
The root meaning of the word 'discipline', in the new pedagogy, is to learn. learning in the present tense. For Krishnamurti, uncoerced attention is the very essence of discipline. Control, he suggested, in its usual construal is the antithesis of order. It is really as much a form of indiscipline as chaos is. The way of actively and engagedly observing and studying first-hand goes beyond force and suppression, on the one hand. and indulgence and license, on the other.[228] A key feature of this path of first-hand acquaintance, it turns out, is unlearning, the art of opening to the actual without the weighty baggage of preconceptions.[229] The path to the silent, receptive mind is the path to the heart of learning.

'Freedom from the known', in this canon, becomes the gate to continual learning and constant discovery. A particular and important species of 'not-thinking' allows one 'to come to one's senses'. No prejudgment is made about what is being sensed. Freedom from routinized and habitual patterns of thinking allows the possibility of new frequencies and modalities of experience to arise. Studies of creative thinking - by Henri Poincare, Wolfgang Kohler, Arthur Koestler and Bernard Lonergan, among many others - were beginning to suggest that a certain kind of cessation of ordinary thinking and its filters allowed the space for deeper intuition to work.

Charles Brooks, Charlotte Selver's husband, had studied in Switzerland with Heinrich Jacoby, who was Gendler's associate for thirty years. He gives some history:

"Charlotte...was one of a few students who brought the Gindler work to the United States before World War II. Since 1938, Charlotte has been actively developing her approach to Gindler's work in this country. During the early years among new people with a new language, she finally settled on the now well-known expression 'sensory awareness' to single out the awareness of direct perception, as distinquished from the intellectual or conventional awareness - the verbalized knowledge - that is still the almost exclusive aim of education, both in the family and in school. 
"Charlotte's work caught on very slowly. Her first advisors were agreed that Americans would never have the patience for it. But in the forties a number of New York psychoanalysts, most notably Erich Fromm, Clara Thompson, and Frederick Perls, became interested and began to study with her. Perls later incorporated much of what he had discovered in his study of sensing into his Gestalt therapy. Then, in 1956, Charlotte Selver met the philosopher and Orientalist Alan Watts, who exclaimed as he worked with her, 'But this is the living Zen!' Thereafter, the two collaborated in a long series of joint seminars, first in New York and then in California.

"In 1963, introduced by Alan Watts, she gave the first experiential workshop at the newly founded Esalen Institute."[230]

The 1960s saw the explosion of psychologies dealing with the new data of immediate consciousness, the so-called 'human potential movement'. The shock wave consisted of many varieties: humanistic (e.g. Carl Rogers), existential and phenomenological (e.g. Rollo May), radical (e.g. R.D.Laing) and psychedelic (e.g. Masters and Houston). 'Fritz' Perls and Alan Watts became the enfants terribles in the radical discoveries of present centered awareness. All these proponents of the new consciousness took the on-looker- spectator-analyzer role or function of Western man's acculturated consciousness as a kind of pathology. The split that had come to seem so natural and productive, the split John Dewey railed against his entire philosophical life between the mental, intellectual, spiritual, on the one hand, and the bodily, emotional and material, on the other - was seen to be responsible for a myriad of problems, both personal and political. The ghost of Descartes' legacy was in the process of being exorcised. 
Perls in his (and Hefferline and Goodman's) classic Gestalt Therapy gave the psychological version of Hegel's 'lordship and bondage' dialectic that Marx so skillfully used in the social-political-economic realm. That which is denied by the psyche (in its 'domestic economy') nonetheless operates in a vital way: it is ourselves in an 'alienated', that is, unrecognized form. History, or in this case, neurosis - individual or collective, is the 'return of the repressed'. The statement, '(The) shut off parts have immense vitality, which needs to be reclaimed...'[231] had enormous political implications that the generation of the $60 \mathrm{~s}-70 \mathrm{~s}$ was quick to see. The line between what was considered personal and what was considered social-political was evaporating. Feelings were no longer seen as merely 'subjective', but as accurate gauges to what was going on in the larger society. But first the seismic registers had to be attended to.

"To the extent that your feeling of actuality has been split off from your workaday personality, the effort to experience actuality will rouse anxiety (masked, perhaps, as fatigue, boredom, impatience, annoyance) - and what specifically rouses your anxiety will be the particular resistance by which you throttle and prevent full experience."[232]

Living for the present, according to Perls, is fatuous; but living in the present enables one to remember the past, anticipate the future and to respond as the occasion demands. [233] The tragedy of life, according to Perls, is that we spend so much of our time in our dodges or escape from the present. In failing to be fully present, we fail to be ourselves. Hence the supreme importance in Perls' lexicon of the 'feeling of actuality'. Ephemerality is the experience of time without attention, the experience of passingness without presence. Ennui and hostility are two poles that express that lack of synchrony. Busy-ness can also express a fleeing from the present. Paul Goodman, Perls' associate and radical reformer, wrote passionately and voluminously on the ways bureaucratic and industrial America distorted and denied feeling and feelings that were incompatible with its aims.[234] 
Perls had a therapeutic and theatric gift for detecting and exaggerating the myriad of postures - self-deprecating, cynical, ingratiating, aggressive, withdrawn, detached, etc. by which his patients refused to encounter the things they were feeling. He would roast sacred psychanalytic cows by feigning extreme boredom when a patient was going on and on in some highly verbal but nonetheless escapist mode. If the patient wasn't truly interested in what he or she was saying, why should he be interested! Excitement, life, the 'feeling of actuality' and attention were the cues to reality. The challenge was to catch the self on the wing, in action, in a gesture or posture in such a way as to reveal the whole structure of the psyche. The whole is physiognomically in the part. Tragedy in existential terms was, as Sartre put it, 'bad faith', the pretense that one has exhausted the totality of one's being in some role or convention or conception. The whole here is not in the part. Finally, with conscious affirmation (Tillich's 'courage to be'), the part can be a way of authentically being the whole. Three ways of saying, 'I'm a waiter!' or 'T'm Miss America!' or 'I'm a philosopher!' or 'T'm a teacher!'...etc.

For Perls as well as Selver, the mode of this kind of investigation needed to be integral. Conventional analysis (both psychoanalytic and scientific) was a mode of distancing the self from the self. Selver proceded via sensory explorations of common activities like walking, sitting, standing, touching and holding. Perls asked his participants to sensorially experiment, not think about, or opine, or speculate on, or interpret, or verbalize. Some of Perls' experiments were called 'feeling the actual', 'sensing opposed forces', 'attending and concentrating', 'differentiating and unifying', 'sharpening the bodysense', 'experiencing the continuity of emotion', 'integrating awareness' and 'converting confluence into contact'.

It all amounted to paying close attention to the flow of experience without the customary judgments and usual divisions. Again, this was personal and political capital, unprocessed wealth. Consciousness was exploding, or, as McLuhan had it, 'imploding'. It was seeing what was there, as if for the first time. 
The trick was to be agile and gentle enough to follow the - most often - nonsequential flow. You had to there fully to perceive fully - especially rapid or subtle or delicate mind-body states. For Krishnamurti, Perls and Selver, Alexander, etc. the dynamics of attention was very different from the strain associated with concentration, the strain of 'trying to do something'. As Alan Watts never tired of saying, this kind of attention was very much like the 'wu-wei' or the Taoist 'not-doing'. It involved letting go of attempts to understand or capture or manipulate phenomena and simply observing, gently being-with what was happening. To 'sense', first of all, was to be sensitive, to assume a generalized state of receptivity that went beyond the sensorial apprehension of any one thing or in any particular modality. This generalized state of receptivity could be called a 'centered state', a state of tranquil alertness, or, in Krishnamurti's phrase, 'choiceless awareness'. In this dynamic field of awareness, there was no cut-and-dried distinction as to what was 'subjective' and what was 'objective'. In fact, in this canon, the formula was rather 'the more personal, therefore, the more universal'!

\section{Marxist Revolutionary Thought and German Critical Sociology}

Another major root of the Counter-culture/New Age complex of the 60s-70s was Marxist revolutionary thought and practice and German critical social theory. ( The latter, particularly the so-called Frankfurt School, along with Weber and Nietzsche, Alan Bloom in the 1980s was to fault with the corruption of American students and the subsequent degradation of American academe.) The latter constituted an epistemological critique, calling for the recognition and legitimacy of a plenitude of new ways of knowing, while the Marxian tradition constituted a thoroughgoing critique of society as a historical phenomenon. 
The doctrinaire Marxist program continued the Renaissance utopian direction. along with the Hegelian emphasis on the historicity of consciousness. There was no consciousness 'antecedent' to society. The inner tensions of a society created consciousness. Marxist revolutionary theory considered itself real 'science' as opposed to circuitous 'justifications' for elites in bourgeois-industrial society. An example of ersatz reasoning was the kind of ideological justification of industrial barons that came out of 'social darwinism', survival of the fittest. The industrial caste system needed everybody in their (working) place, and cogent rationales for needed and lauded behavior. The industrially organized state is, according to Adorno, the embodiment of 'instrumental rationality', and, in the conventional Marxist account, contains the seeds of its own eventual destruction. Contradictions would intensify until a genuine transformation effected justice, literally a 'post-historic' society of genuine harmony.

Frankfurt School philosophers like Theodor Adorno and Herbert Marcuse, emphasized the diminishment of consciousness, the creation of 'one-dimensional man', in the industrial state. Not only work but leisure was carefully orchestrated in such a state, the veneer of 'freedom' and 'options' notwithstanding. In the properly groomed psychic economy of such a state nobody would notice that they weren't free because they would be awash with ersatz affluence and 'possibilities'. Pleasure, narcotics and careful channeling of perception via accommodating media would keep everybody happily amnesiac and in line. All of this didn't take any conscious conspiracy; it was just how 'the System' worked in its self-perpetuation and extension. Weber's sociology attempted to portray the tragic results of the complete 'rationalization of society'.

"But for Adorno this identity rationality always seeks to deny, repress, and violate otherness, difference and singularity. This form of reason - when unmasked - is intrinsically domination; the domination and control over nature inexorably turns into the domination of men over men (and indeed men over women) and culminates in sadomasochistic self-repression and self-mutilation."[235] 
"(H)appiness for Adomo [and for the Marcuse of Eros and Civilization] is not a pale public 'eudaimonia' or private well-being, but an aestheticized, unrepressed sensuous gratification and ease. Adorno...holds up...the vision of a non-antagonistic, non-hierarchical, non-violent, and nonrepressive society."[236]

In the face of a society that is hierarchical, that sets brother against brother, sister against sister, and self against self, revolution and resistance is an appropriate response. So is a responsible and prophetic imagination. Adorno's utopian manifesto could well be emblazoned above all the struggles of the $60 \mathrm{~s}-70 \mathrm{~s}$ :

"The only philosophy which can be responsibly practiced in the face of despair is the attempt to contemplate all things as they would present themselves from the standpoint of redemption. Knowledge has no light but that shed on the world by redemption: all else is reconstruction, mere technique. Perspectives must be fashioned that displace and estrange the world, reveal it to be, with its rifts and crevices, as indigent and distorted as it will appear one day in the messianic light."[237]

The 'messianic light', 'redemption', parousia - the story of the $60 \mathrm{~s}-70 \mathrm{~s} . .$. 
The 60s-70s exposed a thousand fissures - poverty, war (technocrats calculated and 'weighed' the 'risks' of nuclear war as if the standoff expressed sanity rather than institutionalized madness!), racism, class and gender discrimination, mammon-based values (corporate greed and aggrandizement being preeminently respectable) and environmental degradation - in the rigid tectonics of corporate America and Europe. Leftists like Gintis and Bowles ( Schooling in Capitalist America), Ivan Illich (Deschooling Society) and Paulo Freire (The Pedagogy of the Oppressed) and a host of outraged dissidents, saw education as an institution in capitalist society as the betrayal of its potential for human liberation. The 'tracking' of people - where there wasn't wholesale neglect - and the grooming of skills to fit into a society that systematically truncated its members was a travesty. The 'privileged' in this society were also, from a psychic point of view, suffering, shrunken homunculi. Only a reordering of society 'from the standpoint of redemption' would do.

Reformation on the basis of 'industrial logic' would not work. It would only replicate its constitutive divisions and wounds. Only a global consciousness would heal that which revolutionaries revealed. Mao's little red book and an avalanche of utopian proposals, projects and communities all preached the importance of good - whole-hearted, full participation - practice. 'Practice' here meant, not the routine application of theory, but the intimate and continual confrontation of one's actions with one's guiding notions. Practice here also meant, not the mechanical drill of the foreordained and the achievement of the pre-assigned, but rather the personal struggle for liberation, which was, at the same time, the revolutionary struggle for social equity and equality. None would be free until all were free. 
Guru and buddha in spite of himself, Krishnamurti concurred that the mere projection of ideals, no matter how exalted still fell back into the old 'reformist' logic. The projection of ideals was mankind's favorite avoidance of looking at 'what is' and in fact maintains the inequities of society. Everybody agrees on what is virtuous in the abstract and then does the opposite. To say, 'I am bad' expresses a judgment and fixes an identity and doesn't look at the phenomena. To say 'I'm trying to be good' doesn't look at what the disturbance is trying to say. For Krishnamurti, it is the maintenance of notions like God, heaven, the soul, morality and immortality, like blinders, that enables us not to see what is around us. To look directly at brutality (often subtle and socially legitimized), injustice and misery brings about its own transformation. Simply to be aware, without making the divisions of 'inner' and 'outer', and without automatically projecting the opposite, is a truly revolutionary act.

To see clearly, without fear or compulsion, was the state of freedom. The end of the journey was in the beginning. For Krishnamurti there is the Spinozistic assumption that genuine perception leads to real action, integral action, action without a sense of separation. Consciousness of 'what is' is the true initiation into the revolution, a complete turn of 360 degrees, a complete change of heart - 'metanoia' in the Christian vocabulary. True perception=true action=solidarity=love. Personal transformation is ipso facto the transformation of the social/political (dis-)order

In this counter-(the status quo, hierarchical)culture, as Theodore Roszak noted in his dispatches from the front (The Making of a Counter Culture: Reflections on the Technocratic Society and its Youthful Opposition), Marx and Freud were wed. They were married by Marcuse and (a politically reborn classics professor!) Norman $\mathrm{O}$. Brown in their emphasis on the primacy of consciousness in social change.[238]

"From this viewpoint it becomes abundantly clear that the revolution which will free us from alienation [self-self, selfothers, self-and its products] must be primarily therapeutic in character and not merely institutional."[239] 
Revolutionary psychologist Franz Fanon, in his Black Skin, White Masks, showed how racial oppression was maintained by the introjection or internalization of the white oppressor's scheme of values, the repressed psyche dis-esteeming itself in favor of the dominant value-structure. Complexion tone assigned one to limbo. In mid-twentieth century America there were many limbos and ghettoes unacknowledged by the post-war boom and ladder of success. De-sublimation meant political/social empowerment. (Of course, more orthodox Marxists thought that only by changing institutions could there be a correlative change in consciousness.)

Roszak sums up Marcuse, 'So we have a kind of psycho-social inertia in operation which keeps us living in a discipline appropriate to scarcity even while abundance is available'.[240] American capitalism and Soviet communism were not fundamentally different in this regard. "But Marcuse, surveying the practice of both Western and Soviet technocracies, concludes somberly that 'the two antagonistic social systems...join in the general trend of technical progress'. In both cases, we have 'the total mobilization of the individuals for the requirements of competitive total industrialization'."[241] 
Canadian (English professor!) Marshall McLuhan tried to see beyond industrialization by extending Teilhard de Chardin's vision of the evolution of consciousness by seeing technology not as hardware per se but as the creation of a global human nervous system. Electronic logic was organic in its implications - cooperating networks, for instance - whereas industrial machine logic required centralization, specialization, aggressive expansion and the fragmentation of consciousness. McLuhan was Marxian in that he saw any technological innovation as configuring consciousness, be it the spur, the printing press with moveable type, the cartoon, the airplane or the computer. McLuhan was William Jamesian in that he believed that the act of extending consciousness over anything yielded a sense of ownness or possession. Electronic technologies were knitting man and his world together into a veritable 'global village' in the same way industrial technologies had rent the world into competing nation-states. The instantaneity of communication would create a new 'sensus communis'. Pedagogically, the carving up of the world into separate domains or disciplines - whether ontologically or in terms of convenience - was similarly outmoded and misleading. Our minds and sensibilities needed to catch up to the integrations our instruments were demonstrating possible. The lag could be deadly. The difference between mind and body was not so much a difference in kind as the differential of lag. Humanity needed to be an 'integrated circuit'!

Meanwhile, Heidegger and Jung were reading zen, literally and figuratively. In the 1960 's the dramatic mind-body integrations of Zen Buddhism provided a new paradigm of consciousness. The breathtaking and powerful examples of 'no-mind' in action in archery, swordsmanship, karate, and especially in intellectual combat, stopped Western culture in its tracks. The West was fascinated. It was ready to receive something new. The analytic intellect and all its schisms seemed to have finally met its match in the unassuming personalities of two Japanese. One was a scholar and translator, the other a 'roshi' or teacher. Both were embodiments of the new "way". 


\section{5. 'The Eastern Turn'}

The fitth and final root of the new consciousness we shall consider is what we shall call 'the Eastern Turn'. For an old classicist like Gilbert Murray (in his Five Stages of Greek Religion, written in the 30s) the 'turning inward' and the embracing of 'eastern religion' was nothing new. It signalized the decline of a culture no longer able to deal adequately with external challenges. It was a phenomenon that bespoke a 'failure of nerve', a withdrawing from reality. For many in the 1960s, however, the breezes of zen were a breath of fresh air to a culture smothering in its own gases and fumes. The suggestion that there was something beyond the reach of the mind was met with unparalleled interest and excitement. As with the precocious and psychodelic children in Arthur C. Clarke's Childhood's End, there was an extraordinary vista being presented that the old culture of domination and abstraction and ersatz glamor could not grasp. 
First, a couple of prefaces. First, LSD and the reason for the appeal of Zen. The gigantic influx of new data. The need for a simplicity to counter and absorb the wave of multiplicity being experienced. Many, like Richard Alpert/Ram Dass, in being deluged with the megaton explosion of 'psychic' (or 'astral' or 'dimensional' or akashic' or 'paranormal' or 'alternate realities') information gravitated toward the two thousand year old seedbed and immense spiritual culture of India, a congenial haven that seemed to have explored many of these realms before. While reincarnation, for instance, was whispered in Western circles and off-the-record, it was assumed almost commonly as a fact of life in Indian culture. The West had its Swendenborgs and Edgar Cayces, but these were considered eccentrics or showmen or aberrations. India boasted of Patanjali, who set down the first treatise-manual of yoga, Siddartha Gautama, who became the Awakened One or the 'Buddha', Shankara, the extraordinary yogi and metaphysician, and the modern world-saint-sages Ramakrishna and Ramana Maharshi. Aurobindo and Krishnamurti were also Indian. Western spiritual emigres sought out such guides to their startlingly new access to and pan-fusion of information. What was happening and why?

LSD and kindred psychotropics did three things. First, it gave access to realms of information hitherto only frequented by 'psychics' (again for lack of a better term). This was a tuning into special frequencies, or information bands like clairvoyance and precognition.

Second, in intensifying normal life/death/rebirth cycles in the nature of experiencing itself, it gave a distinct sense of the sacred, glimpses ('kensho' in Japanese) of what could only be called 'spiritual reality'. Suddenly, much of the Western mystical experience and tradition became quite vital, understandable and relevant. The direct experiences that underlied developed religions became comprehensible. Indeed, many who took psychotropics took them in a sacramental manner, i.e. with a reverential readiness to receive new and portentious information. They weren't disappointed. 
Third, in a way the experience of LSD simulated the 'average state' of the 'average' denizen of the third quarter of the twentieth century! Saturation with information. Speed and pace of living. Complexity of social-political situations. Alvin Toffler's description of 'future shock', the psychological trauma caused by accelerating waves of change. demands and information, resonated with the condition of many.

Was the Western psyche and education up to coping with the pace and scope of the changes that were taking place? Eons ago nomadic culture had given way to farming culture, which, in turn, had given way to industrial and city-based culture, which was giving way to......what? Speed, complexity and disorientation were taking place. Major shifts and realignments of consciousness. Rather than flow within environments, environments themselves began to flow.

There was a collective felt need for slowing down, clearing and deeply reorienting. The renewed sense of the sacred seemed blatantly violated and drowned out by the society at large. There was a need for a 'still, silent pool' in the midst of all the noise and flux of events. Also, a highly intellectualized culture, one that placed such a premium on all the forms of analytic intelligence (from art to religion to science to philosophy), needed 'grounding'. So called 'out-of-the-body' experience was the norm for Western man! The motifs of deep listening and clearing a 'space for Being' in the later writings of Heidegger accorded with what was being felt as a deep need as the culture of the West rapidly changed.[242] There were different psychic and spiritual requirements needed in the axial shift of Western culture. 
The Vietnam War was part of the crucible of the 60s-70s experience. The war focused and provided a rallying cry for the many movements of social protest swirling in the West, particularly in America. The anti-war movement coalesced with the civil rights movement, the feminist movement, and shock at the recognition of the extent of poverty and disenfranchisement in America. Shock at the degradation of the environment was to be a later theme, although the antennae of the new sensibility (e.g. Rachel Carson) was picking up many manifestations of the same systemic disease. Americans were fighting at the ramparts of their empire in Vietnam - ostensibly containing the Soviet empire - but increasingly the youth in Western societies (and, to some extent, in Eastern Europe as well) were beginning to feel as if they were in the belly of a large beast being positioned to be crushed by opposing jaws. Indeed, the economic depression of the 1930s in America ended only by the United States becoming a world leader, if not the world leader, in armaments. Post-war prosperity was predicated on the arms-military industries. It wasn't hard to take Dr. Strangelove's advice and love the bomb if you worked at Electric Boat. But poets and bohemians were beginning to question the wisdom of such massive investments in death machines. Somehow living under the nuclear umbrella didn't seem to make anyone feel safer. And Pogo was right: less and less did it seem like 'the other' was the enemy.

There was much confrontation, civil disobedience and violence. But some of the best and most characteristic 'weapons' of protest were non-violence, humor, music and collective celebrations. 'Be-in's' were apprenticeships in enjoyment. One cardinal principle of the new consciousnss emerging was that means should accord with ends. 
To use warlike means to achieve peaceful ends was an clear contradiction in the new canon. As a prominent slogan of the times had it, There is no way to peace; peace is the way'. The method or 'means-whereby' couldn't contradict the result. Action should be integral and process, how things were done, was of the essence. Various versions of the "way" differed from method in this respect: 'Method' connoted a series or sequence of steps projected or laid out in advance to achieve a certain end. It tended to forget Korzyski's famous admonitory axiom, 'the map is not the territory!' The word 'method' comes from the Greek 'meta'=after, and 'hodos', meaning road, path or way. Method worked primarily after a goal has been found and the route to it has been codified. Method is therefore a map, an algorithm, or a set of rules, that can be explicitly followed to achieve a particular result. Not so with the "way" or the 'tao' or being-the-path. In the new canon, schematizations of the path all said the true way to achieve a particular goal or end was to be it. 'The way to do is to be', as the Tao Te Ching had it. Not unconscious identification, but conscious being.

The path, in the new heuristics/politics, was transformation, being transformed. Even with the refinement of 'feedback loops', method in the Baconian or scientific organon was essentially a sequence of external steps. The third organon existential logic suggested that the only way to 'find' love was to love, the only way to 'find' peace was to 'be' peace. To reach the other shore with each step of the crossing is the way of true living'.[243] Each step - even and especially mis-steps - in the new compass, was part of the way, part of the journey of action and/or understanding. Each step, taken fully, transformed the whole. Integral action was inherently successful - even if you failed, you would have succeeded because of the nature and quality of your whole-hearted attention and effort. There was nothing 'automatic' or mechanical or absent-minded about this conception of action. Genuine movement was transformative. The difference between a trip and a journey is that, at the end of a journey, you are not the 'same' person.[244] 'Methodology' as opposed to 'hodology' was quite distinct in aims, procedure and practice. 
In line with this new ethos, much of the political resistance in the $60 \mathrm{~s}-70 \mathrm{~s}$ was intentionally celebratory. The best way to find utopia was to be it. If the System, by its very nature, was grim, end-focused and unyielding, the best way to fight it was not to attempt to kill it with the sword - because it thrived on the sword. It 'understood' that language. Determined but non-violent resistance was one way. Not to take it seriously, to laugh at it, to treat it as irrelevant, to be irreverent, to poke fun at, to have fun, to gather together in celebratory ways were other ways. Make music, make love, make meals, make things with your hands and heart. It was the dominant 'vibration' in and by which a context was defined. Right and joyous action rippled across the cosmos in the new cosmology. 'By having a cup of green tea, I helped stop the war'. There was an aesthetic of comprehensive enjoyment that recalled Dewey's notion in Art as Experience that any complete experience was aesthetic in nature. Nothing so threatened the Beast' as happy people. Insouciance was a political act.

Freedomful pleasure was the antithesis of the industrial state. Even in 'peacetime'(sic), pleasure needed to be carefully coupled with narcosis in the solicitous industrial leviathan. Most kinds of pleasure were compatible with the leviathan. Museum art (as well as most programmed entertainment, such as movies and televised spectator sports), in the new aesthetic, was inherently elitist (or contemptuously plebean!) and fit perfectly in with the 'conspicuous consumption'/hierarchical patterns as long as nobody jostled the boat by live experience. 'High art' and 'low entertainment' were categories of oppression at either end of a corrupted scale. Truly satisfying experience, live interaction, genuine encounter, everyday activities and joyful exploration eluded such categories. 
Perhaps the most significant shaper of the new consciousness was the introduction of Buddhism to the West. This, we suggest, ranks with the Greek Platonic-Aristotelian synthesis in the ancient world and Galilean-Newtonian mathematics in the Renaissance as representing a paramount achievement of culture and a transition to a new way of thinking-acting-being, a new 'organon'. One of the significant things about an organon, a new codification of thinking, is - similar to the way Thomas Kuhn describes 'paradigm' that it, in giving a new image of the layout of reality, specifies the direction of research. The nature of the tool suggests what you can do with it. The nature of Buddhism suggested that consciousness per se could be worked with, systematically, and could be transformed. It was a 'technology of the sacred', a way of attaining higher consciousness. The nature of Yoga, the deliberate cultivation of awareness, suggested that the higher states were not just the inexplicable gifts of occasional mystics but accessible to all. Further, it suggested that, for modern man, this form of 'spiritual exercise' represented (psychological) survival! It wasn't a luxury, spiritual or otherwise. It was a necessity, like breathing.

Just as the United States conquered Japan in the Second World War of the industrial titans, so too Japan conquered this country spiritually. (Perhaps because of the irony of the defeated always conquering the victors; perhaps because war is an accelerated form of meeting; perhaps because it filled a void; perhaps all three.) As Houston Smith suggests, the importation of Zen Buddhism from Japan to the United States is a tale of two Suzukis.[245] The first was the prolific and venerable scholar Daisetz Suzuki (18701966), author of the classic Zen and Japanese Culture and The Zen Doctrine of No-Mind. His demeanor and voluminous translations and commentaries intrigued and beguiled Western academicians, students and searchers, especially during the post-war era.[246] 
Westerners understood power and speed. Suzuki's spellbinding ancecdotes about samurai, lightning-quick zen swordmasters and spiritual samurai, like the Japanese genius Hakuin, fascinated Western audiences. Likewise his tales of dramatic illumination, or 'satori', occurring suddenly after years of apparently fruitless but strenuous searching. In his famous bridge-work, Mysticism, Christian and Buddhist, he compared Tennyson and Basho, Eckhart and Saichi, and fondly quoted the maxim, 'man's extremity is God's opportunity'. His recountings of the mysterious and laser-like combat-dialogues, called 'mondos', told Western students that some kind of exchange was going on that went beyond the habitual reach of the intellect. Suzuki had gotten the attention of the West. Each week Western bookstores filled with the puzzling and paradoxical texts of zen treatises and collections of haiku that celebrated perceptions of the fleeting moment and what it revealed. The exotic and the everyday met. Artists were discovering 'happenings' art. Literary zen and taoist paintings were all the rage.

It seemed Western consciousness had been on a procrustean bed. Now everyone was stretching. The Augustine-like figure, the prominent Western monk, Thomas Merton, was on the quest that led him to his Asian Journey and discovery of the Buddhist meditative traditions. International artist Paul Reps published a small and popular collection of zen anecdotes and 'centering exercises' called Zen Flesh, Zen Bones. A sample story:

"Tanzan and Ekido were once traveling together down a muddy road. A heavy rain was still falling.

Coming around a bend, they met a lovely girl in a silk kimono and sash, unable to cross the intersection.

'Come on girl', said Tanzan at once. Lifting her in his arms, he carried her over the mud. Ekido did not speak again until that night when they reached a lodging temple. Then he no longer could restrain himself. 'We monks don't go near females,' he told Tanzan, 'especially not young and lovely ones. It is dangerous. Why did you do that?' T left the girl there,' said Tanzan. 'Are you still carrying her?"'[247]

Or, as one Zen sage put it in a Nietzschean-like aphorism, ' It is easy to keep things at a distance; it is hard to be naturally beyond them.'[248] 
There was something here in these stories that went totally beyond the rat-races and carnivals of the Western world. They were a finger pointing at the moon. an intimation of a new way of life, a new transmission. Another Zen master, when asked about what constituted enlightenment, answered, 'Chopping wood, carrying water - How marvelous!'[249] The appeal of Zen Buddhism was that it simultaneously pointed to a Transcendent One, and yet said that Nirvana was not a realm apart from this world of everyday activities. Zen was both ethereal and earthy. 'What is the Buddha? - Dried shit on a stick!' And then there was the apparent paradox of indulgent hippie 'flower children' seeking out the rigorous discipline of 'zazen', or sitting meditation. Zen was a lodestone aligning the invisible forces.

Alan Watts, that iconoclast, therapist, joker, proselytizer and popularizer of Zen and Taoism, wrote an early pamphlet entitled, 'Beat Zen, Square Zen and Zen'. In it he tried to distinquish between American bohemian zen, strict monastic Japanese zen, and the core freeing insight or realization of the tradition that transcended cultural dress and trappings. In a kindred line of thought, Alfred North Whitehead in his The Aims of Education, describes the phases in the rhythm of learning as stages of 'romanticism', 'precision' and 'generality'. In our sketch Daisetz Suzuki represents the romantic stage in the assimilation of Buddhism into American culture. This was the dramatically tinged zen of the martial arts and abrupt enlightenment or 'satori'. In the United States this stage coincided with a veritable explosion of spiritual adventuring and consciousness-raising techniques, from Arica to est to the Carlos Castenada books to Silva Mind Control to Integral Hatha Yoga to Evolutionary Kundalini Yoga to Transcendental Meditation (TM) to Sufism (the contemplative/mystical branch of Islam) to Tibetan Buddhism, etc., etc.[250] 
But the more serious, nitty-gritty, day-in and day-out, dealing-with-the- inevitabledifficulties stage was left to the unassuming Shunryu Suzuki-Roshi, Buddhist priest and founder of the Zen Center of San Francisco. He literally and figuratively embodied the phase of prosaic, steady discipline and dyed-in-the-wool practice. With him everyday practice was everything, and yet it was 'nothing special'. With him American Buddhism took root in earnest.[251] It was time to roll up one's sleeves.

Shunryu Suzuki came to America in1958 on a short visit (at age 53) and stayed the rest of his life. He died in 1971. During World War II, he had been one of the few Zen priests who had opposed the war and the militaristic policies of the Japanese political establishment. His character was impeccable, his personality was gentle, joyous, humble and serene. His meditational practice was sterling and adamantine and quickly drew interested students.[252] He appreciated the openness and venturesomeness of Americans, their 'beginners' minds'. They likewise appreciated the qualities of his doctrine and his presence. If not love at first sight, it was the basis of a true marriage. He is best known for the collection of talks entitled Zen Mind, Beginner's Mind. These talks and guidelines on Buddhist practice were reminiscent of the 'poems' of the Tao $\mathrm{Te}$ Ching: they were clear and concise and yet had an inexhaustible contemplative quality that 'recycled' the reader back in innumerable times, like the nature of good practice itself. SuzukiRoshi's reference point was the bedrock of actual practice. The talks were ancillary and encouragement to that. Excited interest often passes; steady work and unhurried practice continues to build - that was the tone. 
Suzuki-Roshi reversed the order of widely conceived notion that you practiced to 'get' enlightenment. His emphasis was rather, get enlightened so you can practice! Or, more accurately, just practice in a calm, steady way and revelations will come of their own accord. The 'trick' was more getting rid of unnecessary ideas and clearing the mind of expectations rather than garnering some special experience, or set of spiritual credentials. Meditation had to do with developing equanimity in a present that is constantly changing. (In Buddhist metaphysics, impermanence is one of the three universal characteristics of existence.)

Meditation, as Suzuki-Roshi taught it, was the opposite of 'end-gaining'. In fact, in the Buddhist catechism, it was just that desire and insistence on the one, complete and final experience that was both the honorable 'call' to return to our 'true nature' and, at the same time, that which blocks it at every turn. Suzuki harkened back to the Patriarch Dogen, one of the reformers of Japanese Zen (comparable to St. Benedict in the West), who said there was no end to the quality of good practice. There was no end point by which one could say 'I have arrived!' Meditation was truly a way of life and involved beginning to pay attention to all facets of life, not just the 'important' ones. One of Dogen's most profound metaphysical treatises has to do with the bearing of the cook in a monastery kitchen.[253] As with Brother Lawrence, the handling of vegetables could be a way of 'practicing the presence of God', the mundane an avenue to the sacred.

.What was paramount in Suzuki-Roshi's teaching style was not the end-state of 'nirvana' or enlightenment (although he did not slight that), but rather the quality of mind and effort that attended genuine practice. Once our 'way-seeking mind' was aroused, the aspiration or determination to understand our human condition, it all came down to the qualities of 'mindfulness' and 'right effort'. These were the two seemingly lackluster oxen that could help us find our way home out of what Dante called the 'dark wood' of our essential human perplexity. Dante had Virgil, or reason, as a guide. Suzuki-Roshi suggests a more aboriginal form of reason: 
"The important thing in our understanding is to have a smooth, free-thinking way of observation. We have to think and observe things without stagnation. We should accept things as they are without difficulty. Our mind should be soft and open enough to understand things as they are. When our thinking is soft, it is called imperturbable thinking. This kind of thinking is always stable. It is called mindfulness. Thinking which is divided in many ways is not true thinking. Concentration should be present in our thinking. This is mindfulness. Whether you have an object or not, your mind should be stable and your mind should not be divided. This is zazen.

"It is not necessary to make an effort to think in a particular way. Your thinking should not be one-sided. We just think with our whole mind, and see things as they are without any effort. Just to see, and to be ready to see things with our whole mind, is zazen practice. If we are prepared for thinking, there is no need to make an effort to think. This is called mindfulness. Mindfulness is, at the same time, wisdom. By wisdom we do not mean some particular faculty or philosophy. It is the readiness of the mind that is wisdom."[254]

Keeping the mind - or its essence, attention - in a flowing state of malleable awareness, not letting it stick or get bogged down in an object, let alone submerged, was one ingredient of true practice. Hypnosis, being fixated on or captured by an object, was the very opposite of meditative attention. As Krishnamurti would say, meditation is the freedom to look, unconstrained observation, awareness that is not pinned down or irretrievably invested in an outcome. 
The basic work of meditation is getting unhypnotized on all levels. It is the 'deconditioning' process of pausing and examining non-discursively everyday momenta. Just seeing. And the first step, according to the Buddhists, is voluntarily restraining our 'monkey mind'. The magnificent opus of William James' Principles of Psychology could be summed up as his pointing to the importance of the faculty of attention, which ran across all other 'faculties' or psychic constellations. It is the inner dynamo of reasoning, the medium of love, the taskmaster of work, the birthplace of challenges. Learning how to work with it would be the art of all arts.

"The faculty of voluntarily bringing back a wandering
attention over and over again is the very root of judgment,
character and will. No one is compos sui if he have it not.
An education which should improve this faculty would be
the education par excellence."[our emphasis] [255]

Just this work is the work of meditation. The trick, according to Suzuki-Roshi, is not to constrain thought or try to stop the flow of thought or castigate ourselves - the usual way based on resistance or opposition - but to give our thought 'a big pasture', a large non-judgmental space of observation. Only then will we see how 'mind weeds' become the nourishing stuff of learning through the golden medium, the living enzyme, of attention.

" To give your sheep or cow a large, spacious meadow is the way to control him.... The same way works for you yourself as well. If you want to obtain perfect calmness in your zazen, you should not be bothered by the various images you find in your mind. Let them come, and let them go. Then they will be under control. But this policy is not so easy. It sounds easy, but it requires some special effort. How to make this kind of effort is the secret of practice."[256] 
The other essential ingredient of meditative practice, according to Suzuki-Roshi, is 'right effort'.[257] This is not the pain is gain, or the grit-your-teeth-and-bear-it, strainingto- achieve posture of consciousness. It is not looking for some particular exalted event. Rather it is taking a 'centered' posture of neither leaning forward nor slouching backward, a kind of perpendicularity of consciousness, as it were. It is to maintain the body and mind in a balanced alignment, to take an 'asana', a position that is both comfortable and alert, one that simultaneously expressed both repose and readiness. In many places, Suzuki-Roshi says that this kind of centered sitting - or walking - is tantamount to enlightenment itself.[258] For him, simple 'uprightness' meant something quite physical as well as spiritual, something spiritual as well as physical. 'Right posture' vis-a-vis our experience was more important than any particular experience, no matter how celestially tinged, or hellishly wracked. 'These forms are not the means of obtaining the right state of mind. To take this posture is itself the right state of mind. There is no need to obtain some special state of mind'.[259]

The idea of Practice in Suzuki-Roshi has these dimensions: 1. It is based on our 'Original Boundless Mind', our 'Buddha Nature', the actuality of Truth as it manifests itself in particulars. We can realize 'enlightenment' because we are moment to moment literally the expressions of the Truth. We are not inherently self-existent beings. Practice is possible because the Truth exists. The Truth is not outside ourselves in some separate realm. We ourselves are the 'practice' of Being. 2. Practice is the centering discipline of zazen, the practice of mindful awareness. 3. Practice is (a) 'sangha', supportive community, ultimately the community of all beings. The Western antinomy of theory versus practice in the Buddhist path is a practical resolution. That is, all the mischievous dualisms - selfother, mind-body, emotion- spirit, etc. - do exist. Their resolution, however, is not primarily in the realm of theory or understanding, important as that is, but in the practice of integrating our being. 
'Idealistic practice' creates a 'gaining idea' or ideal that constantly furthers the goal from the practitioner. Obviously, having some notion of a goal is desirable and appropriate. Actually the (a) goal in its concrete embodiment in a person is the greatest inducement to practice. But, says Suzuki-Roshi, practice can be vitiated by an overconcentration on the goal. In focusing on goals exclusively, there is the danger of self betrayal on many fronts: the estrangement of self from self - that is, the distance between what one is and what one wishes to be; pridefulness or conceiving oneself as too close to the goal, despair at feeling oneself too far from the goal; neglect of others in the fanatical identification with the goal; ironic contradictions between ends desired and means chosen. The 'meat' of good practice is in the process, in right effort, in the direct encounter with 'what is' which is always and frequently subtly changing.[260] The mind 'transmigrates' worlds in a blinking of an eye. Trouble or true service can come from any quarter, in a moment, no matter the personal or organizational set-up. 'Global' or non-bound awareness is merely common sense. One must be ready to let go of 'attachment' even to a revered teacher.

One of the unique contributions of Third Organon thinkers or teachers - like Alexander, Perls, Krishnamurti and Suzuki-Roshi - is their pointing out the very real pitfalls of the 'end-gaining' dynamic as it is usually conceived. Process, in this parlance, is literally 'full-bodied', being open to taking all factors into account, including the intention and motivation of the self, as well as the complex fluid chemistry of the total situation as it evolves from moment to moment. Attention to process, that includes the projected goals, the emanating source and the constantly reconfiguring environments, is a mainstay principle and discovery of Organon III. In its canon, the establishment of a project, without the essential component of self-knowledge, is asking for the customary disasters that we as a species have gotten used to. 
Methodology always operates in a limited or delimited context: it fixes a goal and then spells out a series of refinable steps to reach it. It is attention to process in a generalized way. Living process is, however, rarely so neat, is always particular, and is vulnerable to incommensurate novelty. It deals with the full contingency of a present of $n-$ dimensions, albeit grounded necessarily in a given context. The practice of mindful awareness, though at least minimally focused, is neither automatic nor conceptual. It is continual arrival and continual non-attainment. Its home is the present. The 'present' can be 'this potato' or it can be coextensive with eternality as a quality pervading things, as endless mystics have taught. It is a logic of practice that stresses embodiment, presence, hereness. Its essence is non-abstractness - 'when eating, just eat; when walking just walk'. Its ultimate is full consciousness/ full concreteness. Right effort is the effort to be present... ever a challenge. What is before me right now?... What shall I do right now?... Who or what am I right now?...

The meditative state is the access to approaching things and situations with full being, learning how to be complete in the incomplete, at rest in the transient, content in the imperfect. Attaining genuine particularity is attaining genuine universality. Indigent particulars, indigent universals. Garbage in, garbage out. Treasure in, treasure out. In Suzuki-Roshi's words, 'Eternity is in mortality. When you become a mortal being through and through you will acquire immortality'. And perhaps, vice versa. Not to negate plans and contingencies and striving, but to approach them with a full mind and integral sensibility. To see how things are happening is the art, both Deweyan and phenomenological, of tuning to the Totality.

Human planning, the having of goals and the projection of ends, teleology, is an achievement of First Organon thinking. The discovery of the importance of methodology is the primary achievement of Second Organon thinking. Impersonal awareness of actual process, and therefore a potentially self-transformative precision, represents the way of the Third Organon. Three plateaus in learning how to become human. 
Inspired by the personal example of Suzuki-Roshi and others, Zen flourished in the United States. The transmission of Buddhism to America was finally accomplished in the 1970 s by a group of young Americans, some of whom had been John F. Kennedy peacecorpsmen in the 1960s in Southeast Asia. Notable among these were Joseph Goldstein and Jack Kornfield, who studied with a variety of Theravada ('teachings of the elders' or the earliest Buddhist tradition) meditation masters in India, Thailand and Laos. The Viet Nam War also eventually brought the healing, influential and Suzuki-like figure of Thich Nhat Hanh to the United States and Western Europe. Driven from their homeland by aggressive Chinese Communists, Tibetan Buddhist masters also came, notably the flamboyant Chogyam Trungpa, who settled in Colorado, and the ecumenical visionary Tarthang Tulku, who settled in California. Trungpa established the first de facto Buddhist college in the United States, the famous Naropa Institute in the 70s. The charismatic Korean Zen Master Seung Sahn ('Soen Sa Nim') set up residence and home base in Rhode Island.[261]

All the Buddhist traditions saw the meditative state as pivotal in the path of selftransformation or liberation. The work of the 'bodhisattva', or enlightened being, was seen to reside in service to humanity. Compassionate action was seen to be the natural expression of wisdom. Buddhism, like early Christianity, became a leaven in all domains of culture from peacework to breadmaking to a reinvigoration of the arts to a reinterpretation of science to dedicated social service. It was the latest reincarnation of the 'perennial philosophy', the perpetual recovery and newness of seeing the sacred as the animating core of life. And, like all versions of the perennial philosophy, it pointed to a realm beyond reincarnation, beyond philosophies, even beyond religions. True Center has no name. 
Arguably the foremost contemporary exponents of mindfulness meditation practice - so-called 'Vipassana' or Insight Meditation - in the United States are Joseph Goldstein and Jack Kornfield. They collaborated in leading retreats in this country and all over the world. They founded, with their associates, flourishing retreat centers on the east and west coasts. Goldstein's talks, assembled from a thirty-day retreat, The Experience of Insight, is a contemporary meditational classic. Kornfield edited and authored Living Buddhist Masters. They jointly wrote Seeking the Heart of Wisdom: The Path of Insight Meditation, containing exercises and commentaries. The heart of this basal Buddhist practice, however, is to be found in the intensive silent quasi-monastic retreats. It is here that the no-nonsense Gurdjieff-like work of self-recollection is carried on with a minimum of liturgical trappings. It is 'American Buddhism'. Secular professionals, Trappist monks, Jewish hasidics, mainline ministers, housewives, college students all pursue this foundational practice, both simple and exacting.

Mindfulness, learning how to slow down and be fully present to one's experience, is inherently non-sectarian. The Buddha's 'Middle Way', learning how to 'tune' the human organism, beyond the extremes of self-punishing asceticism and the false freedoms of selfindulgence, is similarly non-sectarian in nature. As Suzuki-Roshi put it, meditational practice is all about 'putting oneself in the oven at the right temperature'. The aim is good (human!) bread, tasty and nutritious, sustenance for all. With the humdrum practice of mindfulness everything becomes the 'object' of meditation - thoughts, feelings, emotions, intentions, movements, gestures and everyday activities like eating, walking, bathing, going to the bathroom, going to bed, etc. It's all, in Ram Dass' words, 'grist for the mill'. 
The Vipassana tradition can be seen as representing the generative maturity in the assimilation of Buddhism in America. It maintains the aim of Liberation by means of a very humdrum, but nonetheless foundational practice. It maintains the core discipline of mindfulness that goes back to the time of the Buddha and his 'Discourses on the Foundations of Mindfulness'.[262] It is the nourishing mindset of treatments of disciplines or pursuits as 'the yoga of ...', 'the tao of ...', 'the zen of ...' - that is, their treatment as sacramentally significant or spiritually liberating 'ways'. Meditation is no longer exotic in American culture as a thousand 'growth centers' and institutes and retreat centers attest. Like different forms of 'Oriental medicine' (e.g. visualization techniques, acupuncture), it is being accepted as an adjunct by mainline disciplines (e.g. sports and medicine).[263] But like Greek rhetoric/philosophia and the modern scientific method, its pedagogical and cultural career may just be beginning, even while it retains its primary religious relevance.

Mindfulness is a sensitive instrument par excellence. By teaching the art of how to be with oneself, how to be fully present to one's experience, it teaches the essence of learning how to learn. Thus it is not like programming or training or discipline in the traditional sense. It is rather like learning how to un-program our perpetual flow of judgments and pre-judgments - which are as native to us as breathing - and listen to experience with fresh 'ears'. Stopping and realizing, slowing down and becoming aware: this is an art of appreciation, renewal, self-knowledge, harmony with our work or chosen metier, harmony with others, and, potentially, consecration. When we are awake there is the possibility of genuinely free or voluntary action, acting in 'sync' with ourselves, with others and with the deepest imperative(s) of our nature. It is coming home while being on the road, on the journey. An art/discipline/science of integral being. A new common sense. Not the elimination of all difficulties, but the taking of difficulties in a new way. It is the basis for a curriculum of non-dual education, how to be whole while in process exploring untold domains. Its essence is gentle or non-violent perception and action. 
In truth, the new organon goes beyond opposites like gentleness/firmness into a domain that has no name. Zen Master Seung Sahn's pet name for the realm of integral functioning that exists 'before thinking', prior to thinking in terms of particular measures and systems, prior to thinking in dualistic or oppositional categories, is his teaching phrase 'Don't Know Mind'. Just as philosophy must terminate in the mysticism of One Truth something philosophers as different as Wittgenstein and Heidegger both recognized [264] - so too religion terminates (begins!!??) in a realm that intrinsically has no name and forbids speech. The realm of 'no-thinking' is the realm of full or integral functioning. In Seon Sa Nim's idiom, when there is no gap between 'outside' and 'inside', there is fundamentally 'nothing to point at', nothing to say. The term or description 'buddha' means simply 'awake'. With the inimitable directness and mischievousness characteristic of a zen master, he asks his students, 'What do you want - sex, money, fame, enlightenment...?' [265]

When there is no major "problem" in our lives (even and especially the serious 'dharma' disease of 'wanting enlightenment"!) we can be human beings in the fullest sense, not constantly fighting ourselves (and hence each other). We can really enjoy, we can really work, we can really experience, we can really give. Till that point of personal 'implosion' much hard work and practice is needed. The practice of mindful awareness is an integral part of that apprenticeship. We need to learn the art of seeing how things really affect us. Only then is real transformation, 'dying to the small self', possible. Mindfulness is the work of reclaiming our universal nature, our original visage. The greatest $\sin$ in the world, according to one zen master, is to make God into an object.[266] The second greatest, perhaps, is to make ourselves into an object. In Buddhism, when false objectifications are dissolved, a living universe is revealed - beyond all categories, conceptualizations, schematizations and enmities. 
The practice of mindfulness is meant to extend from the flow of immediate experience to all one's activities, and this indeed has a potentially transforming effect. No longer is it interesting or desirable to do forty things at once. It becomes challenging and interesting to see/feel everything involved in doing just one simple 'mundane' activity like washing the dishes or making the bed or eating a tangerine.[267] Instead of rushing through things to finish, and rushing on to the next thing to finish that, ad nauseam, mindfulness encourages us to give whole-hearted attention to what we are doing. Mindful doing suggests the 'examined life' that zen-master Socrates enjoined.

The regimen of mindfulness also suggests a new ordering of the disciplines, crafts, professions and pursuits entirely. In the West we are used to hierarchies of all sorts: the businessman sees things as mere fodder for capital and profit, the scientist sees everything as potential knowledge, as implicit information, the high-ranking government official sees everything in terms of gradations of power. Mindfulness, in converting all activities into domains of care, suggests the equality of all work. All work, in the Third Canon, is equally valuable when it is done in a centered way. Work done with a 'sacramental' attitude or disposition transforms the doer and the quality of the work done. And it begs for revolutionary changes in how work is done and distributed in society at large. Here rightist reactionaries and leftist radicals are in total agreement. [268] 
Usages such as 'the tao of ...' and 'the zen of ...' in relation to the disciplines, long established or embryonic, suggests that in Organon III all the disciplines of knowledge, artistic projects, commercial pursuits and service-oriented duties be seen as radiating in two directions: one, being rooted in a pre-conceptual center, and ultimately a sense of the sacred; and outward in specialized modalities and, in increasingly interdependent ways, toward a sense of service. Every 'interest', whether momentary or perennial, metabolizes the whole in the direction of the sacred center or the service to all beings that is its completion. This basic process happens anyway: life inherently serves ends beyond itself. Education is what makes this process human, conscious, beautiful (body-ful!) and liberating at every point.

A scathing critic of higher education quotes professor of literature Roger Shattuck:

" 'We spend a good deal of time in universities and colleges
developing and defining interdisciplinary programs...I have
never in my life heard of a single such program that includes
training of the body. Yet we have all read Plato, and
possibly St. Ignatius and Stanislavsky and Artaud and some
Zen or yoga.' Shattuck was reminded of this striking
deficiency by a film sequence he had seen. 'In the slanting
light of dawn a few mature men stood under the trees and
went slowly and attentively through the traditional
movements of T'ai Chi Ch'uan. Calisthenics we would call
it. But this ritual was beautiful and partook visibly of an
intellectual concentration and a spiritual presence... Has
such training and performance been banned forever from
our education?' Shattuck asked. 'Between required
physical education and the huge spectaculars staged for the
public at large there seems to be a physical desert."'[269]

Let that desert bloom! says the Third Organon. Which it has, over several recent decades. 
The locus of attention of the Third Organon is that fertile field of germinating disciplines: the pre-conceptual realm, what Soen Sa Nim refers to as the realm 'before thinking'. To make a terrible but useful pun, in the realm 'before' the "SAP'S" - the sciences, arts and pursuits - there is much valuable work to be done. For instance, 'prior to' mathematics is a kind of generalized heuristics, problem-solving in general, how to handle the relationship between oneself and problems, how to use one's mind, how to work with oneself and others in addressing problems, 'mind over math', etc. Similarly with the body in Third Organon. Rather than being a thing-in-the-world, as per Organon I, or an a scientific object (a system of sub-systems), as per Organon II, the body is a variable field of awareness in Organon III. A mindfulness-oriented discipline like t'ai chi provides 1) re-acquaintance with the body and 2) an avenue or medium for the realization of our deep Center. The 'province' of awareness examines what our actual postures are. We learn a generalized somatics: how we actually inhabit, relate to, express, possess, deny, anxiously minister to, extend gently, forcibly compress, expand and indwell in - or not! our bodies.

'Centering', the art of gently making contact with ourselves, is pivotal to all these new arts. 
Along with minds and bodies: texts, projects, individual disciplines, and grouporganizational practices are all treated correspondingly differently in the three 'organon' approaches. Likewise, with hermeneutics, the interpretation of texts and meanings, and with discussion (discourse) generally. To treat a theme in an aristotelian fashion, for example, would be to translate the discussion, as Mortimer Adler does in his How To Read A Book, into defined terms, major propositions, and structural argument (complete with cogent or not-cogent conclusion). In the scientific canon, a topic is illuminated by the testing for (and quantifying) significant differences - especially in relation to the family of theories that constitute the current paradigm of research. In the Third Organon, a discussion might be best started and then grounded in the perception of nuances of meaning - difference/sameness/pattern/difficulty/tone - from a collective or individually recollected 'centered place'. The complete sounding of a theme might well involve all three of these major methodologies of apprehension/discourse.[270]

Any discipline followed to its 'hodological' conclusion - be it dance or chemistry or accounting - engenders a sense of the Totality and is a liberating art. The sense of NoKnowledge is the highest knowledge.[271] Rather than a ceremonial addendum, No-Mind or No-Knowledge - very different from factual ignorance - becomes the living core of learning. Our "knowledge" becomes utterly dimunitive in relation to 'Big Mind' (in Suzuki-Roshi's teaching phrase), our Boundless Mind or Original Nature, which is alive with endless possibilities. 
The connnecting or 'yoking' of our individual consciousness or small self with our Universal Consciousness or Big Self (again, in Suzuki-Roshi's phrase) is education in the fundamental sense. An apprenticeship in 'mindfulness', the yoga or way of awareness, should be added to the 'three ways' (the trivium, or the basic tools of communication and discourse) and the 'four ways' (the quadrivium, or the endless array of sciences, subject matters, creative activities and collective pursuits). This 'practice of freedom' is the fundamental 'humanity-study' that would enrich all the others. The fundamental humanity is knowing ourselves.

Meditation is the art of proper centering - thereby inviting us to rediscover the sacred in our nature - and the art of proper expanding, or enlarging our power(s) in conformity with the Whole. Such centering is simultaneously grounding and openning. By learning how to be properly 'in the middle' (the golden mean) we go 'backward' and 'forward' at the same time: we come to ourselves as we pursue that which is worthwhile and helpful. Good contemplation is coordinate with good action...and with good community. It is the way of perpetual renewal because it helps us get in touch with our deepest resources, before and beyond concepts and activities. It is education as harmony. Education is precisely Yoga. 


\section{SUMMARY AND CODA}

What we have attempted to do in our historical sketch is to describe three superframeworks, or matrices, that have defined inquiry and research in Western culture. We have called these thought-feeling-action matrices 'organons', after the model of Aristotle's writings on logic. These comprehensive frameworks of understanding with their rules of legimate operation are the expressions of three distinct worldviews: the Classical Greek and Roman (with its primary accommodation, the Christian culture of the Middle Ages), the Modern Scientific Worldview emerging in Renaissance Europe, and the New Age/Perennial Philosophy/Global Culture emerging in late Twentieth Century America.

Each represents a stock of tools, a canon of accepted or preferred procedures, and a vision of the work to be done to make humanity truly humane. Each has a different way of approaching and articulating problems. Each presents education in a different light, has a different core discipline and a different ordering of the disciplines. Different disciplines arose and made sense only in the context of these worldviews and their correlative research methodologies. 'History' made little sense in the cyclically bounded world of the Greeks and in the inward leap to a Transcendent God in Christianity. But it made a lot of sense as a premier discipline in the modern era - given modern emphases, especially in the connection between factuality, the desire for a comprehensive scientific understanding and the aim for human betterment. If human conditions are considered the expression of 'God's will', there is little incentive to improve those conditions. 
Likewise, the study of 'modern' languages makes sense only when and as nationstates were trying to assert themselves. Science and History are 'secular' in their methodology in that they don't recognize any Transcendent or beyond-the-human form of causation. The modern axiom is, if we can't understand it, it isn't operative. If it can't be put into a rational system ('unified field theory'/theory of everything') it doesn't exist. The Third Organon reverses this: the rational is rather the exception, it "covers" only a small part of the omni-field of what is. The Second Organon is promethean: to conquer the world and human affairs by the power of thought, 'forethought', predictive omniscience. The First Organon represents the springtime of rationality, the birth of 'rational' thinking.

Each worldview projected an ideal image of the perfect human person: the cultured aristocrat, participating with due concern in the right ordering of state affairs; the scandalous saint or Christian gentleman; the paradigmatic scientist or scientist cum entrepreneur or the scientist cum statist (or utopian revolutionary): science in the service of power or human betterment; and finally, the whole person, learning how to be aware of himself/herself, 'amateur' (lover) and 'generalist' in a variety of domains, a planetary steward in the evolution of consciousness in the cosmos.

Each successive collection of methodologies represents a plateau in human development. They are not mutually exclusive. Like Kuhnian approximations, each Organon includes the former but goes further in precision, generality and expansion of horizon. Newtonian physics didn't completely nullify Aristotelian common sense and Einsteinian physics didn't trash Galilean-Newtonian mechanics. The holistic-resonantliving universe of awareness denies neither scientific knowledge or conceptual usefulness. But there are decidedly different conceptions of Space - and Time - and sense of coordinates in these worldviews. Different windows, different instrumentation 'panels' and different accents on what is important. A different Gestalt. Different shifts in consciousness. 
Aristotle's Organon, or Organon I, is the product of the Greek genius for abstract thought. The Greeks can almost be said to have 'invented' rationality or abstract thinking. In tribal and empire-based modes of thought had a religious matrix or at least one that presented thought as the deliverances of unquestioned authority. The king was divine and his words were law. The delphic oracle of Greek culture was a remnant of this of this proto-religiousness that saw all things as governed by gods. All the functions of society scientific, philosophic, scientific, governing, artistic, commercial, etc., were fused in the personage of the monarch. As Hegel said in his Philosophy of History, in the pre-Greek world only one, the king, was 'free'. Among the Greeks only a few were free. The Greek contribution was the phenomenon of persuasion and systematic knowing, rhetoric and philosophy. 'What-is' could be understood, comprehended. It was no longer the mystery of nature or the command of a tyrant king.[272] And, within limits, what-is could be modified. There was a certain 'degree' of freedom in people and things which right 'measure' brought to proper consummation.

The paradox of the Greek discovery was that, in speculating that a single primal substance or 'cause' was ultimately responsible for the endless variations in and of things, it also discovered that there were many essences (the Platonic 'eidos'). Every thing had a form or essence or governing pattern for its activity. And things were either themselves or something else: the logic of identity and difference expressed by Aristotle's law of excluded middle'. Things were defined by their dominant form. The 'eidos' of a thing was like the governing aristocrat directing work in his household/domain. Nature and human nature had a definite structure that needed to be adhered to for harmony and optimal activity. The trail of reason in following the structure of things was 'logos', right discourse. This was the sunshine of Aegean common sense, objects displayed in the halcyon light of reason. 
The Christian (or was it the Hebrew...?!) introduction of the Transcendent, the not-to-be-measured, introduced centuries of an uneasy truce between the learning that catalogued the world, and learning that attempted to flee the world or scale the realm of forms to get a reality beyond forms. To what or whom did the Christian knight or gentleman owe his primary allegiance? Consequences flowed from either choice.

If the Greek watchword was limit, structure, measure, the modern exploratory spirit starting in the Renaissance has struggled against it in a different way. It has pushed against limits, cognitively and socially. It has attempted to push back the horizon in all directions, extending it further and further - into the bowels of the atom (the 'uncuttable' in Greek) to mapping the Hubble-defined 'expanding universe'. In this cosmos, to be an entity or thing meant inclusion in a systematic conceptual account with the utmost (i.e. mathematical) precision. Bacon's optimistic manifesto ('the New Atlantis') was followed by Newton's triumph. A 'thing' was now a variable in a mathematical account, an object in a deductive system. Each new discovery heralded a new system and a new science. Like a contagion, each new science begot new discoveries, and, like the European states, new amalgations all the time. There were 'weak' contractual interpretations of the deliverances of physical theory (e.g. Locke) and 'strong' interpretations (e.g. Laplace). The world was sheer space and motion. And authority, as the philosophes of the European Enlightenment insisted, was what human reason made of it on the way to universal theory and universal justice. Successive waves of revolution in Europe and America worked out the implications of this audacious worldview. The problem of the West, as George Orwell, among many others, so trenchantly pointed out, was that each revolution spawned a new elite. Only a few remained truly free. The task for democracies has been, as liberal commentator Benjamin Barber put it in a work of this title: 'an aristocracy of everyone'. 
If the modern era was a kind of violent explosion - and a rationale of inquiry that sanctioned that: the exploitation of material, rationalizing procedures and processes to the point of technical perfection, aggressive expansion of 'markets' (i.e. 'things' being seen as processable goods, commercial entities) - then the Third Organon constituted a kind of implosion. It has attempted to bring together all the shrapnel, all the fragments of Western tendencies and 're-member' who we are. It has been an attempt to 'center' individually and collectively: to non-violently extend consciousness over what we have become. It is an attempt to stop and re-center ourselves against the onrush of societal momentum and acceleration. It is an attempt to develop a culture with a different set of priorties. Its core discipline is the yoga of awareness. It is 'a coming to our senses' and at the same time a rediscovery of the reverential. Against the exploitative mentality, it sees us as participating in a - to use the Buddhist phrase - 'community of all beings'. It sees life everywhere: sentient beings of all different magnitudes and scales. It suggests Quaker-like meditative pausings in order to sustain and nourish civility, discourse and collective enterprise. It suggests new domains to explore (especially in what is thought to be familiar) and new literacies other than verbal and mathematical.

The liberal arts in the West has developed in accord with these different worldviews. In Bruce Kimball's characterization of classical education, 'the artes liberales' emphasized the normative view of the world and the importance of conforming to the 'nature of things'. His delineation of the liberal arts in the modern centuries was that of the 'liberal-free' constellation of thought: the emphasis on critical inquiry, social justice for groups and unimpeded growth for individuals. To this we add the globally-oriented contribution of the New Age/Perennial Philosophy: the liberal arts are the 'liberating arts': the relating of self, work, the modalities of human experience, group affiliations and collective enterprises to the Ultimate Center of existence. The liberal arts are forms of yoga, the practice of freedom. 
The 'Post-Modern Situation' at the end of the Twentieth Century threatens to dissolve the polity of humankind into an indefinite plurality of autonomous centrifugal cultures - always excepting the everpresent possibility of empire by force and/or subliminal persuasion, or disintegration into sheer chaos (or unpredictable disaster!). The meditative/contemplative traditions might provide a counter-balancing centripetal movement, refreshing individuals and revealing deeper affiliations, missions and renewals than our current institutions allow for.

They might provide the backbone for a new kind of higher education: a new 'level' of discourse, a new context for the disciplines, and a new medium for the renewal of organizations (as, for example, with M.Scott Peck's 'community-building' approaches reported in his The Different Drum and A World Waiting To Be Born).

One contemporary philosophic commentator, particularly attuned to post-modern trends and thinkers, and trying to heal the pluralism the West so dearly loves, suggests that " 'We' need to counterbalance these [adversarial and confrontational] practices with cultivating dialogical encounters."[273] True dialogue depends on and requires sensitive, respecting and mindful silence. As genuine silence sustains and upholds genuine speech, meditative practice could be a constructive and nourishing environment for such encounters. It could be part of the philosophic repertoire in a new organon. The nonverbal humanities' could fittingly undergird the verbal, mathematical, technological and untold other humanities by paying attention to a realm both intimate and prior to conceptual divisions.

The Third Organon invites us to an Original Oneness that is not so far away and that honors differences born of grace. Our constant task is to 'yoke' our activities and disciplines to a Center that is both immanent and transcendent, that is both in our midst and forever beyond the galaxies, and that shows itself in unremitting service.

A statement by an exponent of the 'perennial philosophy', in this case a Quaker from the era of the Second World War: 
"What is here urged are inward practices of the mind at deepest levels, letting it swing like the needle, to the polestar of the soul....so that ... we always look out upon all the world through the sheen of the Inward Light, and react toward men spontaneously and joyously from this Inward Center....

"Such practice of inward orientation, of inward... listening, is no mere counsel for special religious groups, for small religious orders, for special 'interior souls', for monks retired in cloisters. It is the secret of the inner life...to be freshly discovered in everyone... It creates an amazing fellowship...and institutes group living at a new level, a society grounded in reverence, history rooted in eternity... ."[274]

'Buddha-Nature' is the 'aristocracy of everyone': dignity, uprightness, awakeness, self-harmony, self-transcendence, the full joining with what is shared universally by all, whether we realize or not. Pedagogy is the practice of freedom at every point, even as we are unfree in a thousand different ways. 


\section{ENDNOTES}

1. Jacob Burckhardt. Force and Freedom (New York: Meridian Books, 1955). Burckhardt in these talks goes into the permutation of these 'forces': religion determined by the state, culture determined by religion, etc. $358-59$.

2. Kenneth Burke. Attitudes Toward History (Boston: Beacon Press, 1959),

3. See, for example, Richard B. Onians, Origins of European Thought About the Body, the Mind, the Soul, the World, Time and Fate (New York: Arno Press, 1973).

4. Friedrich Nietzsche. The Birth of Tragedy and the Genealogy of Morals (New York: Doubleday, 1956).

5. A short account of ancient Greek culture can be found in H.D.F. Kitto's The Greeks (New York: Penguin Books, 1957). A monumental account can be found in Werner Jaeger's Paideia: The Ideals of Greek Culture (New York: Oxford University Press, 1945).

6. See particularly his Genealogy of Morals

7. F. M. Cornford. From Religion to Philosophy (London: Harper Torchbooks, 1957).

8. See Mircea Eliade, Cosmos and History (New York: Harper, 1959); Joseph Campbell, The Hero With a Thousand Faces (New York: Meriden, 1956); Howard Gardner, Frames of Mind (New York: Basic Books, 1983); Lawrence Kolberg, Essays on Moral Development (San Francisco: Harper \& Row, 1981); William Perry, Forms of Intellectual and Ethical Development in the College Years (New York: Hold, Rinehart \& Winston, 1970).

9. See Julian Jaynes, The Origins of Consciousness and the Breakdown of the Bicameral Mind (Boston: Houghton Mifflin, 1990).

10. See Drew Hyland, The Origins of Philosophy, (New York: Putnam, 1973), esp. "Introduction: The Question of Origins".

11. R. G. Collingwood's discussions in The Idea of History (London: Oxford University Press, 1956), e.g. the distinction between 'a chronicle of events' and a 'history', 
the latter introducing causation, perspective and meaning [over a paratactic account of,'and then this happened, and then that happened, and then that happened and then this happened, etc.']

12. See Paul Weiss, History: Written and Lived (Carbondale: Southern Illinois University Press, 1962) for a further discussion of these themes.

13. Bruno Snell, The Discovery of Mind (New York: Harper \& Row, 1960).

14. George Thompson, The First Philosophers (London: Lawrence \& Wishart, 1972).

15. Drew Hyland, ibid.

16. Jaeger, Paideia, vol. 1, Archaic Greece: The Mind of Athens, 3 .

17. The Dialogues of Plato translated by Benjamin Jowett.

18. See the dialogue The Meno which is a cross between Piaget, Euclid, and Jung: Socrates brings out "latent knowledge", propositions of euclidian correctness from an ignorant slave boy. "E-ducere" = 'to lead out' etymologically preserves this conception/usage/tactic.

19. Jaeger, esp. 321-31, "Education and the Political Crisis".

20. The Republic, Book VII.

21. See his The Trial of Socrates (Boston: Little, Brown, 1988).

22. Orators and Philosophers: A History of the Idea of Liberal Education (New York: Teachers College Press, 1986).

23. See the trenchant discussion of Hannah Arendt in 'What is Authority?' with its especial reference to times of 'crisis' in her Between Past and Future (Cleveland: The World Publishing Company, 1961).

24. See Chapter I in Orators and Philosophers for a recitation of 20th Century American nuances. Kimball asserts that there are many often contradictory notions of 'liberal education' because the definitions given are 'normative' and are not informed 'historically'. Succeeding chapters seek to redress that lack of perspective.

25. Kimball, $14 \mathrm{ff}$. 
26. Compare the mythic ecstatic mode in which Plato has Diotima the medium speak in the final portion of the Symposium. The critical dialectic precedes these 'suprarational' outpourings.

27. Kimball, 35.

28. Ibid., Chap II, 'The Foundation of the Artes Liberales'.

29. See F. M. Cornford, Erom Religion to Philosophy (New York: Harper Torchbooks, 1957), esp. Chap VI, The Mystical Tradition'.

30. Kimball, 36.

31. Ibid., esp. 44-55. See also James Bowen, A History of Western Education (London: Methuen \& Co., 1972), vol. 1, chaps. 10-12, and David Hicks, Norms and Nobility (New York: Praeger Publishers, 1981), chap. 8 'The Promise of Christian Paideia'. chaps. 1-5.

32. See Bowen, ibid., and idem, vol. 2 (New York: St. Martin's Press, 1975),

33. Ibid., 1: $241 \mathrm{ff}$.

34. Ibid., loc. cit. Cf. Bowen's treatment of Philo of Alexandria's On the Mating of Preliminary Studies (with wisdom).

35. Ibid., 245.

36. Kimball, $37 \mathrm{ff}$.

37. Ibid., 119-23.

38. Jaeger, op. cit.

39. Ibid., Book Two, chap. 3, The Sophists: The origins of educational theory and the ideal of culture', passim. See esp. 314.

40. Ibid., 306.

41. See John Herman Randall's treatment of these divisions in his Aristotle (New York: Columbia University Press, 1960).

42. Productive Thinking (New York: Harper \& Brothers, 1959), 6.

43. Ibid., 7. 
44. See Bowen, 1: chap. 7, 'Hellenistic Culture', e.g. 158.

45. Ibid., 162.

46. "Augustine's On Music... taught that man did not invent the arts...Man discovered the arts in nature and investigated them as ways of methodizing [our emphasis] what was already present in the world.

"...Augustine wrote On Music soon after his conversion as a part of a grand project (never completed) to compose a set of texts that could be used in teaching the arts to Christians. Throughout the decades of turmoil and responsibility that followed, he turned repeatedly to the subjects that he had raised in those early years exploring again and again the power of the arts, whether used for good or ill. His most mature statement came toward the end of his life in the treatise On Christian Doctrine. To this end he remained convinced that, necessary as they were for ordered social life, the arts were not autonomous, self-justifying techniques, bus rather that each practitioner bent them to serve the object of his love. [our emphasis] As we have seen, love and art intersected. The Christian doctrine of conversion called for a redirection of love away from associations in the physical world to those in the spiritual..."

- Karl Morrison, "Incentives for Studying The Liberal Arts", in The Seven Liberal Arts in the Middle Ages (Bloomington: Indiana University Press, 1983), edited by David Wagner, 43.

47. Henry Osborn Taylor, The Medieval Mind (Cambridge: Harvard University Press, 1949), vol. 1, 222.

48. Ibid. (from Rabanus Maurus, On the Education of the Clergy).

49. Ibid., 224. [etym: 'cum-sidera' = to be with the stars]

50. The Seven Liberal Arts in the Middle Ages, 150-52, ('Arithmetic and the Order of the Liberal Arts').

51. Ibid., 81-85, and Kimball, 71.

52. Bowen, 32.

53. Kimball, 65, from Charles Talbot ed., Ailred of Rievaulx: De Anima.

54. See Alexandre Koyre's telling of this saga in his Erom the Closed World To the Infinite Universe (Baltimore: Johns Hopkins Press, 1957).

55. See Peter Gay's masterful and delectable feast of intellectual history, The Enlightenment: An Interpretation/ The Science of Freedom (New York: W.W. Norton \& Company, 1969). 
57. The Renaissance thinkers and scientists and politicians were just as infatuated with 'motion' and its'laws' as those of us in the 20th century have been with the manifold manifestations of 'energy'. For a fascinating study of key terms as an index-guide to the study of eras and their worldviews, see Carl Becker's The Heavenly City of the Eighteenth Century Philosophers.

58. See McLuhan's philosophy of culture as the introjection (in consciousness) of an externalized technology in his The Gutenberg Galaxy (Toronto: University of Toronto Press, 1962), e.g. 88 and 193.

59. See McLuhan's Understanding Media: Extensions of Man (New York: McGraw-Hill Book Company, 1964) for further elaboration of these themes. McLuhan counterpoints the influence of the alphabet on oral culture, print technology on modern culture and the similarly revolutionary impact of electronic media in the creation of a new global culture.

60. See Henry Adams nostalgic famous characterization of medieval culture in contrast to 19th century modern in his autobiography The Education of Henry Adams (Boston: Houghton Mifflin, 1933) (e.g. the chapter "The Virgin and the Dynamo").

61. Kimball, 125.

62. Ibid., 126-27.

63. Bowen, op. cit., vol. 2, 68. On the growing number of learned and scientific societies, see Bowen, 3: $46 \mathrm{ff}$.

64. Quadrocentro Florence, like 5th century Athens, had the same city-state volatility and delicate balance of military/commercial prowess on the one hand, and intellectual/aesthetic interests on the other - the 'Platonic' academy of Ficino (1433-1499 and Pico dela Mirandola (1463-1494). Civic flowering balanced precariously between the 'vita activa' and the 'vita contemplativa'. (See Bowen, 2: 207-43.)

It should be noted that the flavor of the Platonic configuration historically has had very different valencies: 'Platonic' could and did mean an emphasis on purely mathematical studies, or an abiding interest in otherworldliness, as in the 'Neo-Platonism' of Plotinus, or an extreme interest in the aesthetic, as with some of the Italian humanists and with the poet Shelley for instance. As Gilbert Ryle once put it, all terms of opprobrium end up with the epithet 'Platonic'. And, we may add, all terms of approbation! Plato's richness seems to invite re-interpretation every generation.

65. Bowen, 3: 49. 
66. Bowen, 2: 194.

67. Ibid., 214, from a typical treatise of the time, Vergerio's The Education of the Gentleman.

68. Ibid., 213.

69. See Karen Armstrong's popular but well seasoned A History of God (New York: Alfred A. Knopf, Inc., 1993), esp. chaps.6-8: 'The God of the Philosophers', 'The God of the Mystics', 'A God for Reformers'.

70. Julian Marias, History of Philosophy (New York: Dover Publications, 1967), 249.

71. Wilhelm Windelband, History of Philosophy (New York: Harper Torchbooks, 1958), vol. 2, 383.

72. Quoted in Bowen, 2: 41.

73. See the interesting discussion of Bacon's set of four idols (esp. in relation to Karl Popper and contemporary philosophy of science) in Peter Urbach's Francis Bacon's Philosophy of Science (Lasalle: Open Court Publishing Company, 1987), chap. 4, 83-106. Urbach's treatment of Bacon generally is that his account of induction was not as simplistic as often presented and that he sought a closer union of 'rational' and 'experimental' 'faculties' 'such as has never yet been made'. Bacon's project of union implies that there was already a long and healthy tradition of 'experimentation' he was alluding to, or that at least there was a great deal of experimentation going on. (See Urbach, chap. 5.)

74. Bowen, 3: 44 .

75. Ibid., 80-83.

76. Tbid., 43.

77. Ibid., 67.

78. Ibid., 93-98.

79. Ibid., 89.

80. Ibid., 100.

81. Ibid., 39. 
82. Ibid.

83. Wilheim Dilthey, Introduction to the Human Sciences (Detroit: Wayne State University Press, 1988), 292. Dilthey goes on to say that modern science's quantitatively defined functional concepts steadily replaced the 'Aristotelian Metaphysics' of 'substantial forms'.

84. Hannah Arendt, The Human Condition (New York: Doubleday \& Company, 1959), 262 (chap. 'The Vita Activa and the Modern Age').

85. Ibid., 260.

86. Whitehead, 55.

87. Ibid., chap. 5 passim.

88. Ibid., e.g. Nature cannot be divorced from its aesthetic values...the brooding presence of the whole on to its various parts' (p. 84) 'In a certain sense, everything is everywhere at all times. For every location involves an aspect of itself in every other location. Thus, every spatio-temporal standpoint mirrors the world.' (86) "Value" is the word I use for the intrinsic reality of an event.' (89) '...(The) nature-poetry of the romantic revival was a protest on behalf of the organic view of nature, and also a protest against the exclusion of value from the essence of matter of fact.' (90) The objective of Whitehead's philosophy was the rehabilitation of terms like 'prehension', 'feeling', and 'perception' from an ontologically derivative and secondary status. Such terms bespoke an active, inherently relational, informative and self-transcending process -- to wit, the organic texture of things and nature. In Whitehead's philosophy all entities are in the last analysis alive.

89. Gay, 159-60.

90. Ibid., 160-61.

91. Ibid., see the discussion 187-207.

92. See Windelband, 2: 517-18.

93. Wertheimer, 8.

94. Ibid., 9.

95. See, for example, Karl Popper's Conjectures and Refutations (New York: Basic Books, 1962). 
96. Kimball, chap. 5 passim. Kimball (Appendix II) disputes Harold Laski's influential account of the rise in modern political liberalism by stressing the epistemological skepticism and inquiry as fuelling the modern worldview. (I rather agree with Laski. In any case, individualism and skepticism seem to go hand-in-hand.)

97. For the complex weaving of the two traditions see Kimball, chap. 5. "The Emergence of the Liberal-Free Ideal", passim. The ideal of 'mental discipline'. the disciplining of the mind as opposed to various discrete subjects, was shifting from the 'artes liberales' idiom (i.e. the formation of a gentleman's character) to the training of the mind for scientific purposes and with the new scientific psychology of 'mental faculties' as a guide. And 'classics' were slowly being replaced by 'modern' subjects, notably physics, mathematics and vernacular languages. [See Kimball, esp. 151-53.]

98. See Joseph Schwab, Science, Curriculum and Liberal Education (Chicago: University of Chicago Press, 1978), 252-72 The Comtean Analysis of Structure', etc.

99. Dilthey, 89.

100. Our synopsis of Hegel largely follows Bowen's (3: 262-265) exposition of his Phanomenologie des Geistes and the Philosophy of History. 'Geistes' in German can mean either 'spirit' or 'mind'.

101. For a full account see Stephen Toulmin and June Goodfield's The Discovery of Time (New York: Harper \& Row, 1965), esp. chaps. 7 ('The Earth Acquires a History') and 10 ('History and the Human Sciences').

102. Windelband, 2: 652.

103. Marias, 353.

104. Windelband, ibid.

105. See Henry Adam's famous autobiography The Education of Henry Adams (Boston: Houghton Mifflin, 1933), and his Mont St. Michel and Chartres (Boston: Houghton Mifflin, 1933) for a perceptive view of the nineteenth century 'zeitgeist' in comparison to the medieval worldview.

106. On Haeckel and Fechner see German historian Windleband, 2: 632. On Fechner generally, see Walter Lowrie's biography Fechner: The Religion of a Scientist (New York: Pantheon Books, 1946). Lowrie, incidentally, was one of the translators of Kierkegaard into English.

107. Marias, 379. 
108. Kimball, Chap V 'The Emergence of the Liberal-Free Ideal', passim: but especially Chapter VI, 'Confrontation in America'.

109. Bowen, 3: 306.

110. Ibid., $320 \mathrm{ff}$.

111. Ibid., 296-97.

112. Ibid., 305.

113. Kimball, 271-72.

114. Thomas Mann's two antagonists in The Magic Mountain, Settembrini, the intellectual-liberal, and Naptha, the Jesuit humanist, as they battle for the soul of Hans Castorp, represent the same tension in world-views (and personalities).

115. Kimball, 170-71 (from Sheldon Rothblatt's Tradition and Change in English Liberal Education: An Essay in History and Culture).

116. See Kimball, 166, for a discussion of Harvard President Charles Eliot's 'mental training' as a rationale for subjects to be studied.

117. Ibid., 229.

118. Ibid., 230-31.

119. See, for example, David Livingstone's The Geographical Tradition (Cambridge: Blackwell Publishers, 1992), chap. 'Geography, Race, and Empire'.

120. Bowen, 3: 335, from Froebel's Die Mensherziebring (The Education of Man).

121. Ibid.

122. Richard Bernstein, The New Constellation (Cambridge: MIT Press, 1992), 203.

123. See Bernstein's discussion, ibid., 257.

124. See Karl Lowith, From Hegel to Nietzsche (Garden City: Doubleday, 1967), on the nineteenth century genealogies deriving from Hegel.

125. Bowen, 3: 345. 
126. Tbid.

127. Tbid., 346.

128. Ibid., 350.

129. Ibid., 370-73. Bowen cites a fascinating study by H.B. Dunkel, entitled Herbart and Herbartianism: An Educational Ghost Story, which traces how the prescient theories of a brilliant pedagogist - anticipating James, Bergson, \& Husserl - became embalmed in hidebound and repressive textbook pedagogy, mostly as a result of his American 'translators'!

130. See Marias, 378-392 The Idea of Life', and Bowen, 3:390-94, especially on the Theosophical movement and German Naturphilosophie.

131. Bowen, 3: 245.

132. We are generally following Bowen's account (3: 420-33) of Dewey.

133. Ibid., 426.

134. Kimball, 158. Kimball sees these usages beginning as early as during the Civil War in America.

135. John Herman Randall, "Which Are the Liberating Arts?" American Scholar 13 (1944): 135-48.

136. Ibid., 145.

137. Ibid., 148.

138. Ibid.

139. Kimball, 229-30, esp. the series of references in his footnote \#58.

140. See Sidney Hook's "General Education: The Minimum Indispensibles", in The Philosophy of the Curriculum (Buffalo: Prometheus Books, 1975), edited by Hook/Kurtz/Todorovich, 27-37. Benjamin Barber's An Aristocracy of Everyone (New York: Oxford University Press, 1992) is a recent Deweyan struggle with these themes with the conviction that 'all public education (is) liberal education' (15).

141. Bowen, 3: 428, quoting from The Quest for Certainty. (Gregory Bateson's Toward An Ecology of Mind can easily be seen as a Deweyan update in epistemology.)

142. Ibid., 429. 
143. This movement began its work before World War I and its main exponents - Wolfgang Kohler (1887-1967), Kurt Koffka (1886-1941), and Max Wertheimer (18801943) - all emigrated from Germany to America in the 1930's.

144. See Michael Polanyi, Personal Knowledge (Chicago: University of Chicago Press, 1958), Thomas Kuhn, The Structure of Scientific Revolutions (Chicago: University of Chicago Press, 1962), Norwood Russell Hanson, Patterns of Discovery (Cambridge: Cambridge University Press, 1965), and Paul Feyerabend, Against Method (New York: Verso, 1975).

\section{Wertheimer, 235-36.}

146. The 'New Age' is much too present for there to be a history of it. Some initial, helpful and sympathetic narrative accounts of the new age are: Theodore Roszak, The Making of a Counter Culture (New York: Doubleday \& Company, Inc., 1969), Jacob Needleman, The New Religions (New York: Doubleday \& Company, 1970), Marilyn Ferguson, The Aquarian Conspiracy (New York: St. Martin's Press, 1980), Rick Fields, How the Swans Came to the Lake (Boulder: Shambala, 1981), and Stephen Bachelor, The Awakening of the West (Berkeley: Parallax Press, 1994).

147. P. D. Ouspensky, Tertium Organum (New York: Alfred A. Knopf, 1981), inscription page (from p. 221).

148. Santideva, Entering the Path of Enlightenment: The Bodhicaryavatara of Buddhist Poet Santideva, (New York: The Macmillan Company, 1970).

149. Marias, $254 \mathrm{ff}$.

150. See Robert Bly, News of the Universe (San Francisco: Sierra Club Books, 1980), 10: "By 1750 or so animals are considered to be without consciousness. The people longing to do vivisection, barred by the ancient concept that an animal had a soul, which the Catholic Church, to its credit, carried throughout the Middle Ages, sighed with relief. Now they could get on with it... Women than began the long descent. It appears that in the male psyche, women, earth and the unconscious form a sort of constellation, or triangle. Usually the attitude a man has toward one extends, without his being aware of it...to the others."

\section{Ibid., 38 .}

152. Ibid., 39.

153. See for example the fascinating story of Herman Haupf who reorganized the accountng system of the Pennsylvania Railroad in the 1850's - and its implications, in Hoskin \& Maeve's "Accounting as a Discipline: the Overlooked Supplement, in 
Knowledges: Historical and Critical Studies in Disciplinarity (Charlottesville: University Press of Virginia, 1993), edited by Messer-Davidow, Shumway and Sylvan, 25-53.

154. See Marias, $384-89$, on some of these trends.

155. Interestingly the technology of the cinema was being developed at the time Bergson was writing. It was a source of many of Bergson's metaphors.

156. Bly subtitled his anthology-study News of the Universe 'poems of the twofold consciousness' - meaning poems that attempted to integrate the two ways of seeing.

157. "Marcel developed a very simple distinction between 'problem' and 'mystery'...'A problem is something which I meet, which I find complete before me, but which I can therefore lay siege to and reduce. A mystery is something in which I myself am involved.' [Marcel, Being and Having, p 100] You can solve a problem; all you can do initially with a mystery is acknowledge it, as something in which you are or could be caught up...The mystery of malevolence is in a quite different world from the problem of anger, let's say, or even resentment." - Ralph Harper, On Presence: Variations and Reflections (Philadelphia: Trinity Press International, 1991), 41.

158. Popular and philosophical accounts ranged from the early and mid-century neo-Kantian accounts of Sir Arthur Eddington and Sir James Jeans, both astronomers and both impressed with God's prowess as a mathematician and with the human mind's mathematical structures, to more recent accounts of God's conversion (pace Einstein!) to gambling, (Ian Stewart's Does God Play Dice: The Mathematics of Chaos (Cambridge: Blackwell Publishers, 1989) and the possibility that the entire universe may be a 'vacuum fluctuation'! (See Timothy Ferris Coming of Age in the Milky Way (New York: Anchor Books, 1989), 353, and Heinz Pagels The Cosmic Code: Quantum Physics as the Language of Nature (New York: Bantam Books, 1983), 283: 'The entire universe is a reexpression of sheer nothingness.')

159. We follow the concise summary contained in Arthur March and Ira Freeman's The New World of Physics (New York: Random House, 1962). Also see Ernst Cassirer's presentation of these themes in Substance and Function (Chicago: 1923; Dover Publications)(passim) and Morris Kline's Mathematics and Western Culture (New York: Oxford University Press, 1953), chap. XXVII 'The Theory of Relativity', esp. 451. 171-79.

160. March \& Freeman, esp. chap. 5 'Dematerialization of the Physical World',

161. Tbid., 166-70, The Meaning of Indeterminancy Relations'. Also, see Ferris, 288 ,ff. ('...the manner in which we choose to make the observation...influences the results of the interaction', 289) 
162. Whitehead, see for example, 87 and 138-39.

163. Quoted by March \& Freeman, 168.

164. See John Casti, Paradigms Lost (New York: Avon Books, 1990), 279 ff.

165. Bly, 4-5.

166. Arendt, Between Past and Future, 174.

167. See Dewey's very laudatory Introduction to F. Matthias Alexander's Constructive Conscious Control of the Individual (New York: E. P. Dutton \& Company, 1923), xxi-xxxiii.

168. See the biographical sketch of him by Edward Maisel in The Alexander Technique: The Essential Writings of F. Matthias Alexander (New York: Carol, 1989), 'Introduction' vi-xiv.

169. Michael Polanyi makes similar points in his Personal Knowledge. Wittgenstein also in his Philosophical Investigations (New York: The Macmillan Company, 1958). Cf. Alexander, Conscious Constructive Control in the Individual, chap. 'Imitation': "...in fact, all defects or peculiarities manifested as striking characteristics of the teachers will be found to be the most potent stimuli to the pupil's aptitude for imitation.", 255.

170. Alexander's personal story and seminal discoveries are recounted in The Australian Story' in Maisel, 139-60.

171. Alexander, chap. 'Concentration and the Sustained (continuous) Projection of Orders', 258-71.

172. Ibid., 261.

173. Ibid., 263.

174. John Dewey, from his Introduction to Alexander, xxxii. [How far is it from this statement to the phenomenology of Merleau-Ponty?] Dewey goes on to give a striking confession regarding the canon of the modern world and its faustian results: "Is it not highly probable that this failure gives the explanation of why it is that in mastering physical forces we have ourselves been so largely mastered by them, until we find ourselves incompetent to direct the history and destiny of man." (Ibid.)

Dewey, not prone to overstatement, says a little earlier that "Mr. Alexander has demonstrated a new scientific principle with respect to the control of human behavior, as important as any principle which has ever been discovered in the domain of external nature. Not only this, but his discovery is necessary to complete the discoveries that have 
been made about non-human nature, if these discoveries and inventions are not to end by making us their servants and helpless tools." (Ibid., xxix)

That domain is precisely the realm of self-awareness.

175. Alexander, see especially Part IV, 'Sensory Appreciation in its Relation to Happiness', 291-312.

176. Ibid., 306.

177. Ibid., 307.

178. Alfred Korzybski, Science and Sanity (Lakeville: The International NonAristotelian Library Publishing Company, 1958), 34. ' 'A' is the negation sign of symbol logic that Korzybski uses as an abbreviation for the non-Aristotelian 'orientation' and 's.r.' is Korzybski's abbreviation for 'semantic reaction'.

179. Ibid., 20.

180. Ibid, pp 465-66.

181. Ibid. Korzybski pioneered a number of interesting, if occasionally eccentric, lexicographical devices such as numerical and dated subscripts to reinforce his point. Thus 'apple, Feb. 22, 1993' symbolizes a distinct and unique and meaning-complex-event. For similar treatments and lexicographical brackettings (e.g. specialized quotes) see I.A. Richards' How to read a Page and also Ogden \& Richards' The Meaning of Meaning.

182. Ibid., see 63.

183. Ibid., 468.

184. Tbid., see 555 and 560.

185. His autobiographical account is the famous Meetings With Remarkable Men. See the biographical sketch of this most colorful eccentric in Anne Bancroft's Twentieth Century Mystics and Sages (London: Arkana Books, 1989), 84-102. Gurdjieff's master work is the voluminous All and Everything: Beelzebub's Tales to His Grandson (New York: E. P. Dutton \& Co., Inc., 1950), a kind of Fechnerian voyage through material and psychical cosmoses. Its prose is like reading an amalgam of Jonathan Swift, Buckminster Fuller, Gertrude Stein, James Joyce, Nicholai Tesla, and Timothy Leary!

186. Bancroft, 88-89.

187. Ibid., 89 (quoted from Ouspensky's In Search of the Miraculous). 
188. P. D. Ouspensky In Search of the Miraculous (New York: Harcourt, Brace \& World, Inc., 1949), $351 \mathrm{ff}$.

189. Our account follows the biography of the man and the exposition of his work in Satprem's Sri Aurobindo or The Adventure of Consciousness (Pondicherry: Sri Aurobindo Ashram Press, 1970).

190. Carl Jung, 'Foreword' to The Spiritual Teachings of Ramana Maharshi (Berkeley: Shambhala, 1972), viii-ix.

191. Satprem, 26.

192. Ibid., 27.

193. Ibid., 32.

194. Ibid., 42-43.

195. Ibid., 35.

196. Ibid., 32-33 (Aurobindo quote is from his The Synthesis of Yoga.)

197. Ibid., 34. See also 75.

198. Ibid.

199. Ibid., 47 [Incidentally, Willian James, Henri Bergson, Whitehead, and Aldous Huxley all developed theories that inverted the common image of the brain as the 'producer' of thought. They began to propose an image of the brain, in James' terms, as a filter of/from a much larger field of thought.]

200. Ibid., 52.

201. Ibid., 50.

202. Ibid., 51 (from On Yoga II, Tome One).

203. See the sketch in Bancroft, 63-80. The authorized three volume biography is by Mary Lutyens. See also Krishnamurti: A Biography by Pupal Jayakar. Among Krishnamurti's many talks \& 'dialogues' are his Commentaries on Living ( 3 vols.), The Flight of the Eagle, You Are the World, The Awakening of Intelligence (which includes conversations with quantum theorist David Bohm) and Freedom From the Known. His Think On These Things is a series of deceptively simple conversations with children. 
When D. T. Suzuki, famous Zen Buddhist scholar, was asked who among world figures he thought were 'enlightened', he mentioned Thomas Merton and Krishnamurti.

204. Bancroft, 259, from her sketch of Steiner.

205. See, for example, the chapter 'The Spiritual Embryo' in Maria Montessori's The Secret of Childhood (New York: Ballantine Books, 1977), and Bowen, 3: 404, on Steiner's The Education of the Child in the Light of Anthroposophy.

206. Aldous Huxley, The Perennial Philosophy (New York: Harper Colophon Books, 1970), Introduction, xi. See also ix.

207. Ibid., 12.

208. This description largely follows Ken Wilber's 'psychologia perennis' on the model of Huxley in Wilber's The Spectrum of Consciousness (Wheaton: The Theosophical Publishing House, 1993). See especially chap. VI, 'Surveying the Traditions'. See also phenomonological psychologist Wilson Van Dusen's The Natural Depth in Man. There is an appendix in Van Dusen wherein he gives a compelling and fascinating portrait of one of the most gifted spiritual seers of all time, Emmanuel Swedenborg.

209. Especially his 'The Education of an Amphibian', and 'Knowledge and Understanding' in Aldous Huxley, Tomorrow and Tomorrow and Tomorrow (New York: Signet Books, 1964), 27 and 38-42.

210. Ibid., 9.

211. Ibid., 15-16.

212. Ibid., 22.

213. Ibid., 23.

214. Ibid., 18.

215. Ibid., 27-29.

216. Ibid., 41-42.

217. Ibid., 51.

218. Ibid., 39. Huxley quotes from Albert Jay Nock's Memoirs of a Superfluous Man. 
219. Ibid., 38. Presumably the author, Dr. H. L Dodge, is referring to numeracy and literacy when he says 'fundamentals'. [Wisecrack from the 1990s: the above list doesn't sound so bad!...]

220. Ibid., 41.

221. Ibid., 27 and previous pages, passim.

222. John White, ed., The Highest State of Consciousness (New York: Doubleday \& Company, Inc., 1972), 482.

223. See the moving accounts of his first wife's and his own demise in Bancroft, $15-16$.

224. See John White's The Highest State for the many schematizations of this phenomenon. Also, Marghanita Laski's exhaustive study Ecstasy (Bloomington: Indiana University Press, 1961).

225. See appendix A to Charles Brooks' Sensory Awareness (New York: The Viking Press, 1974), 'Elsa Grindler: "Arbeit Am Menshen"', 229-33.

226. Ibid., 231.

227. Ibid.

228. Krishnamurti, Freedom from the Known (New York: Harper\& Row, Publishers, 1969), 107-8.

229. Ibid., 46.

230. Brooks, 232.

231. Frederick Perls, Ralph Hefferline, and Paul Goodman, Gestalt Psychology (New York: Dell Publishing Co., Inc., 1951), 'Orienting the Self', 22.

232. Ibid., 40 .

233. Ibid., 32.

234. Growing Up Absurd, Communitas, and Community of Scholars were a couple of his diatribes against the social (dis-)order, along with his utopian counterproposals. 
"So Goodman seeks, in his social criticism, the same end always: to scale down selectively our leviathan industrialism to the ethos of village or neighborhood." Roszak, chap. VI 'Exploring Utopia: The Visionary Sociology of Paul Goodman', 200.

235. Richard Bernstein, The New Constellation (Cambridge: MIT Press, 1992), 'The Rage Against Reason', 42.

236. Ibid., 43.

237. Adorno in Minima Moralia, quoted in Bernstein, 43.

238. Roszak, 97.

239. Ibid.

240. Ibid., 111.

241. Ibid., Roszak quoting from Marcuse's Soviet Marxism: A Critical Analysis.

242. See John Caputo, The Mystical Element in Heidegger's Thought (New York: Fordham University Press, 1986).

243. Shunryu Suzuki, Zen Mind, Beginner's Mind (New York: Weatherhill, $1970), 65$.

244. For an interesting culture criticism on the dissolution of 'travel' in advanced capitalistic-industrial society see that chapter in Daniel Boorstin's The Image: A Guide to Pseudo-Events in America (New York: Atheneum, 1961). McLuhan claimed to have put this book on its head by claiming that image was essence.

245. in his 'Preface' to Suzuki, 9.

246. Among the endless stories told of him was one by F.S.C. Northrop of Yale, author of The Meeting of East and West, The Logic of the Sciences and Humanities, etc. At an international conference in Hawaii in the early 50's during the reading of a paper a quick breeze blew in and scattered all the loose papers of the participants. Suzuki Daisetz quietly listening, and who had almost seemed dozing, rapidly shot out his hand and held his papers still. This sort of apparently easeful and lightning quick acting-without-effort (a demonstration of 'no-mind' at work) impressed the academics present. At another international conference, Suzuki gave a short zen-articulated 'listen-to-the-birds-outside' lecture (sermon!). The pithiness seemed to come from a boundless 'empty' mind.

247. Paul Reps, Zen Flesh, Zen Bones (Rutland: Charles E. Tuttle, 1957), 18. 
248. 'Sayings of the Zen Master Bunan', Thomas Cleary, ed., The Original Face: An Anthology of Rinzai Zen (New York: Grove Press, Inc., 1978), 100.

\section{Another more exact translation is}

'(My) supernatural power and marvelous activity -

Drawing water and carrying firewood.'

- from Layman P'Ang, The Recorded Sayings of Layman P'Ang (New York: Weatherhill, 1971), 46.

250. For the best - clearest, fairest, most succinct and psychologically/philosophically cognizant - overview of the various meditative traditions (esp. in America) see Daniel Goleman (former psychology editor for the New York Times) The Meditative Mind: The Varieties of Meditative Experience (New York: G. P. Putnam's Sons, 1988). The aforementioned The New Religions by Jacob Needleman, despite being an early 'report from the front' is a good and sympathetic account giving the 'flavor' of many of these new philosophically oriented 'religions'.

251. Aside from works already bibliographically referred to - notably Rick Fields' How The Swans Came To The Lake - see also the portrait of Suzuki Roshi and immediate successors in Helen Tworkov's Zen in America (San Francisco: North Point Press, 1989).

252. See the descriptive portrait of him by Trudy Dixon in the 'Introduction' by Richard Baker, Suzuki, 18.

253. See one translation and commentary by Rev. Uchiyama in Refining Your Life (New York: Weatherhill, 1983), esp. 49.

254. Suzuki, 115.

255. William James, Principles of Psychology (Dover Publications, 1950), vol. 1, 424, quoted by Goleman, 145 .

Cf. Irving Babbitt in his commentary on the classic Buddhist text, The Dhammapada (New York: New Directions Books, 1965): "Western thinkers from St. Augustine to William James who have sought to deal with the will psychologically are in agreement with one another and with Buddha in at least one particular: will is revealed above all in the act of attention or concentration." (86) And, of course, Jesus in 'where your heart is, so too is your treasure'.

256. Suzuki, 32.

257. The use of such terminology harkens back to the Buddha's famous characterization of the way to liberation from the suffering of the human condition as the 'eightfold noble path': 'right views, right action, right speech, right aspiration, right effort, 
right meditation and right contemplation.' Of the many phrasings of this sequence or octet of qualities see, e.g. Eknath Eswaran's translation of The Dhammapada(Petaluma: Nilgiri Press, 1986), 31, S.Radhakrishman's translation of The Dhammapada (London: Oxford University Press, 1950), 19-21, and Joseph Goldstein's The Experience of Insight (Santa Cruz: Unity Press, 1976), 7-14.

258. The state of mind that exists when you sit in the right posture is, itself, enlightment.' - Suzuki, 28.

259. Tbid., 25.

260. Ibid., 71.

261. For many of the details of these movements and colorful characters, again, the best and most complete account to date is Rick Fields, How the Swans Came to the Lake.

262. See the translation of this discourse in, for example, Nyanaponika Thera's The Heart of Buddhist Meditation (New York: Samuel Weiser, 1973). A very straightforward and helpful account of the practice can be found in Henepola Gunaratana's Mindfulness in Plain English (Boston: Wisdom Publications, 1991).

263. See the hugely popular account of its clinical applications in Jon KabatZinn's Full Catastrophe Living (New York: Delacorte Press, 1990). Also, that author's Wherever You Go, There You Are (New York: Hyperion, 1994). See also Ellen Langer's gerontological groundbreaking study in Mindfulness (Reading: Addison-Wesley Publishing Company, 1989) (praised by Harvard's Jerome Bruner).

264. See the famous ending of Wittgenstein's Tractatus and the study of Heidegger's 'later thought' by John Caputo, The Mystical Element in Heidegger's Thought (New York: Fordham University Press, 1986).

265. Sahn Seung's Dropping Ashes On the Buddha (New York: Grove Press, 1976), named after one of his teaching 'koans' - or unavoidable riddles that can't be penetrated by the reasoning mind, is a collection of his early talks and dialogues. Only Don't Know (San Francisco: Four Seasons Foundation, 1982) is a collection of his teaching letters. He is often referred to by the affectionate title 'Soen Sa Nim'.

266. From Joshu Sasaki-Roshi's lecture "Buddha Is the Center of Gravity", given at Lama Foundation, New Mexico, in 1974.

267. See Nhat Hanh's classic and delightful manual, The Miracle of Mindfulness (Boston: Beacon Press, 1976). 
268. See three treatments of work in this vein: Tarthang Tulku, Skillful Means (Berkeley: Dharma Publishing, 1978), D.M. Dooling, ed., A Way of Working: The Spiritual Dimension of Craft (New York: Parabola Books, 1986), and Matthew Fox's The Reinvention of Work: A New Vision of Livelihood for Our Time (New York: HarperCollins Publishers, 1994). And, of course, all the writings of that conservative exemplar, Wendell Berry. Also E. F. Schumacher's Buddhist manifesto, Small is Beautiful: Economics As If People Mattered (New York: Harper \& Row, Publishers, 1973).

269. Page Smith, Killing the Spirit: Higher Education in America (New York: Viking, 1990), 207.

270. Interesting contrasts may be found in the following treatments of (the phenomenon of) discussion:

Mortimer Adler's Dialectic (New York: Harcourt, Brace \& Company, 1927), an older work more philosophically phrased, and his more recent The Paideia Proposal (New York: Macmillan, 1982) and The Paideia Program (New York: Macmillan, 1984); Arthur Lipman, Ann Margaret Sharp and Frederick Oscanyan's Philosophy in the Classroom (West Caldwell: Universal Diversified Services, Inc., 1977) for a Deweyan treatment of discussion (v. particularly p. 92); and Michael Kahn's recent and suggestive The Tao of Conversation (Oakland: New Harbinger Publications, Inc., 1995).

271. See the graceful elaboration of these themes by the Third Organon thinker, the MIT scientist and administrator R.G. H. Siu in his The Tao of Science (Cambridge: The M. I. T. Press, 1957):

"The dangers in modern higher education do not arise from specialization, which is the common whipping boy of educational critics. Specialization is a necessary feature of learning. It provides a penetrating training for the intellect and an inner devotion to the field... . Specialization is not the source of social inadequacy. We do not gain the 'other' knowledge [intuitive knowledge, 'no-knowledge', enlightenment, knowledge of the totality, sensing the 'undifferentiated', awareness of the 'suchness of nature', etc.] by eliminating the opportunity for deep appreciation. We must add something to it... .

"As a prelude there must be a reorientation...Many educators feel that whereas a physical science course like geology gives technical knowledge, a humanities course like sociology provides 'other' knowledge. This is no so. With the current organization of teaching, nearly all of the university classes are geared to teach only technical knowledge. The exceptions are due not to the substance or arrangement of the curricula prescribed by deans and department heads but to the genius of the individual professors. Whether or not a course provides technical or 'other' knowledge does not depend on the subject matter but on the way it is conducted. [our emphasis] Teaching by the positive method, in which things and events are abstracted out of context from the 
wholeness of nature, can only provide technical knowledge. Treatment of the arts in the 'scientific method' merely mimics the mediocre technological courses in the divorcing the intellect from the deeper qualities of man. The fact that the bits of data under discussion concern poetry and society instead of gausses and ergs makes them no less a kind of technicism.

"The 'other' knowledge can be taught only through an adaptation of the negative approach of the East... .The subject matter is merely the carrier wave, which conveys the modulated nuances and insights of the 'other' knowledge to...the listener.

"...(The instructor) can develop in the student an awareness of the ineffable sensing and feeling beyond formulae and equations. The young man [or woman!] learns that the interposing of silence between words adds drama to speech and the pauses between the notes enhance the vibrance of music... . Guidance...then becomes the unobstructive evoking of wisdom and beauty... ." (Siu, 92-93)

272. Alan Watts, in an essay entitled "The End of Western Mythology: Its Dissolution and Transformation" (originally included in a collection of lectures on "Myth and Dream' edited by Joseph Campbell), gives a rough parallel to our three 'organons' of inquiry: the transition from the 'political image of the universe as ruled and dominated by an essentially violent lawgiver' [and here we would place the Greek discovery of the lawfulness or regularity of nature and human affairs]...to the 'automatic model' of Newtonian Science, working quite nicely with or without humans, to the organic image of the world' in which 'we are not in it as subjects of a king, or as victims of a blind process... We are it!' 'Every individual in this organic myth of the world must look upon himself [sic, before femimism!] as responsible for the world.' His book The Book: On the Taboo against Knowing Who You Are (New York: Collier Books, 1967) is an elaboration of these themes.

273. Bernstein, 338.

274. Thomas Kelly, A Testament of Devotion (New York: Harper \& Row, Publishers, 1941), 32-33. 


\section{BIBLIOGRAPHY}

Adams, Henry. The Education of Henry Adams. Boston: Houghton Mifflin, 1933. Mont-Saint-Michel and Chartres. Boston: Houghton Mifflin, 1933.

Adler, Mortimer J. Art, the Arts, and the Great Ideas. New York: Simon \& Schuster, 1994.

. Dialectic. New York: Harcourt, Brace \& Company, 1927.

How To Read a Book: The Art of Getting a Liberal Education. New York: Simon and Schuster, 1940.

. The Paideia Program: An Educational Syllabus. New York: Macmillan, 1984.

. The Paideia Proposal:An Educational Manifesto. New York: Macmillan, 1982.

Reforming Education: The Opening of the American Mind. New York: Macmillan, 1988.

Alexander, F. Matthias. The Alexander Technique: The Essential Writings of F. Matthias Alexander. Edited by Edward Maisel. New York: Carol, 1989.

. Constructive Conscious Control of the Individual. New York: E. P. Dutton \& Company, 1923.

Arendt, Hannah. Between Past and Future: Six Exercises in Political Thought. Cleveland: The World Publishing Company, 1961.

. The Human Condition. New York: Doubleday \& Company, 1959.

Aristophanes. Five Comedies of Aristophanes. Translated by Benjamin Bickley Rogers.

New York: Doubleday \& Company, Inc., 1955.

Aristotle. The Basic Works of Aristotle. Edited by Richard McKeon. New York: Random House, 1941.

Armstrong, Karen. A History of God: The 4,000-Year Quest of Judaism, Christianity and Islam. New York: Alfred A. Knopf, Inc.; Ballantine Books, 1993. 
Aronowitz, Stanley, and Henry A. Giroux. Postmodern Education: Politics, Culture and Social Criticism. Minneapolis: University of Minnesota Press, 1991.

Augustine, Saint. Concerning the Teacher and On the Immortality of the Soul by St. Aurelius Augustine, Bishop of Hippo. Translated by George G. Leckie. New York: D. Appleton-Century Company, Inc., 1938.

. On Christian Doctrine. Translated by D. W. Robertson, Jr. New York: Liberal Arts Press, 1958.

. The Confessions of St.Augustine. Translated by John K. Ryan. New York: Doubleday \& Company, Inc., 1960.

City of God. Translated by Gerald G. Walsh, S.J., Demetrius B. Zema, S.J., Grace Monahan, O.S.U. and Daniel J. Honan. Edited by Vernon J. Bourke. New York: Doubleday \& Company, Inc., 1958.

Aurobindo, Ghose. The Life Divine. Ponticherry: Sri Aurobindo Ashram, 1970.

Aurobindo, Sri and The Mother. Living Within: The Yoga Approach to Psychological Health and Growth. Compiled by A.S. Dalal. Ojai: Institute of Integral Psychology, 1987.

Bacon, Francis. The Advancement of Learning and New Atlantis. London: Oxford University Press, 1951.

. Novum Organum: With Other Parts of The Great Instauration. Translated and edited by Peter Urbach and John Gibson. Chicago: Open Court Publishing Company, 1994.

Bahm, Archie. Yoga: Union With the Ultimate: A New Version of the Ancient Yoga Sutras of Patanjali. New York: Frederick Ungar Publishing Co., 1961.

Bancroft, Anne. Twentieth Century Mystics and Sages. London: Arkana Books, 1989.

Barber, Benjamin R. An Aristocracy of Everyone: The Politics of Education and the Euture of America. New York: Oxford University Press, 1992.

Batchelor, Stephen. The Awakening of the West: The Encounters of Buddhism and Western Culture. Berkeley: Parallax Press, 1994.

Bergson, Henri. Creative Evolution. Translated by Arthur Mitchell. New York: Random House, Inc., 1944. 
Time and Free Will: An Essay on the Immediate Data of Consciousness.

Translated by F. L. Pogson. New York: Macmillan, 1910.

Two Sources of Religion and Morality. Translated by R. Ashley Audra, Cloudesley Brereton, and W. Horsfall Carter. New York: Doubleday, 1935.

Bensman, Joseph and Robert Lilienfeld. Craft and Consciousness: Occupational Technique and the Development of World Images. New York: Aldine de Gruyter, 1991.

Bernstein, Richard J. Beyond Objectivism and Relativism: Science, Hermeneutics, and Praxis. Philadelphia: University of Pennsylvania Press, 1983.

The New Constellation: The Ethical-Political Horizons of

Modernity/Postmodernity. Cambridge: MIT Press, 1992.

Berry, Wendell. Home Economics. New York: Northpoint Press, 1987.

Bloom, Allan. The Closing of the American Mind: How Higher Education Has Failed Democracy and Impoverished the Souls of Today's Students. New York: Simon and Schuster, 1987.

Bly, Robert. News of the Universe: Poems of Twofold Consciousness. San Francisco: Sierra Club Books, 1980.

Bochenski, J. M. The Methods of Contemporary Thought. New York: Harper \& Row, 1968.

Boorstin, Daniel. The Image: A Guide to Pseudo-Events in America. New York: Atheneum, 1961.

Bowles, S. and Gintis, H. Schooling in Capitalist America: Educational Reform and the Contradictions of Economic Life. New York: Basic Books, 1976.

Bowen, James. A History of Western Education. Vol. 1, The Ancient World: Orient and Mediterranean: 2000 B.C. - A.D. 1054. London: Methuen \& Co., 1972.

.Vol. 2, Civilization of Europe: Sixth to Sixteenth Century. New York: St. Martin's Press, 1975.

. Vol. 3, The Modern West: Europe and The New World. New York: St. Martin's Press, 1981.

Brooks, Charles V. W. Sensory Awareness: The Rediscovery of Experiencing. New York: The Viking Press, 1974. 
Bruner, Jerome S. Toward a Theory of Instruction. New York: W. W. Norton, 1966.

Bucke, R. M. Cosmic Consciousness. New York: Dutton, 1969.

Burckhardt, Jacob. Force and Freedom: An Interpretation of History. Edited by James Hastings Nichols. New York: Meridian Books, 1955.

Burke, Kenneth. Attitudes Toward History. Boston: Beacon Press, 1959.

Campanella, Tommaso. City of the Sun: A Poetic Dialogue. Translated by Daniel J. Donno. Berkeley: University of California Press, 19881.

Campbell, Joseph. The Hero With a Thousand Faces. New York: Meridian Books, 1956.

Capra, Fritjof. The Tao of Physics: An Exploration of the Parallels Between Modern Physics and Eastern Mysticism. New York: Bantam Books, 1984.

. The Tuming Point: Science, Society, and the Rising Culture. New York: Bantam Books, 1982.

Caputo, John D. The Mystical Element in Heidegger's Thought. New York: Fordham University Press, 1986.

Cassirer, Ernst. Language and Myth. Harper and Brothers, 1946; New York: Dover Publications Inc., 1953.

. The Logic of the Humanities. Translated by Clarence Smith Howe. New Haven: Yale University Press, 1961.

. The Philosophy of Symbolic Forms. Vol. 1, Language. Translated by Ralph Manheim. New Haven: Yale University Press, 1953.

. Vol. 2, Mythical Thought. Translated by Ralph Manheim. New Haven: Yale University Press, 1955.

. Vol. 3, The Phenomenology of Knowledge. Translated by Ralph Manheim. New Haven: Yale University Press, 1957.

Substance and Function and Einstein's Theory of Relativity. Translated by William Curtis Swabey and Marie Collins Swabey. Chicago, 1923; Dover Publications, Inc.

Casti, John L. Paradigms Lost: Images of Man in the Mirror of Science. New York: William Morrow and Company, Inc., 1989; Avon Books, 1990. 
Clark, Arthur C. Childhood's End. New York: Harcourt, Brace Janovich, 1953.

Cleary, Thomas, ed. The Original Face: An Anthology of Rinzai Zen. Translated and edited by Thomas Cleary. New York: Grove Press, Inc., 1978.

The Cloud of Unknowing. Translated into Modern English by Clifton Wolters. Baltimore: Penquin Books, 1961.

Collingwood, R. G. The Idea of History. London: Clarendon Press, 1946; Oxford University Press Paperback, 1956.

Comte, Auguste. Introduction to Positive Philosophy. Edited and translated by Frederick Ferre. Indianapolis: Bobbs-Merrill, 1970.

Cornford, F. M. From Religion to Philosophy: A Study in the Origins of Western Speculation. London: Edward Arnold, 1912; Harper Torchbooks, 1957.

Csikszentmihalyi, Mihaly. Elow: The Psychology of Optimal Experience. New York: Harper \& Row, 1990; Harper Perennial, 1991.

Descartes, Rene. The Philosophical Works of Descartes. Translated by Elizabeth S. Haldane and G. R. T. Ross. Vol. 1, New York: Dover Publications, Inc., 1955.

Dewey, John. Art as Experience. New York: Minton, Balch and Co., 1934; Capricorn Books, 1958. Experience and Nature. New York: W.W. Norton and Co., 1929; Dover Books, 1958.

. How We Think. Boston: D. C. Heath and Co., 1910.

The Philosophy of John Dewey. Vol. 1, The Structure of Experience and Vol. 2, The Lived Experience (combined). Edited by John J. McDermott. Chicago: The University of Chicago Press, 1981.

. The Quest for Certainty. New York: Minton, Balch and Co., 1929; Capricorn Books, 1960.

The Dhammapada. Translated from the Pali with an Essay on Buddha and the Occident by Irving Babbitt. New York: Oxford University Press, 1936; New Directions Books, 1965.

Dickinson, G. Lowes. A Modern Symposium. New York: Doubleday, 1905 
Dilthey, Wilhelm. Introduction to the Human Sciences: An Attempt to Lay a Foundation for the Study of Society and History. Translated by Ramon J. Betanzos. Detroit: Wayne State University Press, 1988.

Dogen, Zen Master and Kosho Uchiyama. Refining Your Life: From the Zen Kitchen to Enlightenment. Translated by Thomas Wright. New York: Weatherhill, 1983

Dooling, D. M., ed. A Way of Working: The Spiritual Dimension of Craft New York: Anchor Books, 1979; Parabola Books, 1986.

Eliade, Mircea. Cosmos and History: The Myth of the Eternal Return. New York: Harper, 1959.

Emerson, Margaret. APotter's Notes on Tai Chi Chuan. Ferndale: Artichoke Press, 1988.

Evans-Wentz, W. Y. The Tibetan Book of the Dead or The After-Death Experiences on the Barde Plane. Compiled and edited by W. Y. Evans-Wentz. New York: Oxford University Press, 1960.

Fanon, Franz. Black Skin, White Masks. New York: Grove Press, Inc., 1967.

Fechner, Gustav. Religion of a Scientist. Selections edited and translated by Walter Lowrie. New York: Pantheon Books, 1946.

Ferguson, Marilyn. The Aquarian Conspiracy: Personal and Social Transformation in the 1980's. New York: St. Martin's Press, 1980.

Ferris, Timothy. Coming of Age in the Milky Way. New York: William Morrow and Company, Inc., 1988; Anchor Books, 1989.

Feyerabend, Paul. Against Method. New York: Verso, 1988.

Fields, Rick. How the Swans Came to the Lake: A Narrative History of Buddhism in America. Boulder: Shambhala, 1981.

Foucault, Michel. The Order of Things: An Archeology of the Human Sciences. New York: Random House, Inc., 1970.

Fox, Matthew. The Reinvention of Work: A New Vision of Livelihood for Our Time. New York: HarperCollins Publishers, 1994.

Frankfort, Henri, H. A. Frankfort, John A. Wilson, and Thorkild Jacobsen. Before Philosophy: The Intellectual Adventure of Ancient Man. Baltimore: Penguin Books, 1946. 
Freire, Paulo. Education for Critical Consciousness. New York: Seabury, 1973. Pedagogy of the Oppressed. New York: Seabury, 1970.

Freud, Sigmund. Civilization and its Discontents. London: L. \& V. Wolf, 1930. . Moses and Monotheism. Translated by Katherine Jones. New York: Vintage Press, 1939.

. Totem and Taboo: Resemblances Between the Psychic Lives of Sayages and Neurotics. New York: Moffat, Yard and Company, 1918.

Fuller, R. Buckminster. Nine Chains to the Moon. Carbondale: Southern Illinois University Press, 1938; Arcturus Books, 1963.

Operating Manual for Spaceship Earth. Carbondale: Southern Illinois University Press, 1969.

Galilei, Galileo. Dialogues Concerning Two New Sciences. Translated by Henry Crew and Alfonso de Salvio. New York: McGraw-Hill, 1963.

Gardner, Howard. Frames of Mind: The Theory of Multiple Intelligences. New York: Basic Books, 1983.

Gay, Peter. The Enlightenment: An Interpretation/ The Science of Freedom. New York: W.W. Norton \& Company, 1969.

Gendlin, Eugene. Focusing. New York: Bantam Books, 1981.

Grene, Marjorie, ed. The Anatomy of Knowledge: Papers Presented to the Study Group on the Foundations of Cultural Unity. Amherst: The University of Massachusetts Press, 1969.

Goleman, Daniel. The Meditative Mind: The Varieties of Meditative Experience. New York: G. P. Putnam's Sons, 1988.

Goldstein, Joseph. The Experience of Insight: A Natural Unfolding. Santa Cruz: Unity Press, 1976. Insight Meditation: The Practice of Freedom. Boston: Shambhala, 1994.

Goldstein, Joseph and Jack Kornfield. Seeking the Heart of Wisdom: The Path of Insight Meditation. Boston: Shambhala, 1987. 
Graf von Durckheim, Karlfried. Daily Life as Spiritual Exercise: The Way of

Transformation. Translated by Ruth Lewinnek and P. L. Travers. London: George Allen \& Unwin, Ltd., 1971; Perennial Library, 1972.

Grudin, Robert. The Grace of Great Things: Creativity and Innovation. New York: Ticknor \& Fields, 1990.

Gunaratana, Venerable Henepola. Mindfulness in Plain English. Boston: Wisdom Publications, 1991.

Gurdjieff, G. All and Everything: Beelzebub's Tales to His Grandson. New York: E. P. Dutton \& Co., Inc., 1950.

Views from the Real World: Early Talks. New York: E. P. Dutton \& Co., Inc., 1973.

Hanson, Norwood Russell. Patterns of Discovery: An Inquiry into the Conceptual Foundations of Science. Cambridge: Cambridge University Press, 1965.

Harding, D. E. The Hierarchy of Heaven and Earth: A New Diagram of Man in the Universe. London: Faber and Faber, Ltd., 1952.

Harper, Ralph. On Presence: Variations and Reflections. Philadelphia: Trinity Press International, 1991.

Hegel, G. W. F. The Phenomenology of Mind. Translated by J. B. Baillie. New York: The Macmillan Company, 1949. 1956 .

Philosophy of History. Translated by J. Sibree. New York: Dover Publications,

Heidegger, Martin. Being and Time. Translated by John Macquarrie and Edward Robinson. New York: Harper \& Row Publishers, 1962.

Existence and Being. Chicago: Henry Regnery Company, 1949.

Heider, John. The Tao of Leadership: Lao Tzu's "Tao Te Ching" Adapted for a New Age. New York: Bantam Books, 1986.

Herrigel, Eugen. Zen in the Art of Archery. New York: Pantheon Books, 1953.

Hicks, David V. Norms and Nobility: A Treatise on Education. New York: Praeger Publishers, 1981. 
Hook, Sidney, Paul Kurtz and Miro Todorovich, eds. The Philosophy of the Curriculum: The Need for General Education. Buffalo: Prometheus Books, 1975.

Husserl, Edmund. Ideas: General Introduction to Pure Phenomenology. Translated by W.

R. Boyce Gibson. New York: The Macmillan Company, 1931.

Huxley, Aldous. Brave New World. New York: Harper \& Row, Publishers, 1932.

. Brave New World Revisited. New York: Harper \& Row, Publishers, 1958.

.The Doors of Perception, and Heaven and Hell. New York: Harper \& Row, Publishers, 1956.

. Island. New York: Harper \& Row, Publishers, 1962.

. Tomorrow and Tomorrow and Tomorrow and Other Essays. New York:

Harper \& Row, Publishers, 1952; Signet Books, 1964.

. The Perennial Philosophy. New York: Harper \& Row, Publishers, 1944; Harper Colophon Books, 1970.

Hyland, Drew A. The Origins of Philosophy: Its Rise in Myth and the Pre-Socratics. New York: Putnam, 1973; Humanities Press, 1984.

The I Ching. The Richard Wilhelm Translation rendered into English by Cary F. Baynes. New York: Pantheon Books, 1961.

Illich, Ivan. De-schooling Society. New York: Harper \& Row, Publishers, 1972.

Jaeger, Werner. Paideia: The Ideals of Greek Culture. Vol. 1, Archaic Greece: The Mind of Athens. Translated by Gilbert Highet. New York: Oxford University Press, 1945.

James, William. Essays in Radical Empiricism and A Pluralistic Universe. New York: Longmans, Green and Co., 1940, 1936.

.The Principles of Psychology. Vol. 1, Dover Publications, Inc., 1950.

The Principles of Psychology. Vol. 2, Dover Publications, Inc., 1950.

The Varieties of Religious Experience: A Study in Human Nature. New York: Random House, 1929.

Jaynes, Julian. The Origins of Consciousness and the Breakdown of the Bicameral Mind. Boston: Houghton Mifflin, 1990. 
Jung, C. G. The Structure and Dynamics of the Psyche. New York: Pantheon Books, 1960.

Kabat-Zinn, Jon. Full Catastrophe Living: Using the Wisdom of Your Body and Mind to Eace Stress, Pain, and Illness. New York: Delacorte Press, 1990.

. Wherever You Go, There You Are: Mindfulness Meditation in Everyday Life. New York: Hyperion, 1994.

Kahn, Michael. The Tao of Conversation. Oakland: New Harbinger Publications, Inc., 1995.

Kelly, Thomas R. A Testament of Devotion. New York: Harper \& Row, Publishers, 1941.

Kierkegaard, Soren. Christian Discourses, Etc. Translated by Walter Lowrie. Princeton University Press, 1971.

Kimball, Bruce A. Orators \& Philosophers: A History of the Idea of Liberal Education. New York: Teachers College Press, 1986.

King, Arthur and John Brownell. The Curriculum and the Disciplines of Knowledge. New York: Wiley and Sons, 1966.

Kitto, H. D. F. The Greeks. New York: Penguin Books, 1957.

Kline, Morris. Mathematics in Western Culture. New York: Oxford University Press, 1953.

Koestler, Arthur. The Act of Creation. New York: Macmillan, 1964.

Kohak, Erazim. The Embers and the Stars: A Philosophical Inquiry into the Moral Sense of Nature. Chicago: University of Chicago Press, 1984.

Kohlberg, Lawrence. Essays on Moral Development. Volume 1. 'The Philosophy of Moral Development: Moral Stages and the Idea of Justice'. San Francisco: Harper \& Row, Publishers, 1981.

Kohler, Wolfgang. Gestalt Psychology. New York: H. Liveright, 1929.

Kornfield, Jack. Living Buddhist Masters. Santa Cruz: Unity Press, 1977.

Korzybski, Alfred. Science and Sanity: An Introduction to Non-Aristotelian Systems and General Semantics. Lakeville: The International Non-Aristotelian Library Publishing Company, 1958. 
Koyre, Alexandre. Erom the Closed World to the Infinite Universe. Baltimore: Johns Hopkins Press, 1957.

Krishnamurti, Jiddu. The Awakening of Intelligence. New York: Harper \& Row, Publishers, 1973.

. The First and Last Freedom. Foreword by Aldous Huxley. Wheaton: The Theosophical Publishing House, 1954.

Freedom from the Known. New York: Harper \& Row, Publishers, 1969.

You Are the World. New York: Harper \& Row, Publishers, 1972.

. The Wholeness of Life. New York: Harper \& Row, Publishers, 1979.

Krieger, Martin H. Doing Physics: How Physicists Take Hold of the World Bloomington: Indiana University Press, 1992.

Kubler-Ross, Elisabeth. On Death and Dying. New York: Macmillan, 1969.

Kuhn Thomas S. The Structure of Scientific Revolutions. Chicago: University of Chicago Press, 1962.

Laing, R. D. The Politics of Experience. New York: Ballantine Books, 1975.

Langer, Ellen J. Mindfulness. Reading: Addison-Wesley Publishing Company, 1989.

Langer, Susanne K. Philosophy in a New Key: A Study in the Symbolism of Reason, Rite, and Art. Cambridge: Harvard University Press, 1979.

Lao Tzu. Tao Te Ching. Translated by D. C. Lau. Baltimore: Penquin Books, 1963.

Layman P'ang. The Recorded Sayings of Layman P'ang: A Ninth-Centrury Zen Classic. Translated by Ruth Fuller Sasaki, Yoshitaka Iriya, Dana R. Fraser. New York: Weatherhill, 1971.

Laski, Marghanita. Ecstasy: A Study of Some Secular and Religious Experiences. Bloomington: Indiana University Press, 1961.

Leary, Timothy, Ralph Metzner, and Richard Alpert. The Psychedelic Experience: A Manual Based on the Tibetan Book of the Dead. New York: Citadel Press, 1995.

LeBoyer, Frederick. Birth Without Violence. New York: Alfred A. Knopf, 1975. 
Leggett, Trevor, ed. A First Zen Reader. Rutland: Charles E. Tuttle Co., 1960.

Levey, Joel \& Michelle. The Fine Arts of Relaxation, Concentration, and Meditation: Ancient Skills for Modern Minds. Boston: Wisdom Publications, 1991.

Levi, Albert William. Philosophy as Social Expression. Chicago: University of Chicago Press, 1974.

Levinas, Emmanuel. Totality and Infinity: An Essay on Exteriority. Translated by Alphonso Lingis. Pittsburgh: Duquesne University Press, 1969.

Levine, Stephen. A Gradual Awakening. New York: Doubleday, 1979. Healing Into Life and Death. New York: Doubleday, 1987. Who Dies: An Investigation of Conscious Living and Dying. New York: Doubleday, 1984.

Lipman, Matthew, Ann Margaret Sharp, and Frederick S. Oscanyan. Philosophy in the Classroom. West Caldwell: Universal Diversified Services, Inc., 1977.

Livingstone, David N. The Geographical Tradition: Episodes in the History of a Contested Enterprise. Cambridge: Blackwell Publishers, 1992.

Lonergan, Bernard J. F. , S.J. Insight: A Study of Human Understanding. New York: Longmans, Green and Co, Inc., 1958.

Lowith, Karl. From Hegel to Nietzsche: The Revolution in Nineteenth Century Thought. Garden City: Doubleday, 1967.

Mangalo, Bhikkhu. A Manual of the Practice of Recollection. London: The Buddhist Society, 1970

Mann, John. Learning To Be: The Education of Human Potential. New York: The Free Press, 1972.

Marcel, Gabriel. The Mystery of Being. Vol. 1, Reflection \& Mystery. Chicago: Henry Regnery Company, 1950; Gateway Edition, 1960

March, Arthur and Ira M. Freeman. The New World of Physics. New York: Random House, 1962.

Marcuse, Herbert. Eros and Civilization: A Philosophical Inquiry into Freud. Boston: Beacon Press, 1955; Vintage Edition, 1962. 
Marias, Julian. History of Philosophy. New York: Dover Publications, Inc., 1967.

Maritain, Jacques. Creative Intuition in Art and Poetry. Cleveland: The World Publishing Company, 1953.

. Distinquish to Unite or The Degrees of Knowledge. Translated by Gerald B. Phelan. New York: Charles Scribner's Sons, 1959.

Marrou, H. I. A History of Education in Antiquity. New York: Sheed and Ward, 1956.

Marsh, Colin and George Willis. The Curriculum: Alternate Approaches, Ongoing Issues. Englewood Cliffs: Prentice Hall, 1995.

McLuhan, Marshall. The Gutenberg Galaxy: The Making of Typographic Man. Toronto: University of Toronto Press, 1962; Signet Books, 1969.

. Understanding Media: Extensions of Man. New York: McGraw-Hill Book Company, 1964.

Meister Eckhart. Meister Eckhart: AModern Translation. Translated by Raymond Bernard Blakney. New York: Harper \& Row, Publishers, 1941.

Merriam, Sharan, B. and Rosemary S. Caffarella. Learning in Adulthood: A Comprehensive Guide. San Francisco: Jossey-Bass Publishers, 1991.

Merton, Thomas. The Asian Journal of Thomas Merton. Edited by Naomi Stone et al. New York: New Directions, 1973.

Messer-Davidow, David R. Shumway, and David J. Sylvan, eds. Knowledges: Historical and Critical Studies in Disciplinarity. Charlottesville: University Press of Virginia, 1993.

Metzner, Ralph. Maps of Consciousness. New York: Collier Books, 1971.

Mindell, Arnold and Amy. Riding the Horse Backwards: Process Work in Theory and Practice. London: Arkana, 1992.

Montessori, Maria. The Secret of Childhood. Translated by M. Joseph Costelloe, S. J. New York: Ballantine Books, 1977.

More, Thomas. Utopia. Translated by Paul Turner. New York: Penquin Books, 1965.

Murray, Gilbert. Five Stages of Greek Religion. New York: Doubleday \& Company, 1955. 
Needleman, Jacob. The New Religions. New York: Doubleday \& Company, 1970.

Newman, John Henry Cardinal. The Idea of a University. New York: Doubleday \& Company, 1959.

Nhat Hanh, Thich. Being Peace. Berkeley: Parallax Press, 1987.

The Miracle of Mindfulness: A Manual on Meditation. Boston: Beacon Press, 1976.

Nicholson, Shirley and Brenda Rosen, eds. Gaia's Hidden Life: The Unseen Intelligence of Nature. Wheaton: The Theosophical Publishing House, 1992.

Nietzsche, Friedrich. The Birth of Tragedy and The Genealogy of Morals. Translated by Francis Golffing. New York: Doubleday \& Company, 1956. . Schopenhauer as Educator. Translated by James W. Hillesheim and Malcolm R. Simpson. Chicago: Henry Regnery Company, 1965.

Nyanaponika, Thera. The Heart of Buddhist Meditation: A Handbook of Mental Training Based on the Buddha's Way of Mindfulness. New York: Samuel Weiser, 1973.

Onians, Richard Broxton. Origins of European Thought About the Body, the Mind, the Soul, the World, Time, and Fate. New York: Arno Press, 1973.

Otto, Rudolf. The Idea of the Holy: An Inquiry inte the Non-Rational Factor in the Idea of the Divine and its Relation to the Rational. Translated by John W. Harvey. New York: Oxford University Press, 1958.

Otto, Herbert A. and John Mann, eds. Ways of Growth: Approaches to Expanding Awareness. New York: Viking Press, 1968.

Ouspensky, P. D. In Search of the Miraculous: Fragments of an Unknown Teaching. New York: Harcourt, Brace \& World, Inc., 1949.

Tertium Organum: The Third Canon of Thought. New York: Alfred A. Knopf, 1981.

Pagels, Heinz R. The Cosmic Code: Quantum Physics as the Language of Nature. New York, Bantam Books, 1983.

Peck, M. Scott. The Different Drum: Community Making_and Peace. New York: Simon and Schuster, 1987. 
A World Waiting to Be Born: Civility Rediscovered. New York: Bantam Books. 1993.

Perls, Frederick, Ralph F. Hefferline, and Paul Goodman. Gestalt Therapy: Excitement and Growth in the Human Personality. New York: Dell Publishing Co., Inc., 1951.

Perry, William. Forms of Intellectual and Ethical Development in the College Years. New York: Holt, Rinehart \& Winston, 1970.

Phenix, Philip. Realms of Meaning: A Philosophy of the Curriculum for General Education. New York: McGraw-Hill Book Company, 1964.

Pirsig, Robert M. Zen and the Art of Motorcycle Maintenance: An Inquiry into Values New York: Morrow Quill Paperbacks, 1974.

Plato. The Dialogues of Plato. Translated by Benjamin Jowett. New York: Random House, 1920.

Poincare, Henri. Science and Method. New York: Dover Publications, 1952.

Polanyi, Michael. Personal Knowledge: Towards a Post-Critical Philosophy. Chicago: University of Chicago Press, 1962.

Popper, Karl, Sir. Conjectures and Refutations: The Growth of Scientific Knowledge. New York: Basic Books, 1962. The Open Society and Its Enemies. London: Routledge \& Keagan Paul, 1949.

Ram Dass. Remember Be Here Now. San Cristobal: Lama Foundation, 1971.

Ramana Maharshi. The Spiritual Teaching of Ramana Maharshi. Berkeley: Shambhala, 1972.

Randall, John Herman, Jr. Aristotle. New York: Columbia University Press, 1960. "Which Are the Liberating Arts?" American Scholar 13 (1944) : 135-48.

Reps, Paul, comp. Zen Flesh, Zen Bones: A Collection of Zen and Pre-Zen Writings. Rutland: Charles E. Tuttle, 1957.

Richards, Mary C. Centering in Pottery, Poetry, and the Person. Middletown: Wesleyan University Press, 1964. 
Roszak, Theodore. The Making of a Counter Culture: Reflections on the Technocratic Society and Its Youthful Opposition. New York: Doubleday \& Company, Inc., 1969.

Santideva. Entering the Path of Enlightenment: The "Bodhicaryavatara" of the Buddhist Poet Santideva. Translated by Marion L. Matics. New York: The Macmillan Company, 1970.

Sasaki, Joshu. Buddha is the Center of Gravity. Part of Series II, Package 3 of the Bountiful Lord's Delivery Service. San Cristobal: Lama Foundation, 1974.

Satprem. Sri Aurobindo or The Adventure of Consciousness. Pondicherry: Sri Aurobindo Ashram Press, 1970.

Schubert, William H. Curriculum: Perspective, Paradigm, and Possibility. New York: Macmillan Publishing Company, 1986.

Schumacher, E. F. Small is Beautiful: Economics as if People Mattered. New York: Harper \& Row, Publishers, 1973.

Schwab, Joseph. Science, Curriculum, and Liberal Education: Selected Essays. Edited by Ian Westbury and Neil J. Wilkof. Chicago: University of Chicago Press, 1978.

Seung Sahn, Zen Master. Dropping Ashes on the Buddha: The Teaching of Zen Master Seung Sahn. Compiled and edited by Stephen Mitchell. New York: Grove Press, 1976.

. Only Don't Know: The Teaching Letters of Zen Master Seung Sahn. San Francisco: Four Seasons Foundation, 1982.

Siu, R. G. H. The Tao of Science: An Essay on Western Knowledge and Eastern Wisdom. Cambridge: The M. I. T. Press, 1957.

Smith, Page. Killing the Spirit: Higher Education in America. New York: Viking, 1990.

Snell, Bruno. The Discovery of the Mind: The Greek Origins of European Thought. New York: Harper \& Row, 1960.

Stapledon, Olaf. Star Maker. Los Angeles: Jeremy P. Tarcher, Inc., 1987.

Stewart, Ian. Does God Play Dice: The Mathematics of Chaos. Cambridge: Blackwell Publishers, 1989.

Stone, I. F. The Trial of Socrates. Boston: Little, Brown, 1988. 
Straus, Erwin. The Primary World of the Senses: A Vindication of Sensory Experience. New York: The Free Press of Glencoe, 1963.

Strauss, Leo. Liberalism Ancient and Modern. Ithaca: Cornell University Press, 1989.

Suzuki, D. T. Essays in Zen Buddhism. (First Series), New York: Grove Press, Inc., 1961.

Mysticism, Christian and Buddhist: The Eastern and Western Way. New York: Harper \& Row, Publishers, 1957; Perennial Library, 1971.

. The Zen Doctrine of No-Mind: The Significance of the Sutra of Hui-Neng. London: Rider and Company, 1969.

. Zen and Japanese Culture. New York: Pantheon Books, 1959.

Suzuki, Shunryu. Zen Mind, Beginner's Mind. New York: Weatherhill, 1970.

Taimini, I. K. The Science of Yoga: A Commentary on the "Yoga-Sutras" of Patanjali in the Light of Modern Thought. Wheaton: The Theosophical Publishing House, 1961.

Taylor, Henry Osborn. The Medieval Mind: A History of the Development of Thought and Emotion in the Middle Ages. Vol. 1, Cambridge: Harvard University Press, 1949.

. Vol. 2, Cambridge: Harvard University Press, 1949.

Teilhard de Chardin, Pierre. The Phenomenon of Man. New York: Harper \& Row, 1965.

Thomas a Kempis. The Imitation of Christ. Translated by Leo Sherley-Price. New York: Dorset Press, 1952.

Thompson, George. Studies in Ancient Greek Society: The First Philosophers. London: Lawrence \& Wishart, 1972.

Toffler, Alvin. Future Shock. New York: Bantam Books, 1971.

Toulmin, Stephen and June Goodfield. The Discovery of Time. New York: Harper \& Row, Publishers, 1965.

Trungpa, Chogyam. "Foundations of Mindfulness," in Garuda IV. Berkeley: Shambhala Press, 1976.

. Cutting Through Spiritual Materialism. Berkeley: Shambhala, 1973. 
Meditation in Action. Boulder: Shambhala, 1969.

Tulku, Tarthang. Gesture of Balance:A Guide to Awareness, Self-healing, and Meditation. Berkeley: Dharma Publishing, 1977.

. Openness Mind. Berkeley: Dharma Publishing, 1978.

. Time, Space, and Knowledge: A New Vision of Reality. Berkeley: Dharma Publishing, 1977.

Tworkov, Helen. Zen in America: Profiles of Five Teachers. San Francisco: North Point Press, 1989.

Underhill, Evelyn. Mysticism: A Study in the Nature and Development of Man's Spiritual Consciousness. London: Methuen \& Co., 1962.

Urbach, Peter. Erancis Bacon's Philosophy of Science. La Salle: Open Court Publishing Company, 1987.

Vico, Giambattista. The New Science of Giambattista Vico. Translated by Thomas Goddard Bergin and Max Harold. Ithaca: Cornell University Press, 1968.

Wagner, David, ed. The Seven Liberal Arts in the Middle Ages. Bloomington: Indiana University Press, 1983.

Watts, Alan. "Beat Zen, Square Zen, and Zen," in This Is It. New York: Collier Books, 1967.

. The Book: On the Taboo against Knowing Who You Are. New York: Collier Books, 1967.

. Psychotherapy East and West. New York: Pantheon, 1957.

Weiss, Paul. History: Written and Lived. Carbondale: Southern Illinois University Press, 1962.

Welwood, John, ed. The Meeting of the Ways: Explorations in East/West Psychology. New York: Schocken Books, 1979.

Wertheimer, Max. Productive Thinking. Edited by Michael Wertheimer. New York: Harper \& Brothers, 1959.

White, John, ed. The Highest State of Consciousness. New York: Doubleday \& Company, Inc., 1972. 
Whitehead, Alfred North. Adventures of Ideas. New York: The Macmillan Co., 1933; Mentor Books, 1959.

. The Aims of Education and Other Essays. New York: Free Press, 1967.

Modes of Thought. New York: The Macmillan Co., 1938; Capricorn Books, 1958

Process and Reality: An Essay in Cosmology. New York: The Macmillan Co., 1929; Harper Torchbooks, 1957.

Science and the Modern World. New York: The Macmillan Co., 1925; Mentor Books, 1960.

Wilber, Ken. The Spectrum of Consciousness. Wheaton: The Theosophical Publishing House, 1993.

Willis, George. "The Concept of Experience in Major Curriculum Literature: 1918-1970." $\mathrm{Ph}$. D. diss., The Johns Hopkins University, 1971.

Windelband, Wilhelm. A History of Philosophy Vol. 1, Greek, Roman, and Medieval. New York: The Macmillan Company, 1901; Harper Torchbooks, 1958.

. Vol. 2, Renaissance, Enlightenment, and Modern. New York: The Macmillan Company, 1901; Harper Torchbooks, 1958.

Wittgenstein, Ludwig. Philosophical Investigations. Translated by G. E. M. Anscombe. New York: The Macmillan Company, 1958.

Tractatus Logico-Philosophicus. Translated by D. F. Pears and B. F. McGuiness. London: Routledge \& Kegan Paul, 1961. 